\title{
Estudo das causas de internação hospitalar das crianças de 0 a 9 anos de idade no município de São Paulo
}

Dissertação apresentada à Faculdade de Medicina da Universidade de São Paulo para obtenção do título de Mestre em Ciências

Área de Concentração: Pediatria Orientadora: Profa. Dra. Sandra Josefina Ferraz Ellero Grisi

São Paulo 
Dados Internacionais de Catalogação na Publicação (CIP)

Preparada pela Biblioteca da

Faculdade de Medicina da Universidade de São Paulo

Creprodução autorizada pelo autor

Ferrer, Ana Paula Scoleze

Estudo das causas de internação hospitalar das crianças de 0 a 9 anos de idade no município de São Paulo / Ana Paula Scoleze Ferrer. -- São Paulo, 2009.

Dissertação(mestrado)--Faculdade de Medicina da Universidade de São Paulo. Departamento de Pediatria.

Área de concentração: Pediatria.

Orientadora: Sandra Josefina Ferraz Ellero Grisi.

Descritores: 1.Hospitalização 2.Saúde da criança 3.Morbidade 4.Serviços de saúde da criança

USP/FM/SBD-270/09 


\section{DEDICATÓRIA}

Às minhas amadas filhas, Juliana e Mariana, que me renovam a cada dia e dão sentido às minhas conquistas.

Ao meu querido Fernando, por sua paciência, seu amor e seu apoio nessa e em tantas outras jornadas.

À memória dos meus avós, por tudo o que significaram para mim. 


\section{AGRADECIMENTOS}

À Prof ${ }^{\mathrm{a}} \mathrm{Dr}^{\mathrm{a}}$ Sandra Grisi que, em meio a tantas atribuições, aceitou o desafio de me orientar, conduzindo-me de maneira segura e tranqüila.

À Ana Cecília Sucupira, por suas sugestões sempre pautadas em aguçada perspicácia e, principalmente, por ter sido a primeira pessoa a acreditar no meu potencial, estimulando-me a trilhar esse caminho.

À Sandra Zuccolotto, com quem sempre aprendo muito, por seu envolvimento em meus projetos e por sua enorme generosidade.

À Malu, Daleth, Denise, Silmar e Fabíola, pela torcida, pelo carinho e pelo espírito de equipe, sem o qual nada seria possível.

Aos meus irmãos e grandes amigos, Sérgio e Ricardo, pessoas simplesmente brilhantes que têm o dom de ilustrar a minha vida. A vocês, minha eterna admiração. E ao querido Tiago, por tanto me alegrar.

À Lígia e à Naná, por todo o carinho e amor que sempre me deram e, principalmente, pela dedicação aos cuidados de pessoas queridas.

Ao Fernando e à Maria Amélia, pela ajuda e pelo amor às minhas filhas.

À Silvia M. Sucena Rocha, por sua torcida, sua amizade e seu acolhimento.

Ao $\mathrm{Dr}^{\circ}$ Sérgio Lebeis Nascimento e à Inês, com quem tive a oportunidade de trabalhar e de muito crescer e à Ângela Esposito, por tudo o que já compartilhamos.

Às funcionárias do Instituto da Criança: Adriana, Solange, Carol e Marisa, pela competência e paciência em me atender inúmeras vezes. 
$E$, finalmente, aos meus queridos pais, José e Ebe, meus grandes exemplos, por seu amor incondicional e por sempre terem lutado, permitindo que os meus sonhos se realizem. A vocês, devo tudo o que sou. 


\section{SUMÁRIO}

Lista de gráficos

Lista de tabelas

Lista de siglas

Resumo

Summary

1. Introdução .1

1.1 Situação de saúde da criança e as políticas públicas de atenção à saúde.

1.2 Estudos de morbidade como instrumentos para a gestão em saúde...11

1.3 Jufisticativa

2. Objetivos

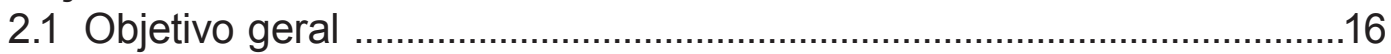

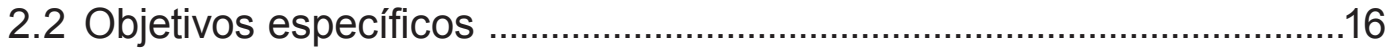

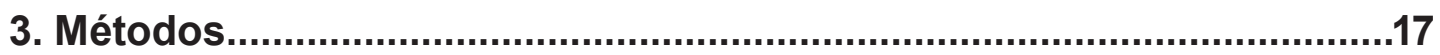

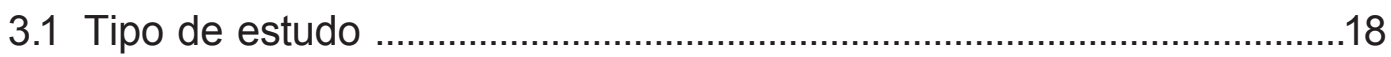

3.2 Período estudado..............................................................................

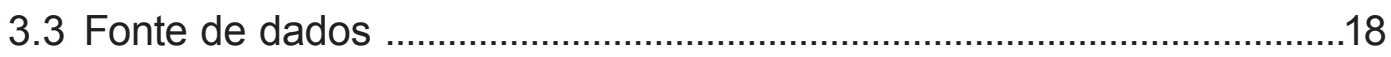

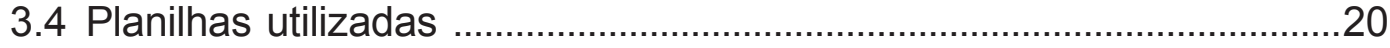

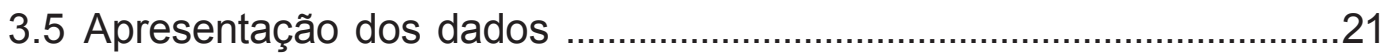

3.6 Aprovação em Comissão de Ética .........................................................23

3.7 Limitações do estudo .....................................................................23

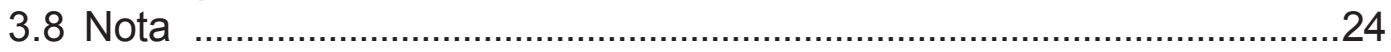

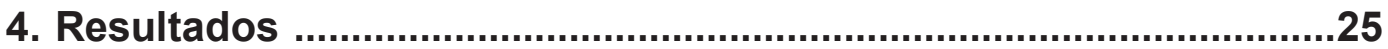

4.1 Apresentação dos resultados ...........................................................26

4.2 Características das internações hospitalares no município de São Paulo e no Brasil...........................................................................26

4.3 Causas de internação hospitalar das crianças de 0 a 9 anos de idade, no município de São Paulo e no Brasil ...............................................35

4.4 Causas de internação hospitalar, estratificadas por faixa etária, no município de São Paulo e no Brasil ..........................................................39

5. Discussão ...................................................................................76

5.1 Características das internações hospitalares no município de São Paulo e no Brasil ...........................................................................77

5.2 A variação do coeficiente de internação entre 2002 e 2006...................78

5.3 As causas de internação hospitalar .......................................................8

5.4 Evolução dos coeficientes de internação nas diferentes causas...........92

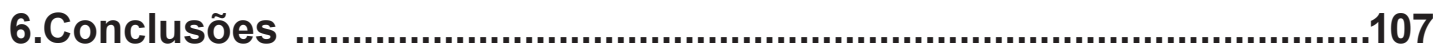

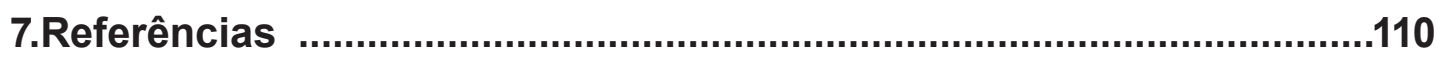

Anexo 


\section{LISTA DE FIGURAS E GRÁFICOS}

Gráfico 1 - Evolução da taxa de mortalidade infantil no Brasil 1990 a 2007

Gráfico 2 - Distribuição (\%) dos gastos do SUS segundo as causas hospitalizações de crianças menores de 5 anos no Brasil - 2001

Gráfico 3 - Proporção (\%) de internações hospitalares de crianças de 0 a 9 anos de idade no total das internações ocorridas no município de São Paulo, nos 5 anos do estudo - 2002 a 2006.

Gráfico 4 - Proporção (\%) de internações hospitalares de crianças de 0 a 9 anos de idade no total das internações ocorridas no Brasil, nos 5 anos de estudo - 2002 a 2006

Gráfico 5 - Distribuição(\%)dasmédias doscoeficientesdeinternações hospitalares por faixa etária, no município de São Paulo e no Brasil, nos 5 anos estudados - 2002 a 2006.

Gráfico 6 - Distribuição (\%) das internações hospitalares das crianças de 0 a 9 anos de idade, por gênero, no município de São Paulo e no Brasil, nos 5 anos estudados - 2002 a 2006.... 31

Gráfico 7 - Evolução do coeficiente de internação hospitalar das crianças de 0 a 9 anos de idade no município de São Paulo e no Brasil - 2002 a 2006.

Gráfico 8 - Distribuição (\%) dos agrupamentos das dez primeiras causas de internação das crianças de 0 a 9 anos de idade, no município de São Paulo, nos 5 anos estudados - 2002 a 2006 .

Gráfico 9 - Evolução do coeficiente de internação hospitalar das crianças menores de 1 ano de idade, no município de São Paulo e no Brasil - 2002 a 2006.

Gráfico 10 - Distribuição (\%) dos agrupamentos das dez primeiras causas de internação das crianças menores de 1 ano de idade, no município de São Paulo, nos 5 anos estudados - 2002 a 2006. 
Gráfico 11 - Evolução dos coeficientes de internação por doenças originadas no período perinatal, das crianças menores de 1 ano de idade, no município de São Paulo e no Brasil-2002 a 2006 .

Gráfico 12 - Evolução dos coeficientes de internação por outros transtornos respiratórios originados no período perinatal, dascriançasmenoresde1 anodeidade, nomunicípiodeSão Paulo e no Brasil - 2002 a 2006

Gráfico 13 - Evolução dos coeficientes de internação por outras afecções originadas no período perinatal, das crianças menores de 1 ano de idade, no município de São Paulo e no Brasil - 2002 a 2006

Gráfico 14 - Evolução dos coeficientes de internação por retardo de crescimento fetal, desnutrição fetal e transtornos relacionados á gestação curta e baixo peso, das crianças menores de 1 ano de idade, no município de São Paulo e no Brasil - 2002 a 2006.

Gráfico 15 - Evolução dos coeficientes de internação por hipóxia intrauterina e asfixia ao nascer, das crianças menores de 1 ano de idade, no município de São Paulo e no Brasil - 2002 a 2006.

Gráfico 16 - Evolução dos coeficientes de internação por doenças respiratórias, das crianças menores de 1 ano de idade, no município de São Paulo e no Brasil-2002 a 2006

Gráfico 17 - Evolução dos coeficientes de internação por pneumonia, dascriançasmenoresde 1 anodeidade, nomunicípiodeSão Paulo e no Brasil - 2002 a 2006.

Gráfico 18 - Evolução dos coeficientes de internação por asma, das crianças menores de 1 ano de idade, no município de São Paulo e no Brasil - 2002 a 2006.

Gráfico 19 - Evolução dos coeficientes de internação por bronquite aguda e bronquiolite aguda, das crianças menores de 1 ano de idade, no município de São Paulo e no Brasil 2002 a 2006.

Gráfico 20 - Evolução dos coeficientes de internação por outras doenças do aparelho respiratório, das crianças menores de 1 ano de idade,nomunicípiodeSãoPauloenoBrasil-2002a2006 
Gráfico 21 - Evolução dos coeficientes de internação por diarréia e gastroenterite de origem infecciosa presumível, das crianças menores de 1 ano de idade, no município de São Paulo e no Brasil - 2002 a 2006

Gráfico 22 - Evolução dos coeficientes de internação por malformações congênitas do aparelho circulatório, das crianças menores de 1 ano de idade, no município de São Paulo e no Brasil - 2002 a 2006

Gráfico 23 - Evolução do coeficiente de internação hospitalar das crianças de 1 a 4 anos de idade, no município de São Paulo e no Brasil - 2002 a 2006.

Gráfico 24 - Distribuição (\%) dos agrupamentos das dez primeiras causas de internação das crianças de 1 a 4 anos de idade, no município de São Paulo, nos 5 anos estudados - 2002 a 2006.

Gráfico 25 - Evolução dos coeficientes de internação hospitalar por doenças respiratórias, das crianças de 1 a 4 anos de idade, no município de São Paulo e no Brasil - 2002 a 2006.. 57

Gráfico 26 - Evolução dos coeficientes de internação hospitalar por pneumonia, das crianças de 1 a 4 anos de idade, no município de São Paulo e no Brasil - 2002 a 2006

Gráfico 27 - Evolução dos coeficientes de internação hospitalar por asma, das crianças de 1 a 4 anos de idade, no município de São Paulo e no Brasil - 2002 a 2006.

Gráfico 28 - Evolução dos coeficientes de internação hospitalar por doenças crônicas de amígdalas e adenóides, das crianças de 1 a 4 anos de idade, no município de São Paulo e no Brasil - 2002 a 2006

Gráfico 29 - Evolução dos coeficientes de internação hospitalar por causas cirúrgicas, das crianças de 1 a 4 anos de idade, no município de São Paulo e no Brasil - 2002 a 2006

Gráfico 30 - Evolução dos coeficientes de internação hospitalar por diarréia e gastroenterite de origem infecciosa presumível, das crianças de 1 a 4 anos de idade, no município de São Paulo e no Brasil - 2002 a 2006 
Gráfico 31 - Evolução dos coeficientes de internação hospitalar por outras doenças do sistema nervoso, das crianças de 1 a 4 anos de idade, no município de São Paulo e no Brasil 2002 a 2006

Gráfico 32 - Evolução dos coeficientes de internação hospitalar por infecções de pele e de tecido subcutâneo, das crianças de 1 a 4 anos de idade, no município de São Paulo e no Brasil - 2002 a 2006

Gráfico 33 - Evolução dos coeficientes de internação hospitalar por malformações congênitas do aparelho circulatório, das crianças de 1 a 4 anos de idade, no município de São Paulo e no Brasil - 2002 a 2006

Gráfico 34 - Evolução do coeficiente de internação hospitalar das crianças de 5 a 9 anos de idade, no município de São Paulo e no Brasil - 2002 a 2006.

Gráfico 35 - Distribuição (\%) dos agrupamentos das dez primeiras causas de internação das crianças de 5 a 9 anos de idade, no município de São Paulo, nos 5 anos estudados - 2002 a 2006.

Gráfico 36 - Evolução dos coeficientes de internação hospitalar por doenças respiratórias, das crianças de 5 a 9 anos de idade, no município de São Paulo e no Brasil - 2002 a 2006.

Gráfico 37 - Evolução dos coeficientes de internação hospitalar por pneumonia, das crianças de 5 a 9 anos de idade, no município de São Paulo e no Brasil - 2002 a 2006

Gráfico 38 - Evolução dos coeficientes de internação hospitalar por asma, das crianças de 5 a 9 anos de idade, no município de São Paulo e no Brasil - 2002 a 2006... 71

Gráfico 39 - Evolução dos coeficientes de internação hospitalar por doenças crônicas de amígdalas e adenóides, das crianças de 5 a 9 anos de idade, no município de São Paulo e no Brasil-2002a2006.

Gráfico 40 - Evolução dos coeficientes de internação hospitalar por causas cirúrgicas, das crianças de 5 a 9 anos de idade, no município de São Paulo e no Brasil - 2002 a 2006. 
Gráfico 41 - Evolução dos coeficientes de internação hospitalar por lesões secundárias a causas externas, das crianças de 5 a 9 anos de idade, no município de São Paulo e no Brasil - 2002 a 2006.

Gráfico 42 - Evolução dos coeficientes de internação hospitalar por outras doenças do sistema nervoso, das crianças de 5 a 9 anos de idade, no município de São Paulo e no Brasil 2002 a 2006.

Figura 1 - Representação esquemática dos fatores envolvidos no uso de serviços de saúde segundo o modelo comportamental de Andersen................................ 


\section{LISTA DE TABELAS}

Tabela 1 - População segundo faixa etária, por ano, no município de São Paulo - 2002 a 2006

Tabela 2 - População segundo faixa etária, por ano, no Brasil 2002 a 2006.

Tabela 3 - Porcentagem das internações das crianças de 0 a 9 anos de idade em relação ao total das internações, no município de São Paulo - 2002 a 2006

Tabela 4 - Porcentagem das internações das crianças de 0 a 9 anos de idade em relação ao total das internações, no Brasil - 2002 a 2006

Tabela 5 - $\quad$ Coeficientes de internação das crianças de 0 a 9 anos de idade, estratificado por faixa etária, no município de São Paulo - 2002 a 2006.

Tabela 6 - Coeficientes de internação das crianças de 0 a 9 anos de idade, estratificado por faixa etária, no Brasil - 2002 a 2006.

Tabela 7 - Porcentagem das internações das crianças do sexo masculino, estratificado por faixa etária, no município de São Paulo e no Brasil - 2002 a 2006.

Tabela 8 - Média de permanência hospitalar (dias), por faixa etária, no município de São Paulo e no Brasil, nos 5 anos estudados - 2002 a 2006

Tabela 9 - Distribuição (\%) das internações hospitalares das crianças de 0 a 9 anos, segundo os capítulos da CID-10 ( $2^{a}$ edição) no município de São Paulo e no Brasil, no período de 2002 a 2006.

Tabela 10 - As dez primeiras causas de internação das crianças de 0 a 9 anos de idade, no município de São Paulo nos 5 anos estudados - 2002 a 2006

Tabela 11 - As dez primeiras causas de internação das crianças menores de 1 ano de idade, no município de São Paulo, nos 5 anos estudados - 2002 a 2006. 
Tabela 12 - Evolução dos coeficientes de internação das dez primeiras causas de internação das crianças menores de 1 ano de idade, no município de São Paulo, comparativamente ao Brasil - 2002 a 2006.

Tabela 13 - As dez primeiras causas de internação das crianças de 1 a 4 anos de idade, no município de São Paulo, nos 5 anos estudados - 2002 a 2006

Tabela 14 - Evolução dos coeficientes de internação das dez primeiras causas de internação das crianças de 1 a 4 anos de idade, no município de São Paulo, comparativamente ao Brasil - 2002 a 2006.

Tabela 15 - As dez primeiras causas de internação das crianças de 5 a 9 anos de idade, no município de São Paulo, nos 5 anos estudados - 2002 a 2006.

Tabela 16 - Evolução dos coeficientes de internação das dez primeiras causas de internação das crianças de 5 a 9 anos de idade, no município de São Paulo, comparativamente ao Brasil - 2002 a 2006......... 69 


\section{LISTA DE SIGLAS}

$\begin{array}{ll}\text { AIDPI } & \text { Atenção Integrada às Doenças Prevalentes na Infância } \\ \text { AIH } & \text { Autorização de Internação Hospitalar } \\ \text { CID } & \text { Classificação Internacional de Doenças } \\ \text { CNES } & \text { Cadastro Nacional de Estabelecimentos de Saúde } \\ \text { DATASUS } & \text { Banco de dados do Sistema Único de Saúde } \\ \text { IBGE } & \text { Instituto Brasileiro de Geografia e Estatísticas } \\ \text { IDB } & \text { Indicadores e Dados Básicos do Brasil } \\ \text { IDI } & \text { Indice de Desenvolvimento Infantil } \\ \text { OMS } & \text { Organização Mundial de Saúde } \\ \text { ONU } & \text { Organização das Nações Unidas } \\ \text { OPAS } & \text { Organização Pan-Americana de Saúde } \\ \text { PACS } & \text { Programa de Agentes Comunitários de Saúde } \\ \text { PNAD } & \text { Pesquisa Nacional por Amostra de Domicílios } \\ \text { PNDS } & \text { Pesquisa Nacional de Demografia e Saúde da Criança } \\ & \text { e da Mulher } \\ \text { PSF } & \text { Programa de Saúde da Família } \\ \text { RIPSA } & \text { Rede Interagencial de Informações para a Saúde } \\ \text { SIH - SUS } & \text { Sistema de Informações Hospitalares do Sistema Único } \\ & \text { de Saúde } \\ \text { SUS } & \text { Sistema Único de Saúde } \\ \text { TRO } & \text { Terapia de Reidratação Oral } \\ \text { UNICEF } & \text { Fundo das Nações Unidas pela Infância } \\ \end{array}$




\section{RESUMO}

Ferrer, APS. Estudo das causas de internação hospitalar das crianças de 0 a 9 anos de idade no município de São Paulo [dissertação]. São Paulo. Faculdade de Medicina, Universidade de São Paulo; 2009.

O perfil de morbidade infantil é um parâmetro importante para a definição das políticas de saúde. Os estudos sobre mortalidade infantil são mais numerosos do que os sobre morbidade e, em especial, os que enfocam as internações hospitalares. Esse estudo teve como objetivo descrever as causas de internação das crianças de 0 a 9 anos de idade, no município de São Paulo, no período de 2002 a 2006, comparando-as aos dados nacionais. Os dados foram obtidos no Sistema de Informações Hospitalares, disponíveis no DATASUS. Nos 5 anos do estudo, ocorreram 451.303 internações de crianças de 0 a 9 anos de idade (16\% do total de internações), com predomínio dos menores de 1 ano de idade (74\%), seguido pelas crianças de 1 a 4 anos (16\%) e, menos frequentemente, as crianças de 5 a 9 anos (10\%). A média de permanência hospitalar foi de 7,3 dias no município e de 6 dias, no Brasil. Enquanto no município o coeficiente de internação aumentou 11\%, no Brasil diminuiu 14\%. As doenças respiratórias foram as principais causas de hospitalização, tanto no município como no Brasil. Em São Paulo a segunda causa de internação foram as afecções originadas no período perinatal $(15,9 \%)$ e, no Brasil, as doenças infecto-parasitárias $(21,7 \%)$. As dez causas principais corresponderam a praticamente metade das internações no município de São Paulo. As internações por doenças respiratórias aumentaram, no município, 31\% entre os menores de 1 ano de idade, $26 \%$ entre 1 e 4 anos e $34 \%$ entre 5 e 9 anos e diminuíram, no Brasil, nas 3 faixas etárias. As hospitalizações por doenças perinatais aumentaram $32 \%$ em São Paulo e $6 \%$ no Brasil. Enquanto as hospitalizações por diarréia 
diminuíram no Brasil, registrou-se aumento no município nos menores de 5 anos. As internações decorrentes de causas externas, mais frequentes entre 5 e 9 anos de idade, aumentaram em São Paulo e mantiveram-se inalteradas no Brasil. No período estudado aconteceram significativas mudanças nas políticas de saúde do município, com a adesão ao Sistema Único de Saúde (SUS) e fortalecimento da Atenção Básica, tendo a Estratégia de Saúde da Família como eixo estruturante. Os fatores determinantes das hospitalizações são múltiplos e interagem de maneira complexa. São discutidos os principais fatores, identificados no município, que podem ter contribuído para o perfil de internações observado.

Descritores: 1. Hospitalização 2 2. Saúde da criança 3 3. Morbidade 4. Serviços de saúde da criança 


\section{SUMMARY}

Ferrer, APS. Causes of hospital admissions among children of $0-9$ years old in São Paulo [dissertation\}.São Paulo. "Faculdade de Medicina, Universidade de São Paulo"; 2009.

Child's morbidity profile is an important parameter for the definition of health policies. Studies on infant mortality are more numerous than those on morbidity and, in particular, those focused on hospitalization. This study aimed to describe the causes of 0 to 9 years old children hospitalization in São Paulo during 2002 to 2006 and to compare them to the national ones. The data were obtained in the Brazilian Hospital Database, available in DATASUS. In the 5 years period analyzed in this study, there were 451.303 hospitalizations for 0 to 9 years old children (16\% of total admissions). There was a predominance of children under 1 year of age (74\%), followed by 1 to 4 years years old children (6\%) and less often, children with 5 to 9 years of age (10\%). The average hospital stay was 7.3 days in the Sao Paulo and 6 days in Brazil. While the coefficient of hospitalization increased in the municipality by $11 \%$, in Brazil it fell $14 \%$. Respiratory diseases were the leading causes of hospitalization, both in Sao Paulo as in Brazil. In Sao Paulo, the second leading cause of hospitalization was diseases originating in the perinatal period (15.9\%) while in Brazil it was infectious and parasitic diseases (21.7\%). In São Paulo, the ten leading causes accounted for almost half of all hospitalization. In the municipality the respiratory illnesses's admissions increased, 31\% of children under 1 year of age, $26 \%$ between 1 and 4 years of age, and $34 \%$ between 5 and 9 years of age while it decreased in Brazil in the 3 age groups. The hospitalization for perinatal diseases increased 32\% in São Paulo and 6\% in Brazil. Although hospitalizations for diarrhea decreased in Brazil, in Sao Paulo they increased in chlidren less than 
5 years old. The admissions due to external causes, most frequent between 5 and 9 years old children, rose in Sao Paulo and remained unchanged in Brazil. In the period studied there were significant changes in health policies of the municipality. The Brazilian national health system (SUS) was implemented in the city, with strengthening of Primary Healthcare and the Family Health Strategy. The determinants of hospital admissions are multiple and interact in complex ways. The main factors which may have contributed to the observed profile of admissions identified in the municipality were discussed.

Descriptors: 1. Hospitalization 2. Child health (public health) 3. Morbidity 4. Child health services 
1.INTRODUÇÃO 


\subsection{SITUAÇÃO DE SAÚDE DA CRIANÇA E AS POLÍTICAS PÚBLICAS DE ATENÇÃO À SAÚDE}

A epidemiologia moderna tem adotado o enfoque de risco como um norteador para a assistência primária à saúde e a parcela da população formada por mães e crianças é considerada um grupo muito vulnerável. Por isso, a atenção à saúde materno-infantil tem sido priorizada nas políticas públicas assistenciais (FIGUEIREDO e MELLO, 2007). Exemplo dessa preocupação é a "Declaração Mundial sobre a Sobrevivência, a Proteção e o Desenvolvimento da Criança", que foi assinada pelo Brasil e por mais de 160 países, durante - Encontro Mundial de Cúpula pela Criança da Organização das Nações Unidas (ONU), em 1990. Por esse documento, os governos comprometeramse a trabalhar em favor da saúde e dos direitos das crianças e das mães. Os objetivos contidos nesta declaração: redução da mortalidade dos menores de 5 anos de idade, redução da mortalidade materna, redução das taxas de desnutrição infantil, acesso à educação, redução do analfabetismo e acesso ao saneamento básico passaram a ser diretrizes para as políticas públicas. Esses objetivos contemplam os principais fatores implicados pelos estudos epidemiológicos no processo saúde-doença: nutrição, renda, saneamento, escolaridade dos membros da família, em particular a materna, e acesso à assistência à saúde (MONTEIRO, 2000). Posteriormente, em 2000, foi assinada a Declaração do Milênio e, em 2002, o documento "Um mundo para as crianças", ambos propostos pela ONU, tendo o Brasil como signatário. Nesses documentos ratificou-se o compromisso de melhorar os indicadores em relação à infância, particularmente com a redução da mortalidade infantil. 
Durante a década de 1990, definiu-se a necessidade de programas de saúde para a população como um todo e para grupos específicos, como o formado por mães e crianças, com uma perspectiva mais coletiva e preventiva (MENDONÇA, 2002). Nesse sentido, o Ministério da Saúde criou, em 1991, o Programa de Agentes Comunitários de Saúde (PACS) e, em 1994, o Programa de Saúde da Família (PSF), ambos no sentido de promover a atenção primária, oferecendo às famílias serviços de saúde preventiva e curativa em suas próprias comunidades, resultando em melhora importante das condições de saúde, particularmente do grupo materno-infantil. O PSF atende às necessidades da população como um todo, mas, em particular, à parcela que não dispõe de fácil acesso a serviços de saúde e tem aumentado muito o número de municípios atendidos e de famílias cadastradas, principalmente na região Nordeste do Brasil (MINISTÉRIO DA SAÚDE, 1998). Conforme levantamento realizado pelo Ministério da Saúde, o aumento da cobertura do PSF contribuiu mais para a queda das taxas de mortalidade infantil que a ampliação do acesso à água tratada ou a criação de novos leitos hospitalares (UNICEF, 2005)

O PSF incorporou a estratégia AIDPI - Atenção Integrada ás Doenças Prevalentes na Infância - uma proposta da Organização Mundial de Saúde (OMS), da Organização Pan-Americana da Saúde (OPAS) e do Fundo das Nações Unidas para a Infância (UNICEF), adotada pelo Ministério da Saúde em 1996. Em resposta aos problemas mais comuns associados aos óbitos de crianças menores de 5 anos de idade em países em desenvolvimento, a estratégia AIDPI foi elaborada no sentido de promover a saúde, propondo medidas de prevenção das doenças (estimulando o aleitamento materno, melhorando as condições nutricionais e atualizando as imunizações) e de diagnosticar e tratar precoce e adequadamente as crianças doentes, por meio de intervenções padronizadas. O principal objetivo da AIDPI é a redução 
da mortalidade das crianças menores de 5 anos, diminuindo a incidência e/ ou a gravidade dos distúrbios nutricionais e das doenças infecciosas, como pneumonia, diarréia, parasitoses intestinais, meningites, tuberculose, malária e sarampo (MINISTÉRIO DA SAÚDE, 1999; VIDAL et al, 2003; FIGUEIREDO e MELLO, 2007).

A redução da mortalidade infantil sempre foi uma das principais metas das políticas públicas para a infância em todos os países, principalmente no primeiro ano de vida, faixa em que se concentra o maior número de óbitos. A taxa de mortalidade infantil é considerada um dos indicadores básicos do desenvolvimento humano por refletir as condições de vida e de assistência à saúde de uma população (MARANHÃO). No Brasil, a taxa de mortalidade infantil vem apresentando uma queda significativa, embora ainda seja alta. Segundo dados do Ministério da Saúde, a taxa de mortalidade infantil apresentou, em média, uma redução de 59\% entre 1990 e 2007, indo de 47,1 para 19,3 para cada mil nascidos vivos (gráfico 1).

Gráfico 1 - Evolução da taxa de mortalidade infantil no Brasil - 1990 a 2007

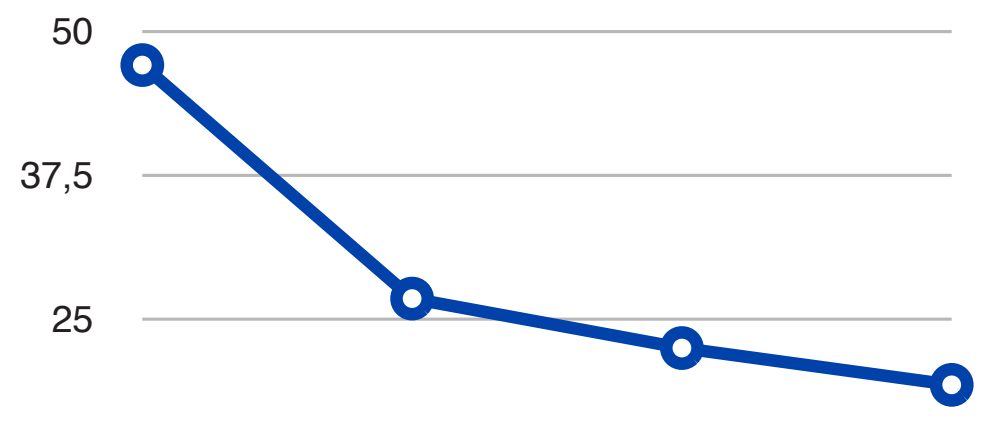

12,5

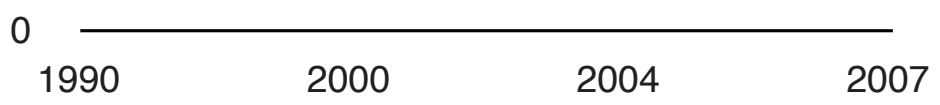


A mudança em relação à mortalidade infantil não foi apenas de queda no número dos óbitos, mas também de alteração nas causas de mortalidade. A melhoria das condições sociais e nutricionais da população provocou uma redução das mortes por doenças infecciosas e parasitárias, principalmente no que diz respeito à diarréia. Houve ainda, redução nos óbitos por doenças respiratórias e aumento proporcional nas causas perinatais. A asfixia durante o parto, a prematuridade e as infecções neonatais são as principais causas de óbito de crianças no Brasil (UNICEF, 2005). A queda na taxa de mortalitade infantil ocorreu basicamente por redução do componente de mortalidade pós-neonatal, isto é, os óbitos que ocorrem entre 28 e 364 dias de vida. A mortalidade neonatal, seja a precoce (entre 0 e 6 dias de vida) ou a tardia (entre 7 e 27 dias de vida), permanece em níveis praticamente constantes, passando a ser o principal componente da mortalidade infantil (LANSKY et al, 2002). A prematuridade e o baixo peso ao nascer são os principais fatores associados à mortalidade neonatal. Enquanto o componente pós-neonatal é um bom indicador das condições de vida da população, o componente neonatal representa as condições perinatais e, portanto, demonstra que, no Brasil, a assistência materno-infantil no pré-natal, no parto e logo após o parto ainda tem muito a melhorar (SCHIRMER, 2000). Uma das iniciativas governamentais no sentido de reforçar os cuidados no período perinatal foi a criação do Pacto Nacional pela Redução da Mortalidade Materna e Neonatal, em 2004, com o objetivo de diminuir a mortalidade materna e neonatal.

Além da manutenção de níveis elevados de mortalidade neonatal, outro fator preocupante em relação à mortalidade infantil é a existência de ampla variação, seja entre os diferentes grupos sociais, seja nas diferentes regiões do Brasil. Apesar dos avanços nas políticas públicas, ainda existem muitas desigualdades sociais e econômicas no país, com reflexo nos indicadores de 
saúde. Assim, a população do quintil mais pobre tem o dobro da mortalidade infantil em relação ao quintil mais rico e, a região nordeste é a mais vulnerável do Brasil, com o dobro da taxa de mortalidade verificada nas regiões Sul e Sudeste (COMISSÃO NACIONAL SOBRE DETERMINANTES SOCIAIS DA SAÚDE, 2008). Os valores médios nacionais tendem a ocultar grandes disparidades entre áreas urbanas e rurais, entre regiões, entre os estados e entre os diferentes municípios.

A melhora observada nos indicadores de mortalidade infantil decorre, além de intervenções específicas do setor saúde, da interação de fatores demográficos, sociais e econômicos. Um instrumento utilizado para acompanhar os avanços atingidos no sentido de melhorar a situação da infância é o Indice de Desenvolvimento Infantil (IDI), o qual contribui para a formulação e monitoramento de políticas públicas voltadas às crianças. O IDI não apenas permite a comparação dos resultados ao longo do tempo como permite comparar regiões distintas, ao incorporar variáveis relacionadas à oferta de serviços de saúde e de educação e à capacidade das famílias em cuidar das crianças. Segundo dados apresentados pelo UNICEF (2005), o IDI nacional melhorou: em 1999, 40\% dos municípios brasileiros apresentavam IDI abaixo de 0,500 (considerado baixo) e, em 2004, 25\% dos municípios mantinham-se nesse patamar. O estado de São Paulo foi o único a atingir o patamar de 0,800 (considerado elevado), com uma condição de alto desenvolvimento infantil.

Embora a taxa de mortalidade infantil venha apresentando, nas últimas décadas, uma redução significativa, os gastos hospitalares pelo Sistema Único de Saúde (SUS) ainda permanecem elevados. De acordo com citação de MARANHÃO, em 2001, a despesa do SUS com as internações de crianças menores de 5 anos superou os 650 milhões de reais. As infecções respiratórias e as diarréias agudas, que apresentaram quedas importantes no número de 
óbitos, ainda têm importante participação nesses custos, ao lado das afecções perinatais (gráfico 2).

Gráfico 2 - Distribuição (\%) dos gastos do SUS segundo as causas de hospitalizações de crianças menores de 5 anos no Brasil 2001

Infecções Respiratórias

Afecções perinatais

Diarréia aguda

Septicemia

$41,5 \%$

Malformações congênitas do aparelho circulatório

Causas externas

Desnutrição

Demais causas

$16 \%$

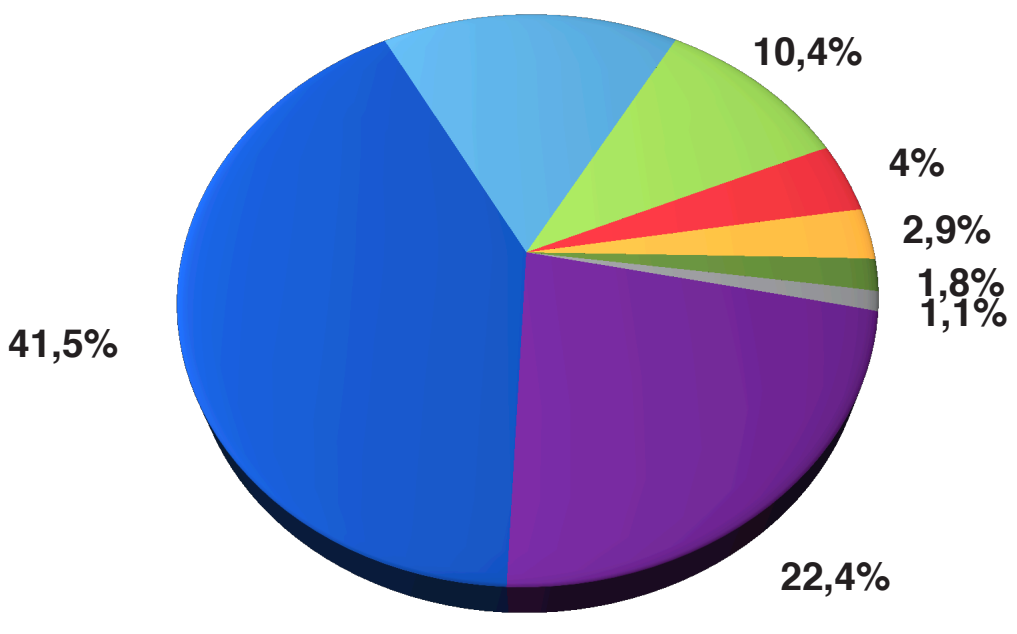

Fonte: Ministério da Saúde

\subsubsection{A situação de saúde da criança no município de São Paulo}

A população estimada do município de São Paulo, em 2009, é de 11.037.590 habitantes, sendo que $15 \%$ deste total corresponde a crianças de 0 a 9 anos de idade.

O município é uma região privilegiada, em termos sociais e econômicos, comparativamente aos demais municípios brasileiros, com um IDI de 0,798, em 2004. Nos inquéritos realizados por MONTEIRO et al em 1984/85 e em 1995/96, verificou-se que ocorreu um aumento na renda e na escolaridade, superiores aos relatados para a população brasileira em geral, além disso, esses autores descreveram melhoras significativas nas condições de moradia, 
de saneamento, de abastecimento de água e de coleta de lixo. Tais mudanças foram acompanhadas de queda na taxa de mortalidade infantil, seguindo a tendência nacional. A taxa de mortalidade em São Paulo já alcançou valores considerados baixos, sendo, em 2006, 12,90 para cada 1000 nascidos vivos.

Contrapondo-se aos dados de mortalidade, verifica-se que a morbidade e prevalência de algumas doenças e agravos ainda permanecem elevadas. MONTEIRO et al relataram que as melhorias nas condições sociais foram acompanhadas por queda na prevalência da desnutrição e da diarréia, porém as doenças respiratórias e a anemia tenderam a aumentar, e o peso ao nascer não apresentou a melhora esperada.

Assim como verificado no Brasil, em São Paulo as taxas de internações hospitalares na faixa etária pediátrica continuam elevadas. Na Pesquisa Nacional de Demografia e Saúde da Criança e da Mulher (PNDS) 12,3\% das crianças menores de 5 anos foram internadas, no Brasil, no ano anterior à pesquisa e, na região Sudeste, este valor foi bastante semelhante $11,6 \%$. As doenças respiratórias foram o principal motivo de internação em todas as regiões. O que diferiu entre a região Sudeste e as demais regiões do país foram as demais causas de hospitalização, enquanto no Sudeste apenas $7,4 \%$ das internações foram por diarréia, na região Nordeste esse valor chegou a $28,4 \%$ e na região Norte a $36,4 \%$. A PNDS não relata a ocorrência de internações por doenças de origem perinatal, mas sabe-se que essas têm sido cada vez mais expressivas. Um estudo sobre os custos de internação, realizado em Minas Gerais (BERENSTEIN, 2005) revelou que a prematuridade destaca-se como um dos principais motivos implicados na elevação dos gastos com procedimentos hospitalares, principalmente nas capitais do Sul e Sudeste, tanto pela freqüência como por apresentar um custo médio bem elevado. 
Com a queda significativa na taxa de mortalidade infantil no período pósneonatal, a preocupação voltou-se para a redução da mortalidade neonatal e para o controle das morbidades, melhorando a qualidade de vida das crianças, visando propiciar condições para que desenvolvam plenamente o seu potencial.

\subsubsection{As políticas de saúde no município de São Paulo}

Para a promoção de boas condições de saúde na infância são importantes a disponibilidade e a qualidade da assistência materno-infantil, ou seja, a atenção à saúde que recebem as gestantes, os recém-nascidos e as crianças. Nesse sentido, são fundamentais a adequada assistência prénatal, os cuidados durante o parto e o seguimento de puericultura, traduzido por cuidados preventivos como as imunizações, orientações para uma adequada alimentação, acompanhamento do crescimento e desenvolvimento, orientações para prevenção de acidentes, além da detecção precoce de doenças e agravos.

Em relação à assistência materno-infantil na cidade de São Paulo, MONTEIRO et al relataram que no período compreendido entre 1984/85 e 1995/96 houve um aumento nas consultas de puericultura no primeiro ano de vida e uma universalização da cobertura vacinal. Porém, observaram como aspectos negativos, a não ampliação dos cuidados de puericultura além do primeiro ano de vida, inadequações na assistência ao parto, com excesso de cesarianas, e uma evolução desfavorável nos cuidados de pré-natal. Esses autores constataram que a maioria das gestantes iniciou o pré-natal tardiamente e com baixo número de consultas. Essas observações foram particularmente mais desfavoráveis na população de renda inferior. Nesse mesmo período, 
TANAKA et al (1989) avaliando a assistência à gestante e ao recém nascido no estado de São Paulo verificaram alta porcentagem de partos cesarianas e uma grande freqüência de óbitos maternos e neonatais evitáveis, concluindo que a assistência pré-natal era de má qualidade.

O sistema de saúde vigente é um dos fatores que pode estar implicado na qualidade da atenção à saúde em São Paulo. O município de São Paulo não fazia parte do SUS e a saúde era estruturada em um sistema de cooperativas, o que constituiu um atraso em relação aos demais municípios. Somente em 2001 a prefeitura de São Paulo passou a integrar o SUS. Com a municipalização, foram criados 41 Distritos de Saúde, que passaram a ser as instâncias descentralizadas de gestão do sistema. A divisão em distritos objetivou facilitar a administração e viabilizar o planejamento e a execução de políticas de saúde fundadas nas necessidades específicas de cada região, dada a enorme desigualdade socioeconômica existente no município. A organização dos serviços de saúde visou o fortalecimento da atenção básica tendo, como eixo estruturante, a Estratégia de Saúde da Família. Houve uma rápida expansão no número de equipes de saúde da família, sendo priorizadas as regiões mais carentes do município e a formação e a capacitação de profissionais de saúde para atuarem no PSF (SECRETÁRIA DE SAÚDE DO MUNICÍPIO DE SÃO PAULO, 2002).

Em relação à saúde infantil, as metas prioritárias foram: redução da morbimortalidade neonatal e o acompanhamento das crianças, priorizando aquelas consideradas de risco. Os critérios de risco adotados foram: baixo peso ao nascer, morte de irmão menor de 5 anos, internação após a alta materna e alguns critérios sociais, como a mãe adolescente ou com condições que dificultassem os cuidados à criança, mãe analfabeta e chefe de família sem fonte de renda. Para atingir essas metas, as diretrizes adotadas foram a 
hierarquização e regionalização dos serviços de saúde, que deveriam estar integrados e articulados, abrangendo os diversos níveis de complexidade. Além do PSF e da incorporação da estratégia AIDPI, foi criado, em 2002, o projeto Nascer Bem, visando assegurar os cuidados necessários às gestantes, um parto seguro e os cuidados ao recém-nascido, para reduzir a mortalidade materna e neonatal (CADERNO TEMÁTICO DA CRIANÇA, 2003). Após a mudança de governo, em março de 2006, o projeto Nascer Bem foi substituído pelo programa Rede de Proteção á Mãe Paulistana, com os mesmos objetivos do projeto anterior.

\subsection{ESTUDOS DE MORBIDADE COMO INSTRUMENTOS PARAA GESTÃO EM SAÚDE}

A epidemiologia não é apenas uma ciência, mas também um instrumento que permite o desenvolvimento de medidas e políticas de saúde adequadas às características de determinada população, de determinado local, em um determinadoperíodo. Estavertentedaepidemiologiafundamenta-seemestudos de situação de saúde (GOLDBAUM, 1996). Isto é, a partir do conhecimento da distribuição e freqüência das doenças e agravos são propostas estratégias e ações específicas à realidade da população estudada.

Esses estudos permitem, ainda, conhecer a prevalência e a incidência das doenças, suas particularidades em diferentes populações relacionadas às diferentes características sociais e demográficas e as suas tendências ao longo do tempo. O conhecimento desses dados é fundamental tanto para a elaboração de estratégias e de ações em saúde como para a avaliação do impacto dessas ações sobre o controle das doenças. 
O perfil de morbimortalidade da população é o resultado da interação de múltiplos fatores interdependentes e é considerado "um indicador relativamente sensível das condições de vida e do modelo de desenvolvimento de uma população" (PRATA, 1992).

Diante do panorama da situação de saúde da criança no município de São Paulo, no qual se verificou redução significativa das taxas de mortalidade infantil não acompanhada por queda na morbidade, fica evidente que pesquisas levando em consideração os padrões de morbidade podem ser mais importantes para a tomada de decisões em saúde pública. Os estudos de morbidade captam aspectos do processo saúde-doença que escapam das estatísticas de mortalidade, uma vez que estas informam apenas sobre o evento final deste complexo processo. Além disso, os estudos de morbidade constituem um importante complemento aos dados fornecidos pelos estudos de mortalidade (LAURENTI, 1987).

Alguns autores consideram as informações sobre taxas e causas de internação importantes indicadores da qualidade da assistência oferecida e também indicadores indiretos da resolubilidade ambulatorial (SILVA et al, 1999). Segundo STARFIELD (1992), os estudos sobre a morbidade hospitalar permitem a avaliação do acesso, da longitudinalidade e da qualidade da assistência prestada pelos serviços de atenção primária.

A morbidade hospitalar, embora represente a parcela mais grave e que teve acesso à internação, tem especial importância por representar a fração que absorve a maior quantidade de recursos dentro da política assistencial (FRANCISCO et al, 2004). Além dos custos, a hospitalização de uma criança a coloca em um ambiente estranho, podendo haver conseqüências psicológicas e iatrogênicas (SILVA et al, 1999). 
Além das estatísticas hospitalares, são consideradas outras fontes de informação da morbidade os registros de consultas ambulatoriais, os dados fornecidos pela notificação compulsória de algumas doenças e os inquéritos domiciliares. Em comparação a essas outras fontes de informação, as estatísticas hospitalares são consideradas mais completas do que as obtidas das consultas ambulatoriais e das doenças de notificação compulsória e de mais fácil execução que os inquéritos domiciliares (LEBRÃO, 1997),

Ao se trabalhar com as informações sobre morbidade hospitalar é fundamental considerar que os dados obtidos não representam apenas a ocorrência de internações por determinadas doenças, mas traduzem o complexo processo saúde-doença, em que estão envolvidos inúmeros aspectos como oferta de recursos, acesso aos serviços, políticas de saúde, além das necessidades da população.

\subsection{JUSTIFICATIVA}

As mudanças sociais e econômicas provocaram, no mundo todo, um fenômeno conhecido por transição epidemiológica, representado por redução expressiva na prevalência de doenças infecto-contagiosas, melhora no padrão nutricional, e aumento da prevalência de doenças crônico-degenerativas e das decorrentes de causas externas. Essas transformações, associadas a mudanças no padrão demográfico, foram responsáveis por alterações no padrão de morbimortalidade da população. Assim, no Brasil e, particularmente no município de São Paulo, observou-se redução expressiva das taxas de mortalidade infantil, embora a morbidade ainda permaneça elevada, tornando cada vez mais importantes os estudos sobre morbidade na infância. Entretanto, esses estudos não são freqüentes, particularmente os que abordam as causas de internação. 
O conhecimento da morbidade, principalmente da parcela responsável por hospitalizações, é importante por permitir avaliar a assistência oferecida, refletir a qualidade da atenção primária, favorecendo a gestão em saúde e a adoção de políticas voltadas para as necessidades da população. A avaliação da morbidade ao longo de um período e, em determinada região, é ainda mais representativa dessas necessidades de saúde.

Justifica-se, portanto, a realização de estudos sobre a morbidade hospitalar infantil, principalmente se considerarmos uma região onde as taxas de mortalidade infantil são baixas, como o município de São Paulo. A realização desse estudo, durante um período de marcadas mudanças nas políticas de saúde, como os anos iniciais do SUS e da expansão do PSF, o torna ainda mais significativo. 
2.OBJETIVOS 


\subsection{OBJETIVO GERAL}

Estudar as causas de internação hospitalar das crianças de 0 a 9 anos de idade e sua evolução no período de 2002 a 2006, no município de São Paulo.

\subsection{OBJETIVOS ESPECÍFICOS}

1. Descrever as causas de internação hospitalar das crianças de 0 a 9 anos de idade, estratificando-as por faixa etária, no município de São Paulo, no período de janeiro de 2002 a dezembro de 2006.

2. Analisar a evolução das dez primeiras causas de internação das crianças de 0 a 9 anos de idade, nas diferentes faixas etárias, no município de São Paulo, no período de janeiro de 2002 a dezembro de 2006.

3. Comparar os resultados obtidos no município com os dados nacionais.

4. Discutir os possíveis fatores condicionantes da evolução das internações tendo por base os programas de saúde da criança e as políticas de saúde vigentes à época do estudo. 
3.MÉTODOS 


\subsection{TIPO DE ESTUDO}

Trata-se de um estudo de corte transversal descritivo e analítico sobre as internações de crianças de 0 a 9 anos de idade, segundo o local de ocorrência: município de São Paulo e Brasil, durante um período de cinco anos.

\subsection{PERÍODO ESTUDADO}

Foram avaliadas as hospitalizações que ocorreram de janeiro de 2002 a dezembro de 2006.

A escolha do período de estudo levou em consideração:

1. Início em 2002 porque o município de São Paulo passou a integrar o SUS a partir de 2001.

2. Término em 2006 para que as informações contidas no banco de dados estivessem atualizadas e completas, uma vez que pode haver uma latência de, pelo menos, 6 meses entre a ocorrência do evento e a sua inclusão no sistema de informação.

\subsection{FONTE DE DADOS}

Os dados da pesquisa foram obtidos do banco de dados contido no Sistema de Informações Hospitalares dos SUS (SIH-SUS), disponível no endereço eletrônico: http://w3.datasus.gov.br/datasus/datasus.php, selecionadose as opções: "Informações de Saúde" - "Epidemiológicas e Morbidade" "Morbidade Hospitalar" - "Geral”, por local de internação, de 1984 a 2007.

O SIH - SUS é um banco de dados originado nas Autorizações de Internação Hospitalar (AlH), um formulário preenchido em todas as internações 
hospitalares subsidiadas pelo SUS que é utilizado para o reembolso financeiro dessas hospitalizações.

Várias publicações têm avaliado o SIH - SUS como fonte de informação e, apesar de alguns problemas descritos, o tem qualificado como uma importante ferramenta para a vigilância epidemiológica e para a avaliação de ações em saúde (CARVALHO, 1997). Os problemas descritos são a confiabilidade do diagnóstico e do preenchimento da $\mathrm{AlH}$, principalmente por dois motivos: a codificação das doenças feita por pessoas não preparadas para a função (LEBRÃO, 1997) e a possibilidade de ocorrência de fraudes, já que é instrumento para o reembolso financeiro (PEREIRA, 1995). As principais vantagens encontradas na utilização do SIH - SUS são: a abrangência nacional, o grande volume de dados disponível, o fácil acesso às informações e o curto intervalo de tempo entre a ocorrência do evento e o registro no sistema (CAMPOS et, 2000). Portanto, o uso do SIH - SUS é validado como importante fonte de informações relacionadas à morbidade, ao desempenho da assistência e ao uso dos serviços, permitindo a avaliação e a melhoria da atenção em saúde (BITTENCOURT et al, 2006; CAMPOS et al, 2000; CANDIAGO, et al, 2007; MENDES et al, 2000; PORTELA et al, 1997).

BITTENCOURT et al avaliando a produção científica envolvendo o SIH SUS e a sua aplicação em saúde coletiva, encontraram publicações focalizando as mudanças nos perfis de morbimortalidade hospitalar ao longo do tempo e as comparações das causas de internações por regiões geográfcas. Conforme descrito, "O estudo da tendência temporal das causas das internações permitiu aos autores levantar hipóteses sobre influências de transformações demográficas, epidemiológicas e de práticas médicas nas últimas décadas ... a análise espacial evidenciou desigualdades regionais na situação de saúde e no acesso à assistência hospitalar". 


\subsection{PLANILHAS UTILIZADAS}

Para a obtenção dos dados a serem analisados, foram feitas as seguintes planilhas no sistema TABNET do DATASUS, no programa Excel 97 do Microsoft Office:

1. Número de internações, por faixa etária, em cada ano:

- Linha: faixa etária 1 (menor de 1 ano, 1 a 4 anos, 5 a 9 anos, 10 a 14 anos, 15 a 19 anos, 20 a 29 anos, 30 a 39 anos, 40 a 49 anos, 50 a 59 anos, 60 a 69 anos, 70 a 79 anos, 80 anos ou mais).

- Coluna: ano de competência (2002, 2003, 2004, 2005, 2006).

- Conteúdo: Internações.

2. Número de internações, por gênero, por faixa etária, em cada ano:

- Linha: faixa etária 1 (menor de 1 ano, 1 a 4 anos, 5 a 9 anos).

- Coluna: ano de competência (2002, 2003, 2004, 2005, 2006).

- Conteúdo: Internações.

Primeiro fez-se a planilha selecionando-se o sexo masculino e, depois, o sexo feminino.

3. Média de permanência hospitalar, por faixa etária:

- Linha: faixa etária 1 (menor de 1 ano, 1 a 4 anos, 5 a 9 anos, 10 a 14 anos, 15 a 19 anos, 20 a 29 anos, 30 a 39 anos, 40 a 49 anos, 50 a 59 anos, 60 a 69 anos, 70 a 79 anos, 80 anos ou mais).

- Coluna: ano de competência (2002, 2003, 2004, 2005, 2006).

- Conteúdo: Média de permanência hospitalar. 
4. Causa de internação, segundo o capítulo do CID - 10 revisado:

- Linha: capítulo do CID-10 revisado.

- Coluna: Ano de competência (2002, 2003, 2004, 2005, 2006).

- Conteúdo: Internações.

A planilha foi feita para as internações das crianças de 0 a 9 anos, selecionado-se as três faixas etárias etárias (menor de 1 ano, 1 a 4 anos, 5 a 9 anos).

5. Causa de internação, conforme a morbidade:

- Linha: lista de morbidade do CID-10 revisado.

- Coluna: Ano de competência (2002, 2003, 2004, 2005, 2006).

- Conteúdo: Internações.

A primeira planilha foi feita para as internações das crianças de 0 a 9 anos de idade, selecionando-se as 3 faixas etárias (menor de 1 ano, 1 a 4 anos, 5 a 9 anos) e, depois, foram feitas as planilhas para cada faixa etária separadamente.

Todas as planilhas foram feitas, segundo o local de internação, tanto para o município de São Paulo como para o Brasil.

\subsection{APRESENTAÇÃO DOS DADOS}

Os dados resultantes da pesquisa são apresentados em freqüências, proporções e coeficientes de internação.

Os coeficientes de internação foram calculados para relativizar o número absoluto de internações à população avaliada, permitindo a comparação de populações de diferentes faixas etárias, dos diversos anos estudados e de 
diferentes regiões geográficas. Assim, o coeficiente de internação $(\mathrm{Cl})$ foi calculado para cada 1000 crianças, conforme a fórmula:

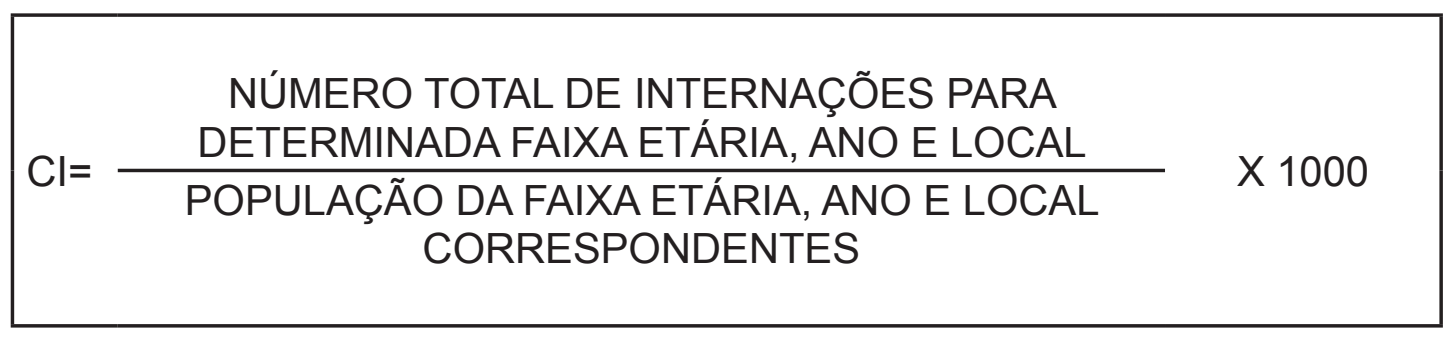

Os dados referentes à população foram obtidos no mesmo endereço eletrônico, selecionando-se "IDB - Indicadores e dados básico do Brasil", cuja origem dos dados é o Instituto Brasileiro de Geografia e Estatística (IBGE). Assim, foram adotados os números apresentados nas tabelas 1 e 2 .

Tabela 1 - População segundo faixa etária, por ano, no município de São Paulo - 2002 a 2006

\begin{tabular}{cccccc}
\hline Faixa Etária & $\mathbf{2 0 0 2}$ & $\mathbf{2 0 0 3}$ & $\mathbf{2 0 0 4}$ & $\mathbf{2 0 0 5}$ & $\mathbf{2 0 0 6}$ \\
\hline Menor 1 ano & 180456 & 181388 & 183348 & 184428 & 165030 \\
\hline 1 a 4 anos & 698328 & 696621 & 693033 & 691058 & 704235 \\
\hline 5 a 9 anos & 801906 & 789795 & 764336 & 750309 & 880372 \\
\hline TOTAL & $\mathbf{1 6 8 0 6 9 0}$ & $\mathbf{1 6 6 7 8 0 4}$ & $\mathbf{1 6 4 0 7 1 7}$ & $\mathbf{1 6 2 5 7 9 5}$ & $\mathbf{1 7 4 9 6 3 7}$ \\
\hline
\end{tabular}


Tabela 2 - População segundo faixa etária, por ano, no Brasil - 2002 a 2006

\begin{tabular}{cccccc}
\hline Faixa Etária & $\mathbf{2 0 0 2}$ & $\mathbf{2 0 0 3}$ & $\mathbf{2 0 0 4}$ & $\mathbf{2 0 0 5}$ & $\mathbf{2 0 0 6}$ \\
\hline Menor 1 ano & 3230339 & 3232749 & 3237676 & 3240434 & 3194038 \\
$\mathbf{1}$ a 4 anos & 13130775 & 13115991 & 13083991 & 13066332 & 13478910 \\
$\mathbf{5}$ a 9 anos & 16406183 & 16325462 & 16153863 & 16059207 & 17892311 \\
\hline TOTAL & $\mathbf{3 2 7 6 7 2 9 7}$ & $\mathbf{3 2 6 7 4 2 0 2}$ & $\mathbf{3 2 4 7 5 5 3 0}$ & $\mathbf{3 2 3 6 5 9 7 3}$ & $\mathbf{3 4 5 6 5 2 5 9}$ \\
\hline
\end{tabular}

Fonte: IBGE

\subsection{APROVAÇÃO EM COMISSÃO DE ÉTICA}

O projeto de pesquisa, sob o protocolo de pesquisa $n^{\circ} 1219 / 07$, foi avaliado pela Comissão de Ética para Análise de Projetos de Pesquisa - CAPPesqda Diretoria Clínica do Hospital das Clínicas e da Faculdade de Medicina da Universidade de São Paulo, em 20/02/2008, e recebeu aprovação (ANEXO 1).

O título da pesquisa foi modificado após o exame de qualificação por ter se considerado mais adequado a mudança da faixa etária, dadas as especificidades encontradas entre 10 e 14 anos de idade.

\subsection{LIMITAÇÕES DO ESTUDO}

Algumas limitações do estudo puderam ser previamente consideradas:

1. As internações hospitalares, objeto de estudo, não representam toda a morbidade, por refletirem apenas a morbidade mais grave, que motivou hospitalização, e os casos que tiveram acesso à internação hospitalar. 
2. Estão incluídas apenas as internações hospitalares financiadas pelo SUS, excluindo-se as financiadas por seguros e planos de saúde e por fontes privadas.

3. O período de estudo, cinco anos, é um intervalo curto para permitir a análise de tendências.

\subsection{NOTA}

Alguns nomes utilizados na CID-10 são muito longos para a utilização em tabelas, desta maneira, adotou-se um termo simplificado de alguns desses nomes, conforme o quadro 1. Fica subentendido, que a utilização do termo simplificado corresponde ao nome completo da CID-10.

Quadro 1 - Sinonímia dos termos simplificado utilizados na pesquisa e os nomes correspondentes da CID-10

\begin{tabular}{|c|c|}
\hline Termo simplificado & Nome correspondente da $\mathrm{Cl}-10$ \\
\hline Outras afecções perinatais & $\begin{array}{c}\text { Outras afecções originadas no } \\
\text { período perinatal }\end{array}$ \\
\hline $\begin{array}{c}\text { Outros transtornos respiratórios } \\
\text { perinatais }\end{array}$ & $\begin{array}{l}\text { Outros transtornos respiratórios } \\
\text { originados no período perinatal }\end{array}$ \\
\hline $\begin{array}{l}\text { Retardo de crescimento fetal, } \\
\text { prematuridade e baixo peso }\end{array}$ & $\begin{array}{l}\text { Retardo de crescimento fetal, } \\
\text { desnutrição fetal, transtornos } \\
\text { relacionados à gestação de curta } \\
\text { duração e baixo peso ao nascer }\end{array}$ \\
\hline Diarréia e gastroenterite infecciosa & $\begin{array}{l}\text { Diarréia e gastroenterite de origem } \\
\text { infecciosa presumível }\end{array}$ \\
\hline Bronquite aguda e bronquiolite & $\begin{array}{l}\text { Bronquite aguda e bronquiolite } \\
\text { aguda }\end{array}$ \\
\hline Fimose & $\begin{array}{l}\text { Prepúcio redundante, fimose e } \\
\text { parafimose }\end{array}$ \\
\hline
\end{tabular}


4.RESULTADOS 


\subsection{APRESENTAÇÃO DOS RESULTADOS}

Os resultados obtidos serão apresentados em três etapas:

- Dados que permitem ter uma idéia geral do número de internações de crianças de 0 a 9 anos no município de São Paulo e compreender o comportamento dessas internações.

- As principais causas de internação das crianças de 0 a 9 anos de idade no município de São Paulo.

- Posteriormente, tendo em vista as especificidades das crianças nas diferentes faixas etárias, as quais determinam perfis diferentes de mortalidade e morbidade e consequentemente de internações, procedeu-se a análise individualizada em cada uma dessas faixas etárias. Foram considerados os seguintes grupos etários: menores de 1 ano, 1 a 4 anos e 5 a 9 anos, que correspondem às divisões utilizadas pelo IBGE e pelo Sistema de Informações do DATASUS.

Todos esses dados serão comparados com os obtidos para o Brasil.

\subsection{CARACTERÍSTICAS DAS INTERNAÇÕES HOSPITALARES NO MUNICÍPIO DE SÃO PAULO E NO BRASIL}

O estudo descreve as causas de internação hospitalar, subsidiadas pelo SUS, das crianças de 0 a 9 anos de idade, no município de São Paulo e no Brasil, no período de janeiro de 2002 a dezembro de 2006. Segundo 
informações da Pesquisa Nacional por Amostra de Domicílios (PNDA) de 2003, 41,7\% das internações de crianças e adolescentes de 0 a 13 anos de idade, no município de São Paulo foram subsidias pelo SUS. No Brasil essa porcentagem foi de $73,3 \%$.

No período estudado ocorreram 451.303 internações de crianças de 0 a 9 anos de idade no município de São Paulo. As hospitalizações dessa faixa etária corresponderam a $16 \%$ do total das hospitalizações ocorridas no município neste período (gráfico 3).

Gráfico 3 - Proporção (\%) de internações hospitalares de crianças de 0 a 9 anos de idade no total das internações ocorridas no município de São Paulo, nos 5 anos do estudo - 2002 a 2006

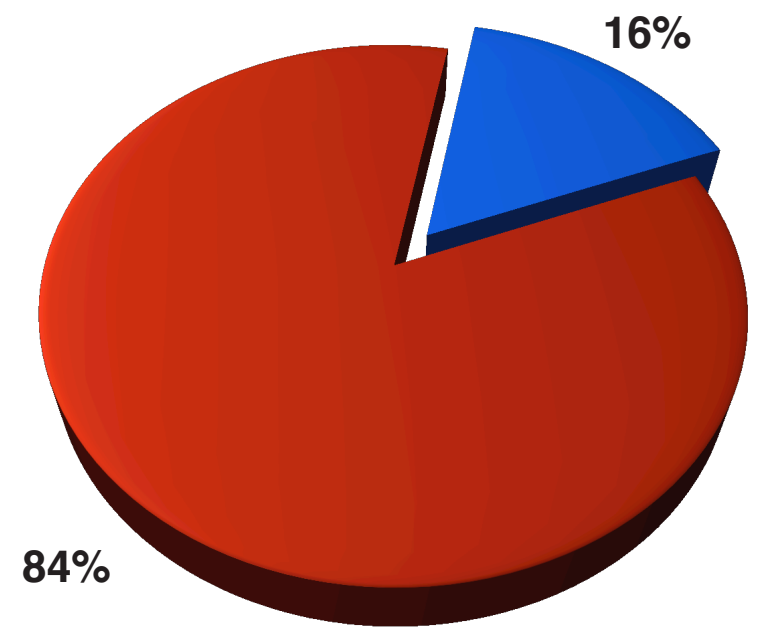

0 a 9 anos

Outras idades 
No Brasil, do total de 9.915 .772 internações ocorridas nos 5 anos estudados, $17 \%$ foram de crianças de 0 a 9 anos de idade (gráfico 4 ).

Gráfico 4 - Proporção (\%) de internações hospitalares de crianças de 0 a 9 anos de idade no total das internações ocorridas no Brasil, nos 5 anos de estudo - 2002 a 2006

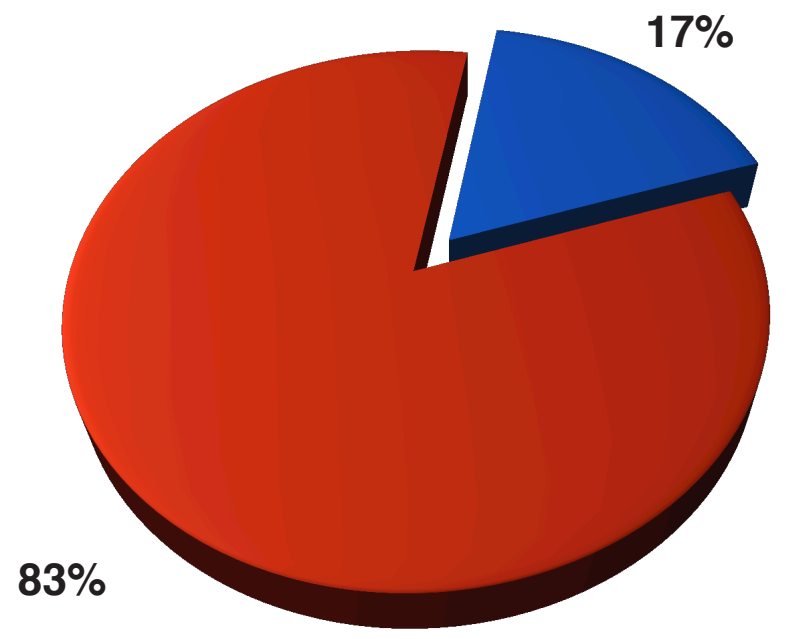

0 a 9 anos

Outras idades

O porcentual das internações da faixa etária estudada em relação às internações das demais idades mostrou pouca variação ao longo dos cinco anos estudados, tanto no município como no Brasil (tabelas 3 e 4).

Tabela 3 - Porcentagem das internações das crianças de 0 a 9 anos de idade em relação ao total das internações, no município de São Paulo - 2002 a 2006

\begin{tabular}{ccc}
\hline Ano & $\begin{array}{c}\text { Número de internações } \\
\text { das crianças de } \mathbf{0} \text { a 9 anos }\end{array}$ & $\begin{array}{c}\text { Número total das } \\
\text { internações }\end{array}$ \\
\hline 2002 & $81.917(15,7 \%)$ & 519.265 \\
\hline 2003 & $91.017(16,2 \%)$ & 561.530 \\
2004 & $90.307(15,9 \%)$ & 567.883 \\
\hline 2005 & $93.445(15,7 \%)$ & 592.992 \\
\hline 2006 & $94.617(15,7 \%)$ & 601.399 \\
\hline TOTAL & $\mathbf{4 1 5 . 3 0 3 ( 1 5 , 8 \% )}$ & $\mathbf{2 . 8 4 3 . 0 6 9}$ \\
\hline
\end{tabular}


Tabela 4 - Porcentagem das internações das crianças de 0 a 9 anos de idade em relação ao total das internações, no Brasil - 2002 a 2006

\begin{tabular}{ccc}
\hline Ano & $\begin{array}{c}\text { Número de internações } \\
\text { das crianças de } \mathbf{0} \text { a 9 anos }\end{array}$ & $\begin{array}{c}\text { Número total das } \\
\text { internações }\end{array}$ \\
\hline 2002 & $2.088 .631(17,8 \%)$ & 11.713 .749 \\
2003 & $2.054 .538(17,6 \%)$ & 11.638 .194 \\
2004 & $1.958 .349(17,0 \%)$ & 11.492 .883 \\
2005 & $1.923 .436(16,8 \%)$ & 11.429133 \\
2006 & $1.890 .818(16,6 \%)$ & 11.338 .039 \\
\hline TOTAL & $\mathbf{9 . 9 1 5 7 7 2 ( 1 7 , 2 \% )}$ & $\mathbf{5 7 . 6 1 1 . 9 9 8}$ \\
\hline
\end{tabular}

Para permitir a comparação do número de internações nas diferentes faixas etárias, anos e localização geográfica, calculou-se os coeficientes de internação. No município de São Paulo e no Brasil o coeficiente de internação das crianças menores de 1 ano de idade foram consideravelmente maiores que os coeficientes de internação das crianças das demais idades, em todo o período estudado (tabelas 5 e 6 e gráfico 5).

Tabela 5 - Coeficientes de internação das crianças de 0 a 9 anos de idade, estratificado por faixa etária, no município de São Paulo - 2002 a 2006

\begin{tabular}{cccc}
\hline \multirow{2}{*}{ Ano } & \multicolumn{3}{c}{ Coeficiente de internação (por 1000 crianças) } \\
\cline { 3 - 4 } & Menor de 1 ano & 1 a 4 anos & 5 a 9 anos \\
\cline { 1 - 3 } 2002 & 188,25 & 41,13 & 23,96 \\
2003 & 206,81 & 46,43 & 26,78 \\
2004 & 208,10 & 43,64 & 28,65 \\
2005 & 201,48 & 46,28 & 32,38 \\
2006 & 228,48 & 45,45 & 28,28 \\
MÉDIA & $\mathbf{2 0 6 , 6 2}$ & $\mathbf{4 4 , 5 8}$ & $\mathbf{2 8 , 0 1}$ \\
\hline
\end{tabular}


Tabela 6 - Coeficientes de internação das crianças de 0 a 9 anos de idade, estratificado por faixa etária, no Brasil - 2002 a 2006

\begin{tabular}{cccc}
\hline \multirow{2}{*}{ Ano } & \multicolumn{3}{c}{ Coeficiente de internação (por 1000 crianças) } \\
\cline { 3 - 4 } & Menor de 1 ano & 1 a 4 anos & 5 a 9 anos \\
\cline { 1 - 1 } 2002 & 216,17 & 70,01 & 28,71 \\
2003 & 215,51 & 68,59 & 28,06 \\
2004 & 206,08 & 64,50 & 27,67 \\
2005 & 200,97 & 62,36 & 28,47 \\
2006 & 196,32 & 59,39 & 25,88 \\
\hline MÉDIA & 207,01 & 64,97 & $\mathbf{2 7 , 7 5}$ \\
\hline
\end{tabular}

Gráfico 5 - Distribuição (\%) das médias dos coeficientes de internações hospitalares por faixa etária, no município de São Paulo e no Brasil, nos 5 anos estudados - 2002 a 2006

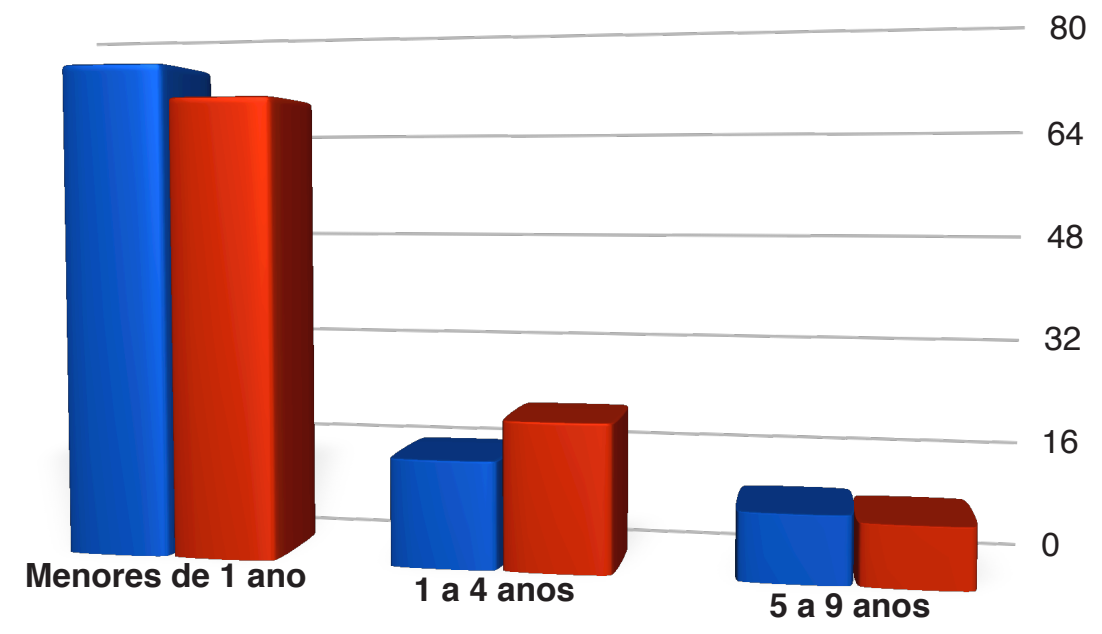


Em relação à distribuição das hospitalizações de acordo com o gênero, tanto no município de São Paulo como no Brasil, houve predomínio no sexo masculino, com valores muito semelhantes nas duas localidades, 57\% e 56\%, respectivamente (gráfico 6).

Gráfico 6 - Distribuição (\%) das internações hospitalares das crianças de 0 a 9 anos de idade, por gênero, no município de São Paulo e no Brasil, nos 5 anos estudados - 2002 a 2006

Masculino

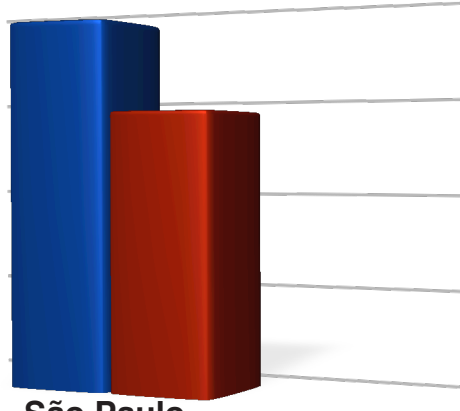

São Paulo

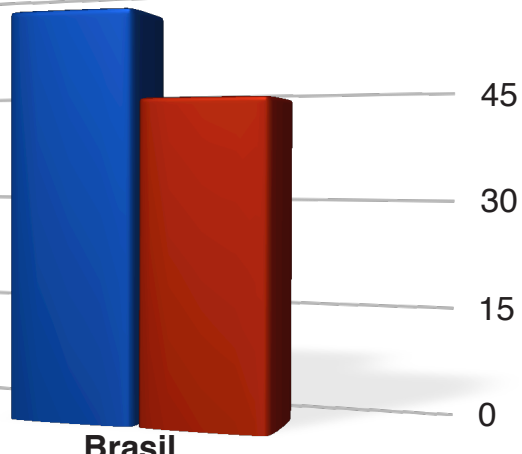

Brasil

60 
Ao se estratificar as internações por faixas etárias (menores de 1 ano, de 1 a 4 anos e de 5 a 9 anos) o predomínio de internações no sexo masculino é observado em todas as faixas etárias, em todos os anos estudados, no município de São Paulo e no Brasil (tabela 7).

Tabela 7 - Porcentagem das internações das crianças do sexo masculino, estratificado por faixa etária, no município de São Paulo e no Brasil - 2002 a 2006

\begin{tabular}{ccccccc}
\hline \multirow{2}{*}{ Ano } & \multicolumn{3}{c}{ São Paulo } & \multicolumn{3}{c}{ Brasil } \\
\cline { 2 - 7 } & $\begin{array}{c}\text { Menores } \\
\text { de 1 ano }\end{array}$ & $\begin{array}{c}1 \text { a } 4 \\
\text { anos }\end{array}$ & $\begin{array}{c}5 \text { a } 9 \\
\text { anos }\end{array}$ & $\begin{array}{c}\text { Menores } \\
\text { de 1 ano }\end{array}$ & $\begin{array}{c}1 \text { a } 4 \\
\text { anos }\end{array}$ & $\begin{array}{c}5 \text { a } 9 \\
\text { anos }\end{array}$ \\
\cline { 1 - 7 } 2002 & 55,6 & 56,8 & 59,7 & 56,1 & 55 & 57,6 \\
2003 & 56,4 & 57,5 & 59,8 & 56,1 & 55,4 & 58,2 \\
\hline 2004 & 55,2 & 57,8 & 60 & 56 & 55,5 & 58,4 \\
\hline 2005 & 54,4 & 57 & 59,8 & 55,7 & 57,4 & 56,7 \\
\hline 2006 & 55,8 & 58,2 & 59,5 & 55,8 & 55,7 & 58,2 \\
\hline
\end{tabular}


A média de permanência hospitalar, considerando-se todas as internações ocorridas no período estudado, foi de 7,3 dias no município de São Paulo e de 6 dias no Brasil. A tabela 8 mostra, no entanto, que a média de tempo de hospitalização variou bastante nas diferentes faixas etárias. Observa-se que em São Paulo o tempo médio de internação hospitalar das crianças menores de 1 ano foi maior que nas demais faixa etárias, somente superada pela faixa etária dos maiores de 80 anos.

Tabela 8 - Média de permanência hospitalar (dias), por faixa etária, no município de São Paulo e no Brasil, nos 5 anos estudados 2002 a 2006

\begin{tabular}{ccc}
\hline \multirow{2}{*}{ Faixa etária } & \multicolumn{2}{c}{ Média de permanência hospitalar (dias) } \\
\cline { 2 - 3 } Menor de 1 ano & São Paulo & Brasil \\
\hline 1 a 4 anos & 9,5 & 7,0 \\
\hline 5 a 9 anos & 5,4 & 4,1 \\
\hline 10 a 14 anos & 5,3 & 3,8 \\
\hline 15 a 19 anos & 6,8 & 4,2 \\
\hline 20 a 29 anos & 4,6 & 3,4 \\
\hline 30 a 39 anos & 5,4 & 4,1 \\
40 a 49 anos & 6,9 & 6,6 \\
\hline 50 a 59 anos & 8,6 & 8,8 \\
\hline 60 a 69 anos & 8,7 & 8,6 \\
\hline 70 a 79 anos & 9,1 & 7,9 \\
\hline 8 anos ou mais & 9,3 & 7,2 \\
\hline Idade ignorada & 10,5 & 6,9 \\
\hline TOTAL & 6,1 & 5,8 \\
\hline
\end{tabular}


Para comparar a evolução do número de internações entre as diferentes faixas etárias, ao longo dos 5 anos estudados, analisando-se as populações das duas localidades, município de São Paulo e Brasil, foram utilizados os coeficientes de internação para cada 1000 habitantes da faixa etária, do ano e da localidade avaliada. Assim, verificou-se que o coeficiente de internações hospitalares das crianças de 0 a 9 anos, no município de São Paulo variou de 48,74 em 2002, para 54,07 em 2006. Observou-se tendência oposta com os dados nacionais, indo de 63,74 para 54,70 (gráfico 7).

Gráfico 7 - Evolução do coeficiente de internação hospitalar das crianças de 0 a 9 anos de idade no município de São Paulo e no Brasil -2002 a 2006

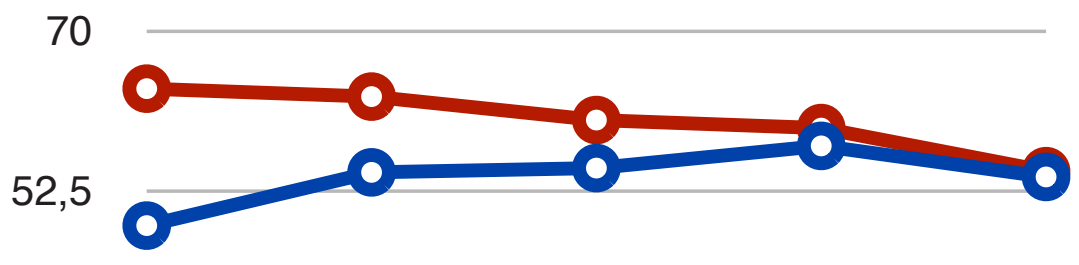

São Paulo

Brasil

\section{5}

17,5

0 $2002 \quad 2003 \quad 2004 \quad 2005 \quad 2006$ 
4.3 CAUSAS DE INTERNAÇÃO HOSPITALAR DAS CRIANÇAS DE 0 A 9 ANOS DE IDADE, NO MUNICÍPIO DE SÃO PAULO E NO BRASIL.

A tabela 9 apresenta a distribuição das hospitalizações da população estudada conforme os capítulos da CID-10 (2 $2^{\mathrm{a}}$ edição), no município de São Paulo e no Brasil, no período de 2002 a 2006. As doenças respiratórias são as principais causas de internação, na faixa etária estudada, tanto no município como no Brasil, correspondendo a 32,5 e $38,4 \%$ das hospitalizações, respectivamente. As afecções originadas no período perinatal são a segunda causa no município $(15,9 \%)$ e a terceira no Brasil $(10,1 \%)$. As doenças do aparelho digestivo, que incluem as hérnias, são o terceiro motivo de hospitalização no município (8\%) e o quarto no Brasil. Por outro lado, as internações por doenças infecciosas e parasitárias, capítulo da CID-10 no qual estão incluídas as diarréias agudas de origem infecciosa, são responsáveis por $7,9 \%$ das internações no município, sendo a $4^{\text {a }}$ causa, enquanto no Brasil são o $2^{\circ}$ motivo de hospitalização, correspondendo a $21,7 \%$ das internações. 
Tabela 9 - Distribuição (\%) das internações hospitalares das crianças de 0 a 9 anos, segundo os capítulos da CID-10 (2a edição) no município de São Paulo e no Brasil, no período de 2002 a 2006

\begin{tabular}{|c|c|c|}
\hline \multirow{2}{*}{ Capítulo do CID-10 } & São Paulo & Brasil \\
\hline & \% (posição) & \% (posição) \\
\hline X. Doenças do aparelho respiratório & $32,5\left(1^{a}\right)$ & $38,4\left(1^{a}\right)$ \\
\hline $\begin{array}{c}\text { XVI .Algumas afecções originadas no período } \\
\text { perinatal }\end{array}$ & $15,9\left(2^{\mathrm{a}}\right)$ & $10,1\left(3^{\mathrm{a}}\right)$ \\
\hline XI. Doenças do aparelho digestivo & $8,0\left(3^{a}\right)$ & $6,4\left(4^{a}\right)$ \\
\hline I. Algumas doenças infecciosas e parasitárias & $7,9\left(4^{\mathrm{a}}\right)$ & $21,7\left(2^{\mathrm{a}}\right)$ \\
\hline $\begin{array}{l}\text { XIX. Lesões, enven€ } \\
\text { conseqüências d }\end{array}$ & $6,2\left(5^{a}\right)$ & $4,9\left(5^{\mathrm{a}}\right)$ \\
\hline $\begin{array}{r}\text { XVII. Malformações congênitas, } \\
\text { anomalias cromossô }\end{array}$ & $6,1\left(6^{a}\right)$ & $2,5\left(8^{a}\right)$ \\
\hline XIV. Doenças do aparelho geniturinário & $4,6\left(7^{\mathrm{a}}\right)$ & $3,2\left(6^{a}\right)$ \\
\hline VI. Doen & $3,7\left(8^{a}\right)$ & $1,7\left(10^{a}\right)$ \\
\hline XII. Doenças da pele e & $2,8\left(9^{a}\right)$ & $1,3\left(11^{a}\right)$ \\
\hline II. Neo & $2,6\left(10^{a}\right)$ & $1,8\left(9^{\mathrm{a}}\right)$ \\
\hline $\begin{array}{l}\text { III. Doenças do se } \\
\text { hematopoéticos e algur }\end{array}$ & $1,6\left(11^{\mathrm{a}}\right)$ & $0,7\left(15^{\mathrm{a}}\right)$ \\
\hline $\begin{array}{r}\text { XVIII. Sintomas, sinais } \\
\text { exames clínicos e de labo } \\
\text { em outr }\end{array}$ & $1,3\left(12^{\mathrm{a}}\right)$ & $1,0\left(12^{a}\right)$ \\
\hline $\begin{array}{l}\text { XXI. Fatores que exercem inf } \\
\text { estado de saúde e o contato } \\
\text { saúde }\end{array}$ & $1,3\left(13^{\mathrm{a}}\right)$ & $0,8\left(14^{a}\right)$ \\
\hline $\begin{array}{l}\text { IV. Doenças endócrinas, nutricionais e } \\
\text { metabólicas }\end{array}$ & $1,3\left(14^{a}\right)$ & $2,9\left(7^{\mathrm{a}}\right)$ \\
\hline VII. Doenças dos olhos e anexos & $1,1\left(15^{\mathrm{a}}\right)$ & $0,3\left(18^{\mathrm{a}}\right)$ \\
\hline $\begin{array}{r}\text { XIII. Doenças do sisteI } \\
\text { tecido c }\end{array}$ & $1,0\left(16^{a}\right)$ & $0,9\left(13^{a}\right)$ \\
\hline VIII. Doenças do ouvido e da apófise mastóide & $0,7\left(17^{a}\right)$ & $0,3\left(17^{a}\right)$ \\
\hline IX. Doenças do aparelho circulatório & $0,7\left(18^{a}\right)$ & $0,4\left(16^{a}\right)$ \\
\hline V. Transtornos mentais e comportamentais & $0,1\left(19^{a}\right)$ & $0,03\left(20^{a}\right)$ \\
\hline $\begin{array}{l}\text { XX. Causas externas de morbidade e de } \\
\text { mortalidade }\end{array}$ & $0,04\left(20^{a}\right)$ & $0,04\left(19^{a}\right)$ \\
\hline CID 10 não disponível, nầ & $0,02\left(21^{a}\right)$ & $0,03\left(21^{a}\right)$ \\
\hline XV. Gravidez, parto e puerpério & $0,01\left(22^{a}\right)$ & $0,007\left(22^{a}\right)$ \\
\hline
\end{tabular}


No município de São Paulo, as dez primeiras causas de internação das crianças de 0 a 9 anos de idade, no período de 2002 a 2006, corresponderam a aproximadamente metade do total das hospitalizações desta faixa etária, nesses anos. Essas causas estão apresentadas na tabela 10.

Tabela 10 - As dez primeiras causas de internação das crianças de 0 a 9 anos de idade, no município de São Paulo nos 5 anos estudados - 2002 a 2006

\begin{tabular}{cccc}
\hline Causa & $\begin{array}{c}\text { Número de } \\
\text { internações }\end{array}$ & $\begin{array}{c}\text { \% no } \\
\text { total das } \\
\text { internações }\end{array}$ & $\begin{array}{c}\text { \% entre as } \\
10 \text { primeiras } \\
\text { causas de } \\
\text { internação }\end{array}$ \\
\hline Pneumonia & 76.460 & 16,94 & 34,47 \\
\hline Asma & 31148 & 6,90 & 14,04 \\
\hline $\begin{array}{c}\text { Outras afecções perinatais } \\
\text { Outros transtornos }\end{array}$ & 22869 & 5,06 & 10,31 \\
\hline $\begin{array}{c}\text { Respiratórios perinatais } \\
\text { fetal, prematuridade e de crescimento } \\
\text { baixo peso }\end{array}$ & 22.341 & 4,95 & 10,07 \\
\hline $\begin{array}{c}\text { Diarréia e gastroenterite } \\
\text { infecciosa }\end{array}$ & 16624 & 3,68 & 7,49 \\
\hline $\begin{array}{c}\text { Hérnia inguinal } \\
\text { Bronquite aguda e } \\
\text { bronquiolite }\end{array}$ & 11.548 & 2,55 & 5,21 \\
\hline $\begin{array}{c}\text { Doenças crônicas } \\
\text { das amígdalas e das } \\
\text { adenóides }\end{array}$ & 9.871 & 2,18 & 4,20 \\
\hline $\begin{array}{c}\text { Malformações congênitas } \\
\text { aparelho circulatório }\end{array}$ & 9.220 & 2,24 & 4,56 \\
\hline
\end{tabular}


As doenças respiratórias agrupadas (pneumonia, asma, bronquite aguda e bronquiolite aguda e doenças crônicas das amígdalas e adenóides) corresponderam a $58 \%$ e o conjunto das doenças originadas no período perinatal (outras afecções originadas no período perinatal, outros transtornos respiratórios originados no período perinatal e retardo de crescimento fetal, desnutrição fetal e transtornos relacionados à gestação curta e baixo peso ao nascer) a $28 \%$ das internações entre as dez primeiras causas, no município de São Paulo (gráfico 8). É importante citar que o termo "outras afecções originadas no período perinatal" inclui transtornos relacionados à gestação prolongada e peso elevado ao nascer, transtornos cardiovasculares, doenças hemorrágicas do feto e do recém-nascido, enterocolite necrotizante, convulsões do recém-nascido, distúrbios metabólicos, icterícias, entre outros. O termo "outros transtornos respiratórios originados no período perinatal" inclui o desconforto respiratório do recém-nascido, pneumonia congênita, síndrome de aspiração neonatal, enfisema, hemorragia pulmonar e doença respiratória crônica originada no período perinatal.

Gráfico 8 - Distribuição (\%) dos agrupamentos das dez primeiras causas de internação das crianças de 0 a 9 anos de idade, no município de São Paulo, nos 5 anos estudados - 2002 a 2006

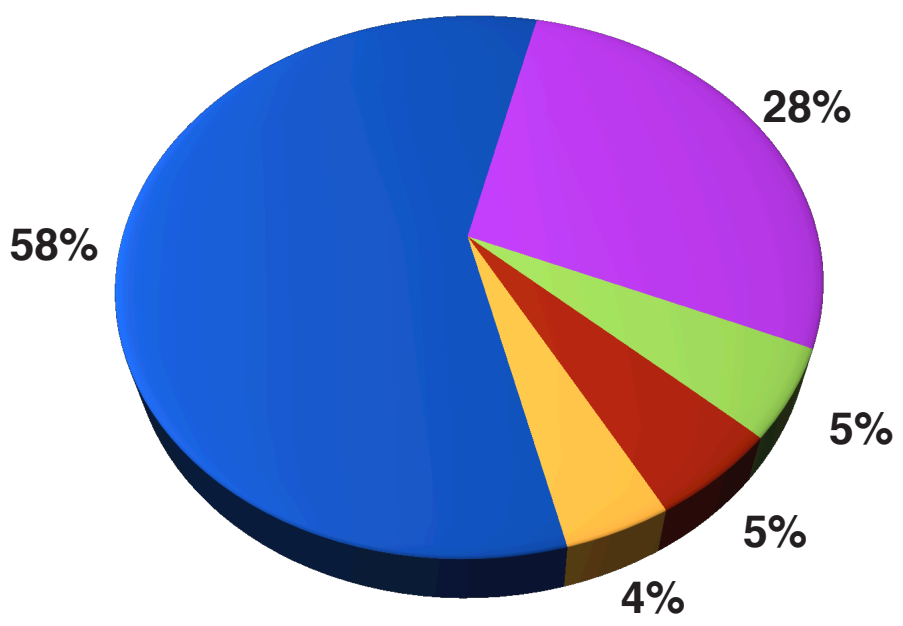

Doenças Respiratórias

Diarréia e Gastroenterite infecciosa

Hérnia inguinal

Malformações congênitas do aparelho circulatório

Doenças originadas no período perinatal 


\subsection{CAUSAS DE INTERNAÇÃO HOSPITALAR, ESTRATIFICADAS POR} FAIXA ETÁRIA, NO MUNICÍPIO DE SÃO PAULO E NO BRASIL.

\subsubsection{Internações das crianças menores de 1 ano de idade}

A evolução dos coeficientes de internação das crianças menores de 1 ano de idade, durante o período de 2002 a 2006, mostrou aumento no município de São Paulo (188,25 para 228,78) e diminuição no Brasil (216 para 196,32). Observa-se no gráfico 9 que houve uma inversão dos coeficientes de internação comparando-se as duas regiões.

Gráfico 9 - Evolução do coeficiente de internação hospitalar das crianças menores de 1 ano de idade, no município de São Paulo e no Brasil - 2002 a 2006

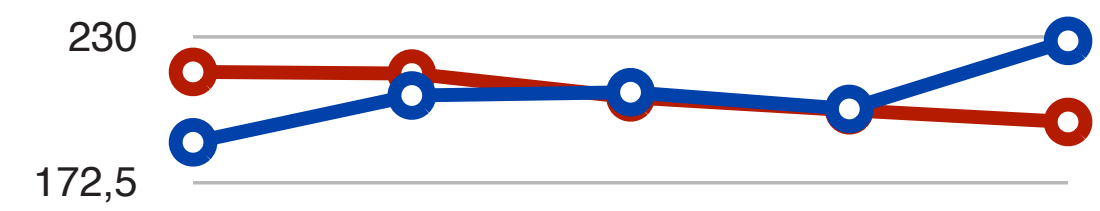

São Paulo

Brasil

115

57,5

$\begin{array}{lllll}0 & 2006\end{array}$


A tabela 11 apresenta as dez primeiras causas de internação das crianças menores de 1 ano de idade, no município de São Paulo, considerando-se o total das hospitalizações dessa faixa etária, nos 5 anos estudados.

Tabela 11 - As dez primeiras causas de internação das crianças menores de 1 ano de idade, no município de São Paulo, nos 5 anos estudados - 2002 a 2006

\begin{tabular}{|c|c|c|c|}
\hline Causa & $\begin{array}{l}\text { Número de } \\
\text { internações }\end{array}$ & $\begin{array}{c}\text { \% no } \\
\text { total das } \\
\text { internações }\end{array}$ & $\begin{array}{c}\% \text { entre as } \\
10 \text { primeiras } \\
\text { causas de } \\
\text { internação }\end{array}$ \\
\hline Pneumonia & 34.729 & 18,82 & 26,31 \\
\hline Outras afecções perinatais & 22.826 & 12,37 & 17,29 \\
\hline $\begin{array}{l}\text { Outros transtornos } \\
\text { respiratórios perinatais }\end{array}$ & 21.810 & 11,82 & 16,52 \\
\hline $\begin{array}{l}\text { Retardo de crescimento } \\
\text { fetal, prematuridade e } \\
\text { baixo peso }\end{array}$ & 16.623 & 9,0 & 12,59 \\
\hline $\begin{array}{c}\text { Bronquite aguda e } \\
\text { bronquiolite }\end{array}$ & 9.376 & 5,08 & 7,1 \\
\hline Asma & 9.235 & 5,0 & 6,99 \\
\hline $\begin{array}{l}\text { Outras doenças do } \\
\text { aparelho respiratório }\end{array}$ & 5.066 & 2,74 & 3,83 \\
\hline $\begin{array}{l}\text { Diarréia e gastroenterite } \\
\text { infecciosa }\end{array}$ & 4.961 & 2,68 & 3,75 \\
\hline $\begin{array}{l}\text { Malformações congênitas } \\
\text { do aparelho circulatório }\end{array}$ & 4.231 & 2,29 & 3,2 \\
\hline $\begin{array}{l}\text { Hipóxia intrauterina e } \\
\text { asfixia ao nascer }\end{array}$ & 3.140 & 1,7 & 2,37 \\
\hline
\end{tabular}

As doenças originadas no período perinatal agrupadas (outras afecções originadas no período perinatal, outros transtornos respiratórios originados no período perinatal, retardo de crescimento fetal, desnutrição fetal e transtornos 
relacionados à gestação curta e baixo peso ao nascer e hipóxia intrauterina e asfixia ao nascer) foram responsáveis por $49 \%$ das hospitalizações entre as dez primeiras causas de internação das crianças menores de 1 ano de idade e as doenças respiratórias agrupadas (pneumonia, bronquite aguda e bronquiolite aguda, asma e outras doenças do aparelho respiratório) por $44 \%$ dessas internações (gráfico 10). Vale mencionar que o termo "outras doenças do aparelho respiratório" é utilizado para se referir a infecções agudas não especificadas das vias aéreas inferiores, abscesso de pulmão e mediastino, derrame pleural, pneumotórax, edema pulmonar entre outras doenças menos freqüentes na prática pediátrica.

Gráfico 10 - Distribuição (\%) dos agrupamentos das dez primeiras causas de internação das crianças menores de 1 ano de idade, no município de São Paulo, nos 5 anos estudados - 2002 a 2006

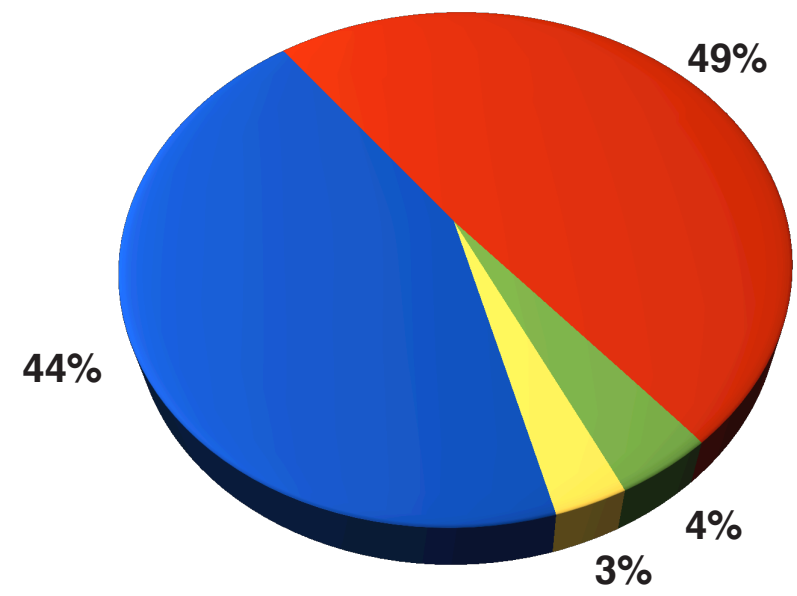

Doenças Respiratórias

Diarréia e Gastroenterite infecciosa

Doenças originadas no período perinatal

Malformações congênitas do aparelho circulatório

A tabela 12 traz a evolução dos coeficientes de internação, de cada uma das dez principais causas de internação das crianças menores de 1 ano de idade, ao longo do período estudado, no município de São Paulo, comparando-os aos encontrados no Brasil. 
Tabela 12 - Evolução dos coeficientes de internação das dez primeiras causas de internação das crianças menores de 1 ano de idade, no município de São Paulo, comparativamente ao Brasil - 2002 a 2006

\begin{tabular}{|c|c|c|c|c|c|c|}
\hline \multirow[t]{2}{*}{ Causa } & \multirow[t]{2}{*}{ Região } & \multicolumn{5}{|c|}{$\begin{array}{l}\text { Coeficiente de internação } \\
\text { (por } 1000 \text { crianças) }\end{array}$} \\
\hline & & 2002 & 2003 & 2004 & 2005 & 2006 \\
\hline \multirow{2}{*}{ Pneumonia } & São Paulo & 30,06 & 43,29 & 43,0 & 34,96 & 43,11 \\
\hline & Brasil & 45,31 & 48,80 & 44,91 & 40,11 & 40,50 \\
\hline \multirow{2}{*}{$\begin{array}{l}\text { Outras afecções } \\
\text { perinatais }\end{array}$} & São Paulo & 24,70 & 24,55 & 24,75 & 26,94 & 26,69 \\
\hline & Brasil & 13,31 & 12,98 & 13,87 & 15,18 & 15,43 \\
\hline \multirow{2}{*}{$\begin{array}{l}\text { Outros transtornos } \\
\text { respiratórios } \\
\text { perinatais }\end{array}$} & São Paulo & 17,36 & 21,42 & 23,67 & 26,14 & 34,09 \\
\hline & Brasil & 16,75 & 16,23 & 16,41 & 17,28 & 17,52 \\
\hline \multirow{2}{*}{$\begin{array}{l}\text { Retardo e } \\
\text { crescimento fetal, } \\
\text { prematuridade e } \\
\text { baixo peso }\end{array}$} & São Paulo & 16,74 & 19,22 & 18,80 & 18,71 & 19,48 \\
\hline & Brasil & 15,36 & 15,22 & 15,16 & 16,27 & 16,01 \\
\hline \multirow{2}{*}{$\begin{array}{l}\text { Bronquite aguda e } \\
\text { bronquiolite }\end{array}$} & São Paulo & 9,17 & 10,16 & 10,90 & 10,04 & 12,27 \\
\hline & Brasil & 6,91 & 7,05 & 7,60 & 7,53 & 8,01 \\
\hline \multirow{2}{*}{ Asma } & São Paulo & 9,26 & 11,0 & 10,52 & 9,57 & 11,34 \\
\hline & Brasil & 11,06 & 11,01 & 10,30 & 8,92 & 8,43 \\
\hline \multirow{2}{*}{$\begin{array}{l}\text { Outras doenças } \\
\text { do aparelho } \\
\text { respiratório }\end{array}$} & São Paulo & 7,05 & 5,28 & 4,79 & 5,27 & 5,95 \\
\hline & Brasil & 6,02 & 5,54 & 5,18 & 4,78 & 4,56 \\
\hline \multirow{2}{*}{$\begin{array}{c}\text { Diarréia e } \\
\text { gastroenterite } \\
\text { infecciosa }\end{array}$} & São Paulo & 4,36 & 4,86 & 5,84 & 6,02 & 6,71 \\
\hline & Brasil & 15,62 & 15,76 & 14,59 & 14,08 & 13,11 \\
\hline \multirow{2}{*}{$\begin{array}{l}\text { Malformações } \\
\text { congênitas } \\
\text { do aparelho } \\
\text { circulatório }\end{array}$} & São Paulo & 4,75 & 4,92 & 4,88 & 4,25 & 4,84 \\
\hline & Brasil & 1,90 & 1,93 & 2,05 & 2,07 & 2,09 \\
\hline \multirow{2}{*}{$\begin{array}{l}\text { Hipóxia intrauterina } \\
\text { e asfixia ao nascer }\end{array}$} & São Paulo & 4,27 & 3,80 & 3,07 & 3,07 & 3,30 \\
\hline & Brasil & 2,87 & 2,46 & 2,26 & 2,29 & 2,21 \\
\hline
\end{tabular}


As hospitalizações por doenças originadas no período perinatal (outras afecções originadas no período perinatal, outros transtornos respiratórios originados no período perinatal, retardo de crescimento fetal, e transtornos relacionados à gestação curta e baixo peso ao nascer e hipóxia intrauterina e asfixia ao nascer) mantiveram-se praticamente inalteradas no território nacional, mas apresentaram um aumento de 32\% no município de São Paulo (gráfico 11).

Gráfico 11 - Evolução dos coeficientes de internação por doenças originadas no período perinatal, das crianças menores de 1 ano de idade, no município de São Paulo e no Brasil - 2002 a 2006

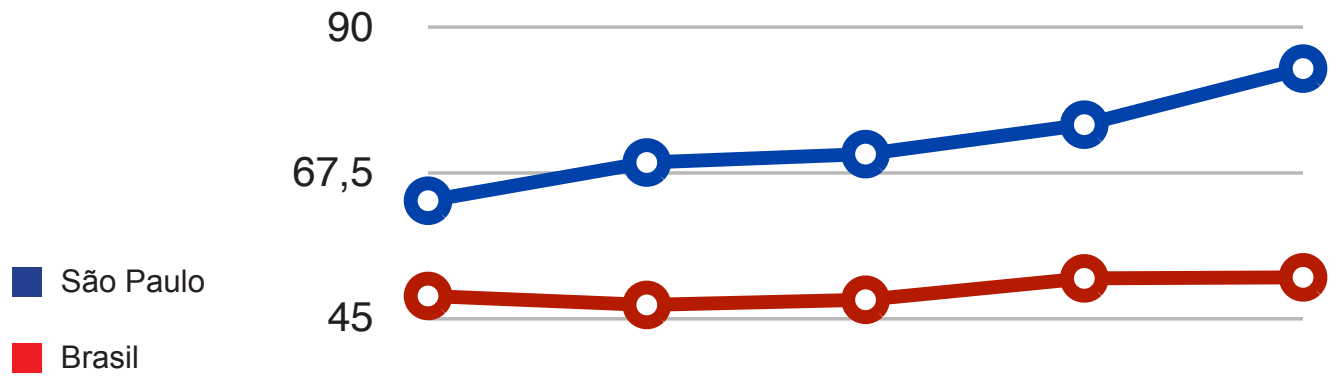

22,5

0 $2002 \quad 2003 \quad 2004 \quad 2005 \quad 2006$

Os gráficos 12 a 15 mostram a evolução de cada uma das doenças perinatais separadamente. Observa-se que no município de São Paulo, os outros transtornos respiratórios originados no período perinatal apresentaram aumento mais expressivo, enquanto que a hipóxia intrauterina e asfixia ao nascer diminuíram como causa de internação e os coeficientes de internação das outras afecções originadas no período perinatal e o retardo de crescimento fetal, desnutrição fetal e transtornos relacionados 
à gestação curta e baixo peso ao nascer apresentaram pouca variação no período. No Brasil, as variações foram ainda menores que no município.

Gráfico 12 - Evolução dos coeficientes de internação por outros transtornos respiratórios originados no período perinatal, das crianças menores de 1 ano de idade, no município de São Paulo e no Brasil - 2002 a 2006

40

São Paulo

Brasil

20

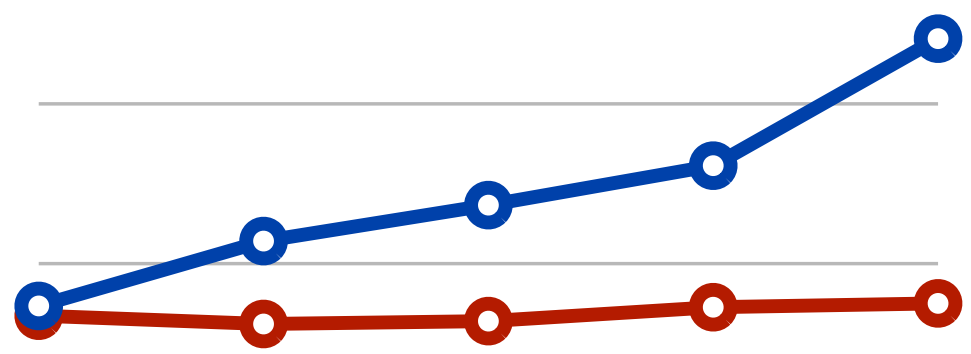

10

0

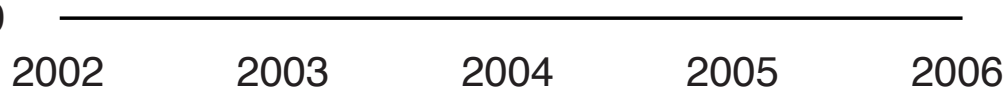

Gráfico 13 - Evolução dos coeficientes de internação por outras afecções originadas no período perinatal, das crianças menores de 1 ano de idade, no município de São Paulo e no Brasil - 2002 a 2006

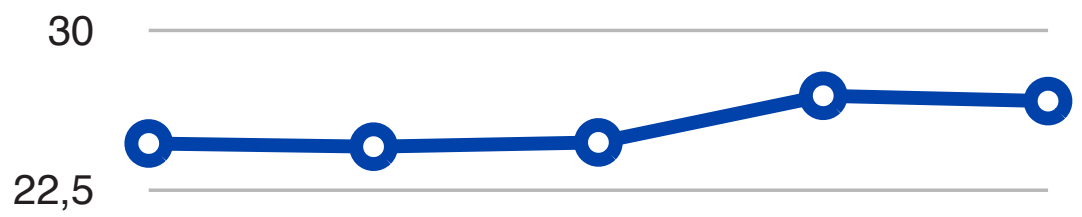

São Paulo

Brasil

15

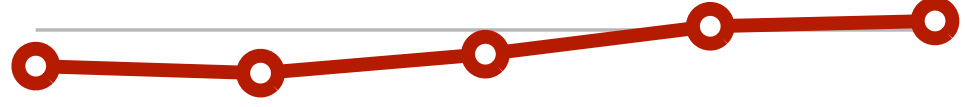

7,5

0

$\begin{array}{lllll}2002 & 2003 & 2004 & 2005 & 2006\end{array}$


Gráfico 14 - Evolução dos coeficientes de internação por retardo de crescimento fetal, desnutrição fetal e transtornos relacionados à gestação curta e baixo peso, das crianças menores de 1 ano de idade, no município de São Paulo e no Brasil - 2002 a 2006

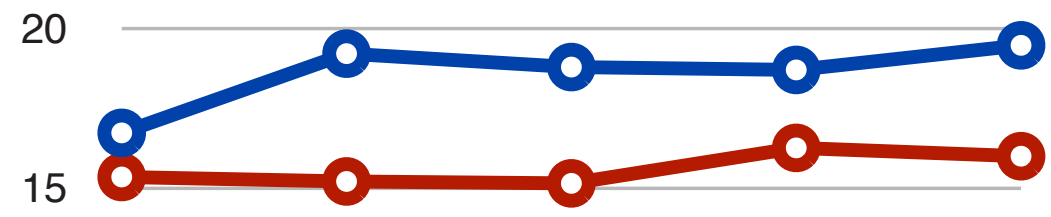

São Paulo

Brasil

$$
10
$$

5

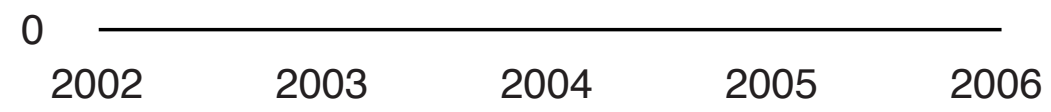

Gráfico 15 - Evolução dos coeficientes de internação por hipóxia intrauterina e asfixia ao nascer, das crianças menores de 1 ano de idade, no município de São Paulo e no Brasil - 2002 a 2006

São Paulo

Brasil

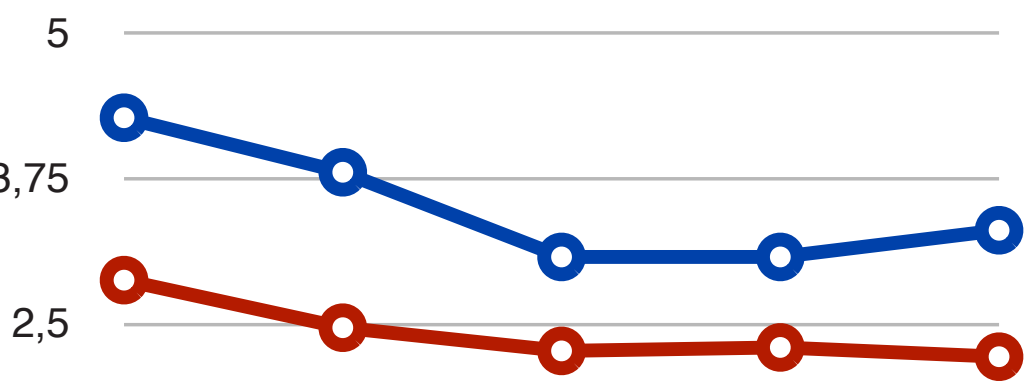

1,25

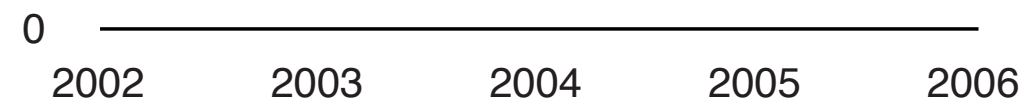


Os coeficientes de internação por doenças respiratórias (pneumonia, asma, bronquite aguda e bronquiolite aguda e outras doenças do aparelho respiratório), nas crianças abaixo de 1 ano de idade, eram menores no município de São Paulo em 2002 em relação ao Brasil, foram praticamente iguais nas duas regiões em 2003, 2004 e 2005 e, em 2006, ficaram maiores no município (gráfico 16).

Gráfico 16 - Evolução dos coeficientes de internação por doenças respiratórias, das crianças menores de 1 ano de idade, no município de São Paulo e no Brasil - 2002 a 2006

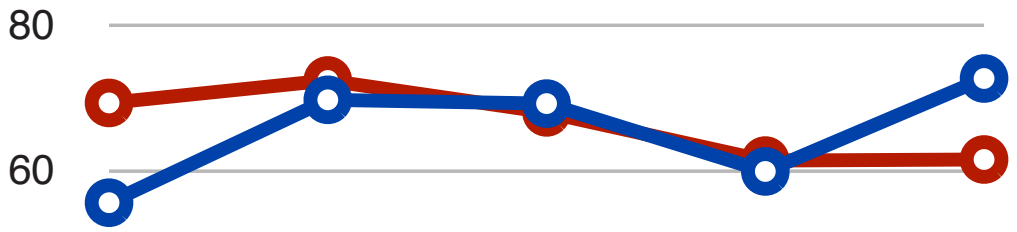

São Paulo

Brasil
40

20

0 $\begin{array}{lllll}2002 & 2003 & 2004 & 2005 & 2006\end{array}$ 
A seguir, apresenta-se a evolução de cada uma das causas respiratórias separadamente (gráficos 17 a 20).

As internações por pneumonia, das crianças menores de 1 ano de idade no município, aumentaram de 2002 a 2003, caíram em 2005, mas voltaram a aumentar em 2006, ficando maiores que no início do período estudado e se igualando às internações do Brasil, onde verificou-se queda dessas internações (gráfico 17).

Gráfico 17 - Evolução dos coeficientes de internação por pneumonia, das crianças menores de 1 ano de idade, no município de São Paulo e no Brasil - 2002 a 2006

São Paulo

Brasil

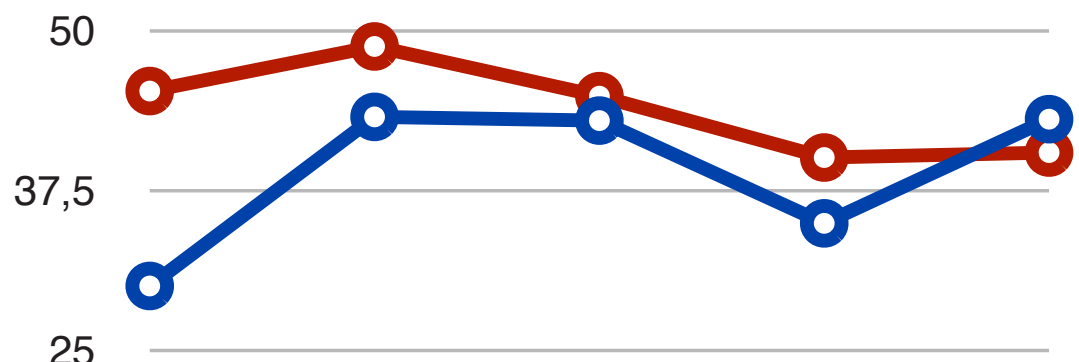

25

12,5

0 $2002 \quad 2003 \quad 2004 \quad 2005 \quad 2006$ 
No SIH-SUS as hospitalizações que aparecem classificadas como asma apresentaram comportamento semelhante àquelas por pneumonia, com a diferença de que o aumento observado no município e a queda no Brasil fizeram com que os coeficientes no município ficassem maiores que os observados em âmbito nacional ao final do período estudado (gráfico 18).

Gráfico 18 - Evolução dos coeficientes de internação por asma, das crianças menores de 1 ano de idade, no município de São Paulo e no Brasil - 2002 a 2006

\section{2}

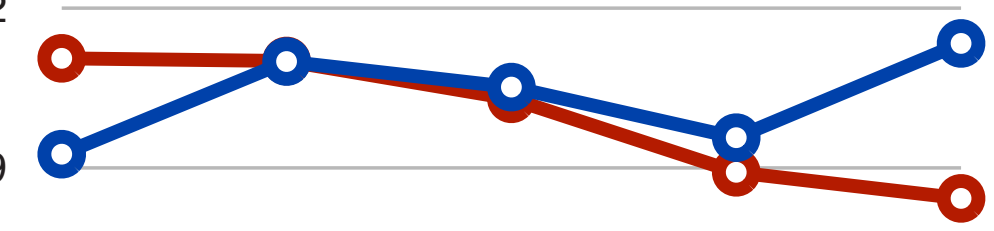

São Paulo

Brasil

\section{6}

3

$\begin{array}{lllll}0 & & & & \\ 2002 & 2003 & 2004 & 2005 & 2006\end{array}$


Os coeficientes de internação por bronquite aguda e bronquiolite aguda sempre foram maiores em São Paulo que no Brasil, além disso, apresentaram aumento no período avaliado e variaram menos no Brasil (gráfico 19).

Gráfico 19 - Evolução dos coeficientes de internação por bronquite aguda e bronquiolite aguda, das crianças menores de 1 ano de idade, no município de São Paulo e no Brasil - 2002 a 2006

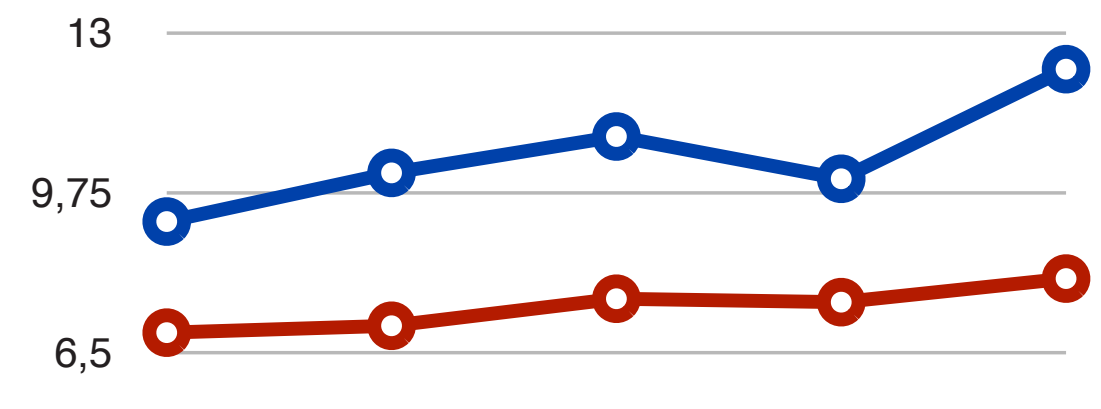

3,25

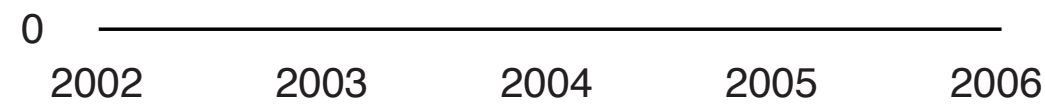


As internações por outras doenças do aparelho respiratório diminuíram, no município, de 2002 a 2004, quando voltaram a aumentar, mas sem atingir os valores observados inicialmente. No Brasil, os coeficientes de internação por essas causas evoluíram com declínio durante todo o período analisado (gráfico 20).

Gráfico 20 - Evolução dos coeficientes de internação por outras doenças do aparelho respiratório, das crianças menores de 1 ano de idade, no município de São Paulo e no Brasil - 2002 a 2006

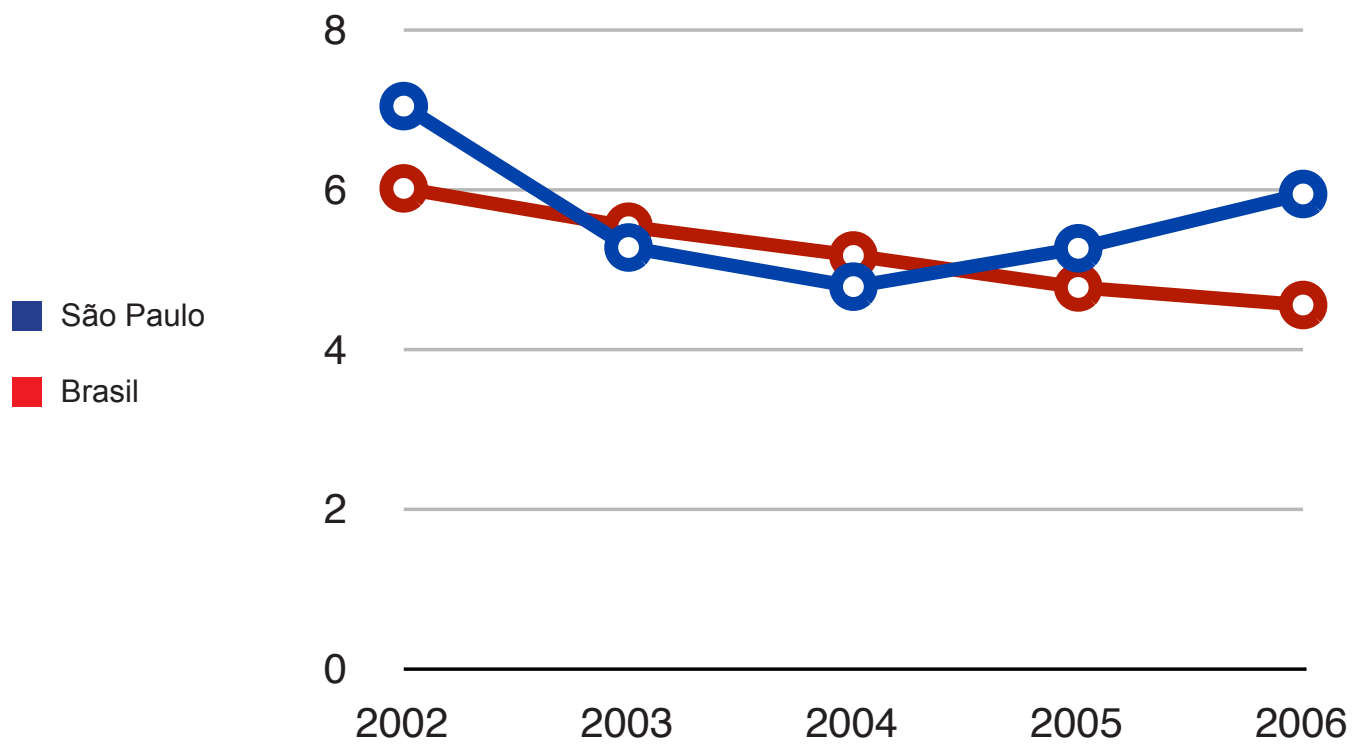


O gráfico 21 mostra que as internações por diarréia e gastroenterite de origem infecciosa presumível, nos menores de 1 ano de idade, aumentaram 1,5 vezes, no período estudado, no município, enquanto caíram 1,2 vezes no Brasil, embora permaneçam maiores nesse último.

Gráfico 21 - Evolução dos coeficientes de internação por diarréia e gastroenterite de origem infecciosa presumível, das crianças menores de 1 ano de idade, no município de São Paulo e no Brasil - 2002 a 2006

20

15

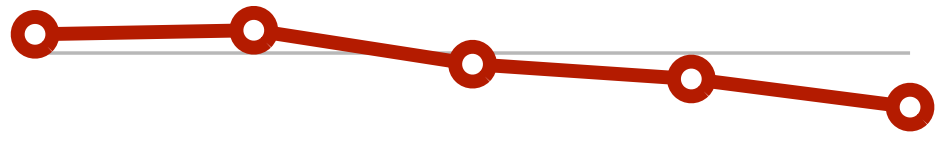

São Paulo Brasil

10

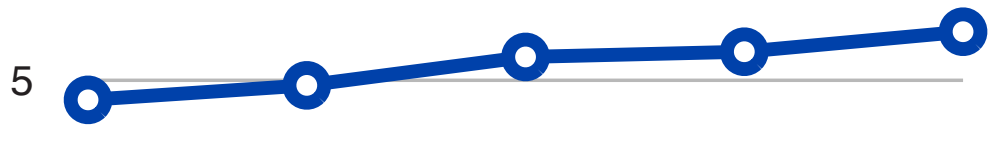

0 $\begin{array}{lllll}2002 & 2003 & 2004 & 2005\end{array}$ 
As internações por malformações congênitas do aparelho circulatório apresentaram queda no município em 2005, mas voltaram aos valores iniciais em 2006. No Brasil, essas internações praticamente não se modificaram (gráfico 22).

Gráfico 22 - Evolução dos coeficientes de internação por malformações congênitas do aparelho circulatório, das crianças menores de 1 ano de idade, no município de São Paulo e no Brasil - 2002 a 2006

\section{5}

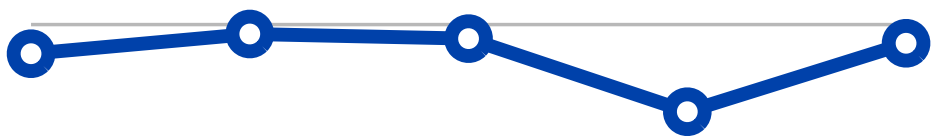

3,75

São Paulo

Brasil

\section{2,5}

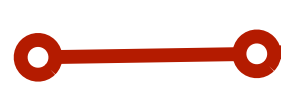

1,25

0

$2002 \quad 2003 \quad 2004 \quad 2005 \quad 2006$




\subsubsection{Internações das crianças de 1 a 4 anos de idade}

As internações das crianças na faixa etária de 1 a 4 anos de idade aumentaram em 10\% no município de São Paulo e diminuiram 15\% no Brasil (gráfico 23).

Gráfico 23 - Evolução do coeficiente de internação hospitalar das crianças de 1 a 4 anos de idade, no município de São Paulo e no Brasil - 2002 a 2006

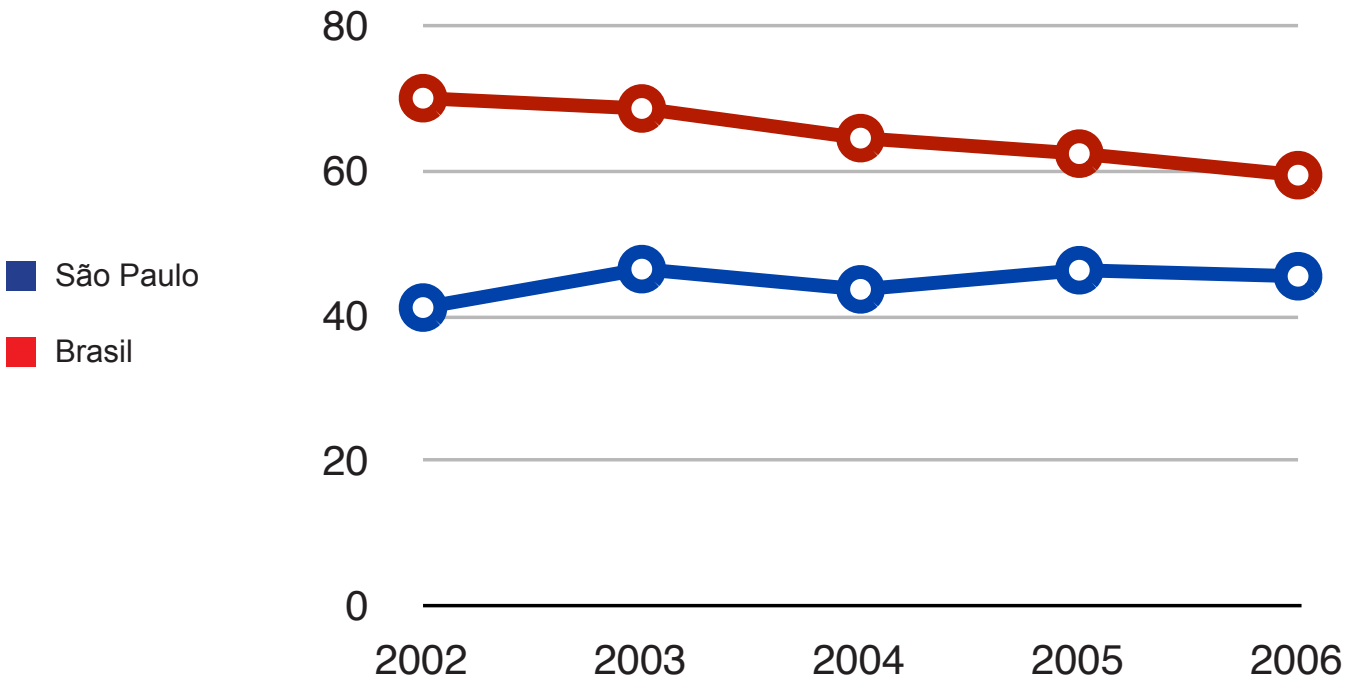


A tabela 13 traz as dez primeiras causas de internação das crianças de 1 a 4 anos de idade no município de São Paulo, nos 5 anos estudados.

Tabela 13 - As dez primeiras causas de internação das crianças de 1 a 4 anos de idade, no município de São Paulo, nos 5 anos estudados - 2002 a 2006

\begin{tabular}{|c|c|c|c|}
\hline Causa & $\begin{array}{l}\text { Número de } \\
\text { internações }\end{array}$ & $\begin{array}{c}\% \text { no } \\
\text { total das } \\
\text { internações }\end{array}$ & $\begin{array}{c}\% \text { entre as } \\
10 \text { primeiras } \\
\text { causas de } \\
\text { internação }\end{array}$ \\
\hline Pneumonia & 32.568 & 20,96 & 40,46 \\
\hline Asma & 14.893 & 9,58 & 18,50 \\
\hline $\begin{array}{c}\text { Diarréia e gastroenterite } \\
\text { infecciosa }\end{array}$ & 5.291 & 3,40 & 6,57 \\
\hline Outras hérnias & 5.057 & 3,25 & 6,28 \\
\hline Hérnia inguinal & 4.958 & 3,19 & 6,16 \\
\hline Fimose & 4.446 & 2,86 & 5,52 \\
\hline $\begin{array}{l}\text { Infecções de pele e de } \\
\text { tecido subcutâneo }\end{array}$ & 3.759 & 2,42 & 4,67 \\
\hline $\begin{array}{c}\text { Doenças crônicas de } \\
\text { amígdalas e adenóides }\end{array}$ & 3.421 & 2,20 & 4,25 \\
\hline $\begin{array}{l}\text { Malformações congênitas } \\
\text { do aparelho circulatório }\end{array}$ & 3.194 & 2,05 & 3,96 \\
\hline $\begin{array}{c}\text { Outras doenças do sistema } \\
\text { nervoso }\end{array}$ & 2.899 & 1,86 & 3,60 \\
\hline
\end{tabular}


Na faixa etária de 1 a 4 anos de idade, as doenças respiratórias (pneumonia, asma e doenças crônicas de amígdalas e adenóides) foram responsáveis por $63 \%$ das internações, entre as dez primeiras causas de hospitalização da faixa etária, durante os anos de 2002 a 2006 (gráfico 24).

Gráfico 24 - Distribuição (\%) dos agrupamentos das dez primeiras causas de internação das crianças de 1 a 4 anos de idade, no município de São Paulo, nos 5 anos estudados - 2002 a 2006

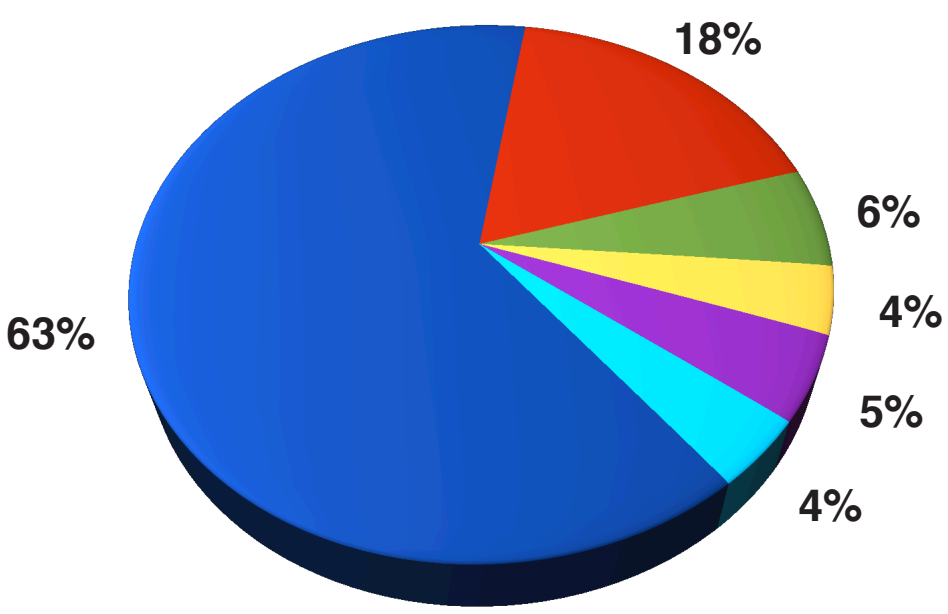

Doenças Respiratórias

Diarréia e Gastroenterite infecciosa

Outras doenças do sistema nervoso

- Causas cirúrgicas

Malformações congênitas do aparelho circulatório

- Infecções de pele e tecido subcutâneo 
Na tabela 14 é expressa a evolução dos coeficientes de internação das dez principais causas de internação nessa faixa etária, em São Paulo e no Brasil.

Tabela 14 - Evolução dos coeficientes de internação das dez primeiras causas de internação das crianças de 1 a 4 anos de idade, no município de São Paulo, comparativamente ao Brasil - 2002 a 2006

\begin{tabular}{|c|c|c|c|c|c|c|}
\hline \multirow{2}{*}{ Causa } & \multirow{2}{*}{ Região } & \multicolumn{5}{|c|}{$\begin{array}{c}\text { Coeficiente de internação } \\
\text { (por } 1000 \text { crianças) }\end{array}$} \\
\hline & & 2002 & 2003 & 2004 & 2005 & 2006 \\
\hline \multirow{2}{*}{ Pneumonia } & São Paulo & 7,02 & 10,14 & 9,17 & 9,95 & 10,45 \\
\hline & Brasil & 17,37 & 17,52 & 16,02 & 14,94 & 14,57 \\
\hline \multirow{2}{*}{ Asma } & São Paulo & 4,07 & 4,34 & 4,27 & 4,55 & 4,12 \\
\hline & Brasil & 9,05 & 8,24 & 7,68 & 7,02 & 6,13 \\
\hline \multirow{2}{*}{$\begin{array}{c}\text { Diarréia e } \\
\text { gastroenterite } \\
\text { infecciosa }\end{array}$} & São Paulo & 0,95 & 1,41 & 1,52 & 1,75 & 1,94 \\
\hline & Brasil & 5,45 & 5,91 & 5,67 & 5,96 & 6,07 \\
\hline \multirow{2}{*}{ Outras hérnias } & São Paulo & 1,55 & 1,42 & 1,32 & 1,39 & 1,55 \\
\hline & Brasil & 0,97 & 0,97 & 0,96 & 0,96 & 0,90 \\
\hline \multirow{2}{*}{ Hérnia inguinal } & São Paulo & 1,68 & 1,65 & 1,35 & 1,25 & 1,16 \\
\hline & Brasil & 1,68 & 1,60 & 1,51 & 1,43 & 1,32 \\
\hline \multirow{2}{*}{ Fimose } & São Paulo & 0,43 & 1,60 & 1,48 & 1,26 & 1,59 \\
\hline & Brasil & 0,17 & 0,59 & 0,59 & 0,55 & 0,57 \\
\hline \multirow{2}{*}{$\begin{array}{l}\text { Infecções de pele e } \\
\text { tecido subcutâneo }\end{array}$} & São Paulo & 0,79 & 0,90 & 1,01 & 1,49 & 1,19 \\
\hline & Brasil & 0,33 & 0,41 & 0,45 & 0,52 & 0,51 \\
\hline \multirow{2}{*}{$\begin{array}{c}\text { Doenças crônicas } \\
\text { de amígdalas e } \\
\text { adenóides }\end{array}$} & São Paulo & 1,19 & 0,99 & 0,92 & 0,85 & 0,93 \\
\hline & Brasil & 0,67 & 0,70 & 0,76 & 0,80 & 0,79 \\
\hline \multirow{2}{*}{$\begin{array}{l}\text { Malformações } \\
\text { congênitas } \\
\text { de aparelho } \\
\text { circulatório }\end{array}$} & São Paulo & 0,92 & 1,04 & 0,88 & 0,81 & 0,91 \\
\hline & Brasil & 0,26 & 0,26 & 0,24 & 0,24 & 0,24 \\
\hline \multirow{2}{*}{$\begin{array}{l}\text { Outras doenças de } \\
\text { sistema nervoso }\end{array}$} & São Paulo & 0,60 & 0,71 & 0,79 & 0,98 & 1,05 \\
\hline & Brasil & 0,14 & 0,16 & 0,16 & 0,18 & 0,18 \\
\hline
\end{tabular}


Os coeficientes de internação por doenças respiratórias (pneumonia, asma e doenças crônicas de amígdalas e adenóides), nas crianças de 1 a 4 anos de idade, apresentaram aumento de 12,3 para 15,5 em São Paulo e queda de 27,1 para 21,5 no Brasil (gráfico 25).

Gráfico 25 - Evolução dos coeficientes de internação hospitalar por doenças respiratórias, das crianças de 1 a 4 anos de idade, no município de São Paulo e no Brasil - 2002 a 2006

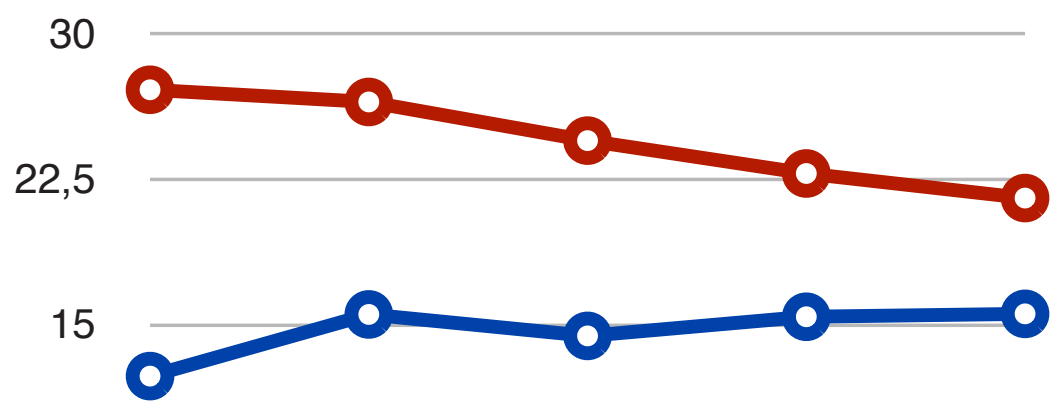

7,5

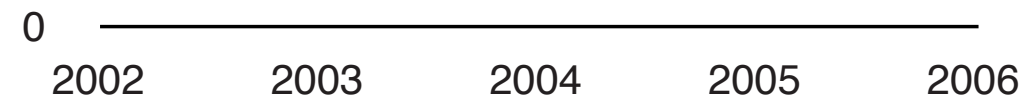


As hospitalizações por pneumonia, nesta faixa etária, aumentaram no município em 5\%, de 2002 a 2006, e cairam 16\% no Brasil neste mesmo período (gráfico.26).

Gráfico 26 - Evolução dos coeficientes de internação hospitalar por pneumonia, das crianças de 1 a 4 anos de idade, no município de São Paulo e no Brasil - 2002 a 2006

20

15
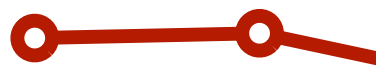

São Paulo

Brasil

10

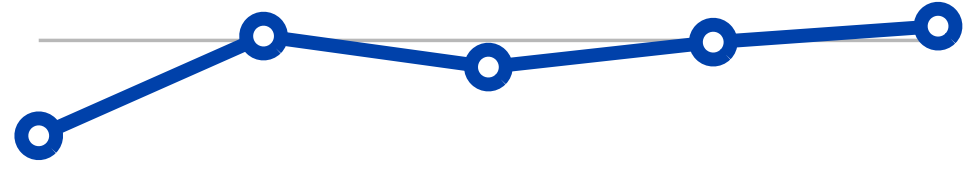

5

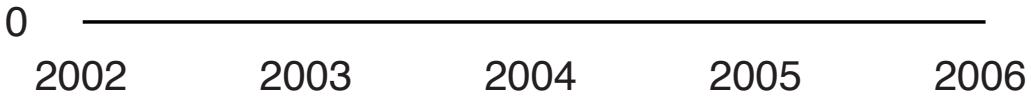


Enquanto as hospitalizações por asma pouco se alteraram em São Paulo, apresentaram queda no Brasil, nas crianças de 1 a 4 anos de idade, no período pesquisado (gráfico 27).

Gráfico 27 - Evolução dos coeficientes de internação hospitalar por asma, das crianças de 1 a 4 anos de idade, no município de São Paulo e no Brasil - 2002 a 2006

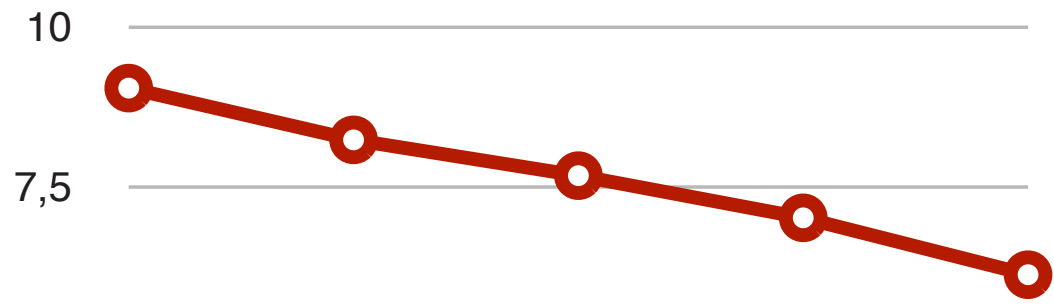

São Paulo

Brasil

5

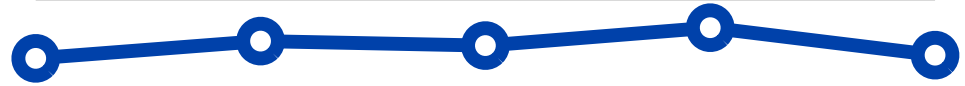

2,5

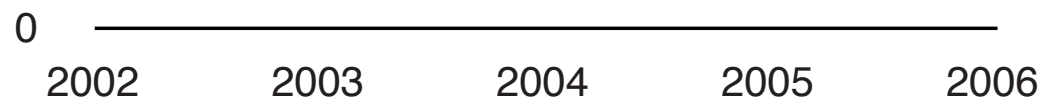


As hospitalizações decorrentes de doenças crônicas de amígdalas e adenóides apresentaram tendências opostas às demais causas respiratórias, aumentaram no Brasil e diminuíram no município, comparando-se os valores de seus coeficientes em 2002 e em 2006 (gráfico 28).

Gráfico 28 - Evolução dos coeficientes de internação hospitalar por doenças crônicas de amígdalas e adenóides, das crianças de 1 a 4 anos de idade, no município de São Paulo e no Brasil 2002 a 2006

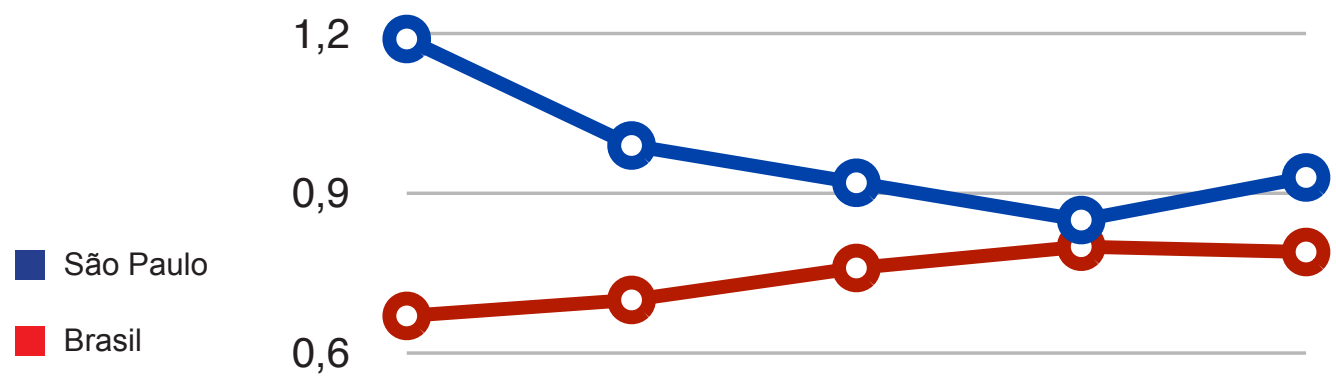

0,3

0

$2002 \quad 2003 \quad 2004 \quad 2005 \quad 2006$


Agrupando-se as causas cirúrgicas (hérnia inguinal, outras hérnias e prepúcio redundante, fimose e parafimose), observa-se pouca variação nas internações no Brasil e flutuação no município de São Paulo, onde são mais freqüentes (gráfico 29). O termo "outras hérnias" é utilizado para hérnia umbilical, hérnia diafragmática, hérnia femural e hérnia abdominal.

Gráfico 29 - Evolução dos coeficientes de internação hospitalar por causas cirúrgicas, das crianças de 1 a 4 anos de idade, no município de São Paulo e no Brasil - 2002 a 2006

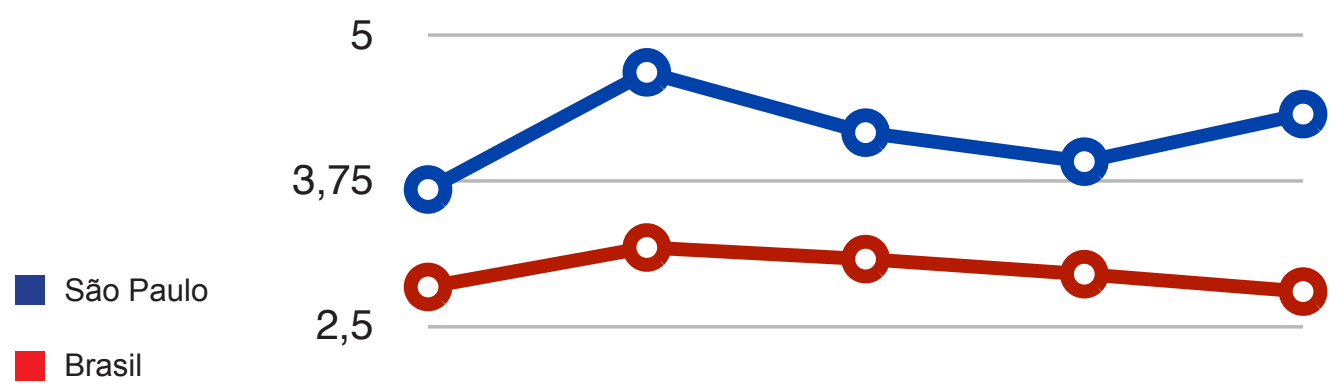

1,25

0 $2002 \quad 2003 \quad 2004 \quad 2005 \quad 2006$ 
As internações por diarréia e gastroenterite de origem infecciosa presumível dobraram no município de São Paulo, no período de 2002 a 2006, nas crianças de 1 a 4 anos de idade e aumentaram em 11\% no Brasil (gráfico 30), embora os coeficientes nesse último ainda sejam bem maiores.

Gráfico 30 - Evolução dos coeficientes de internação hospitalar por diarréia e gastroenterite de origem infecciosa presumível, das crianças de 1 a 4 anos de idade, no município de São Paulo e no Brasil - 2002 a 2006

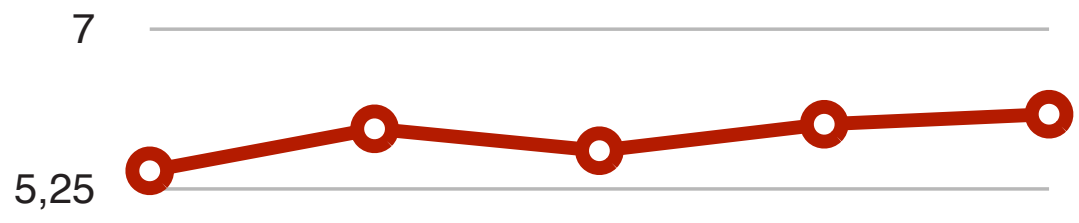

São Paulo

Brasil

\section{3,5}

1,75

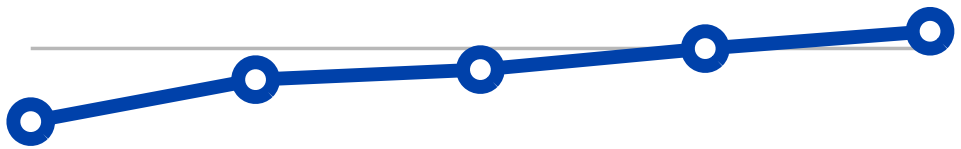

0 $\begin{array}{lllll}2002 & 2003 & 2004 & 2005 & 2006\end{array}$ 
As internações por outras doenças do sistema nervoso não variaram no Brasil, mas no município apresentaram um aumento nos coeficientes de internação de 0,6 para 1,0 (gráfico 31). O termo "outras doenças do sistema nervoso" inclui: atrofias musculares e espinais, doenças extrapiramidais, síndromes vasculares cerebrais, polineuropatia inflamatória, miopatias, miastenia gravis, neuropatias hereditárias e idiopáticas, hidrocefalia, transtornos do sistema nervoso pós-procedimentos, como hipotensão liquórica pós-punção, etc.

Gráfico 31 - Evolução dos coeficientes de internação hospitalar por outras doenças do sistema nervoso, das crianças de 1 a 4 anos de idade, no município de São Paulo e no Brasil - 2002 a 2006
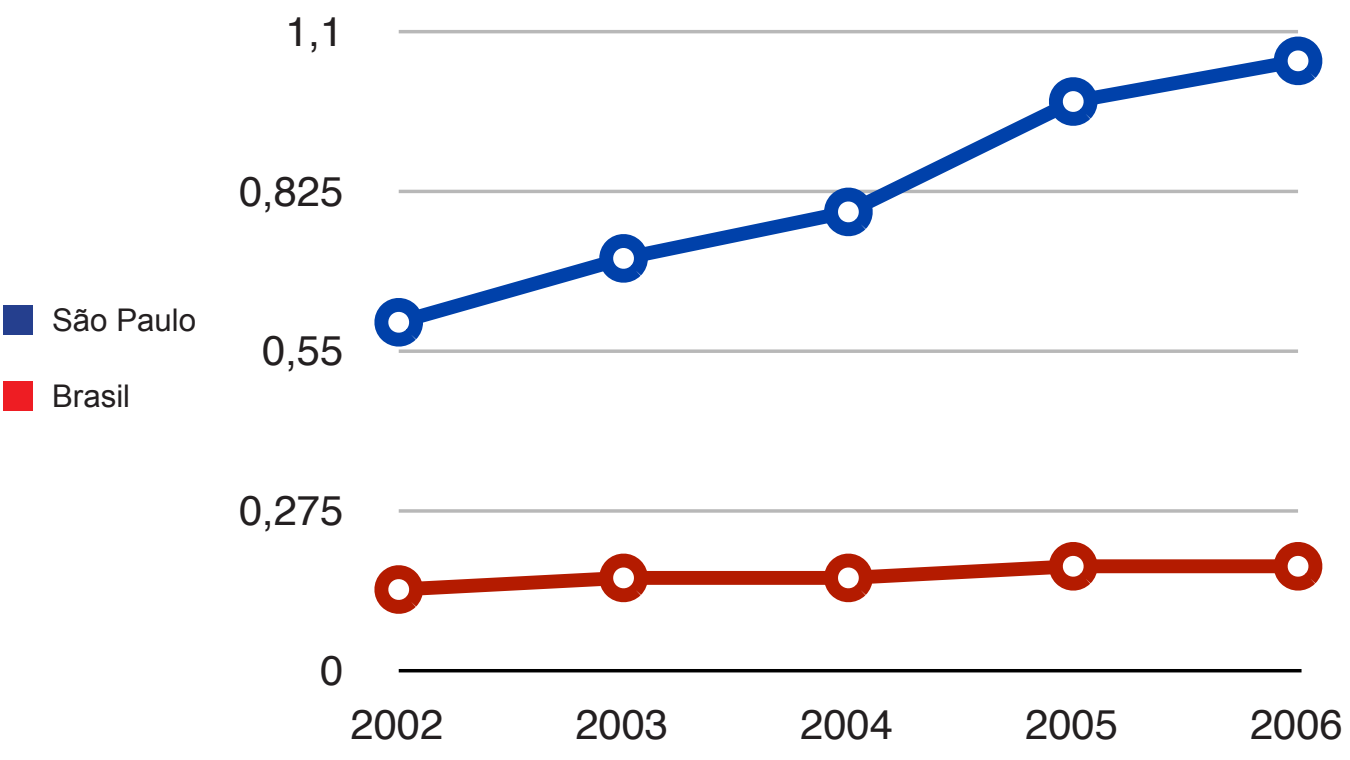
Os coeficientes de internação por infecções de pele e de tecido subcutâneo aumentaram, nesta faixa etária, de 2002 a 2005 e voltaram a cair em 2006, no município, embora seus valores tenham ficado maiores que em 2002. No Brasil também se observou um aumento nessas internações (gráfico 32).

Gráfico 32 - Evolução dos coeficientes de internação hospitalar por infecções de pele e de tecido subcutâneo, das crianças de 1 a 4 anos de idade, no município de São Paulo e no Brasil - 2002 a 2006
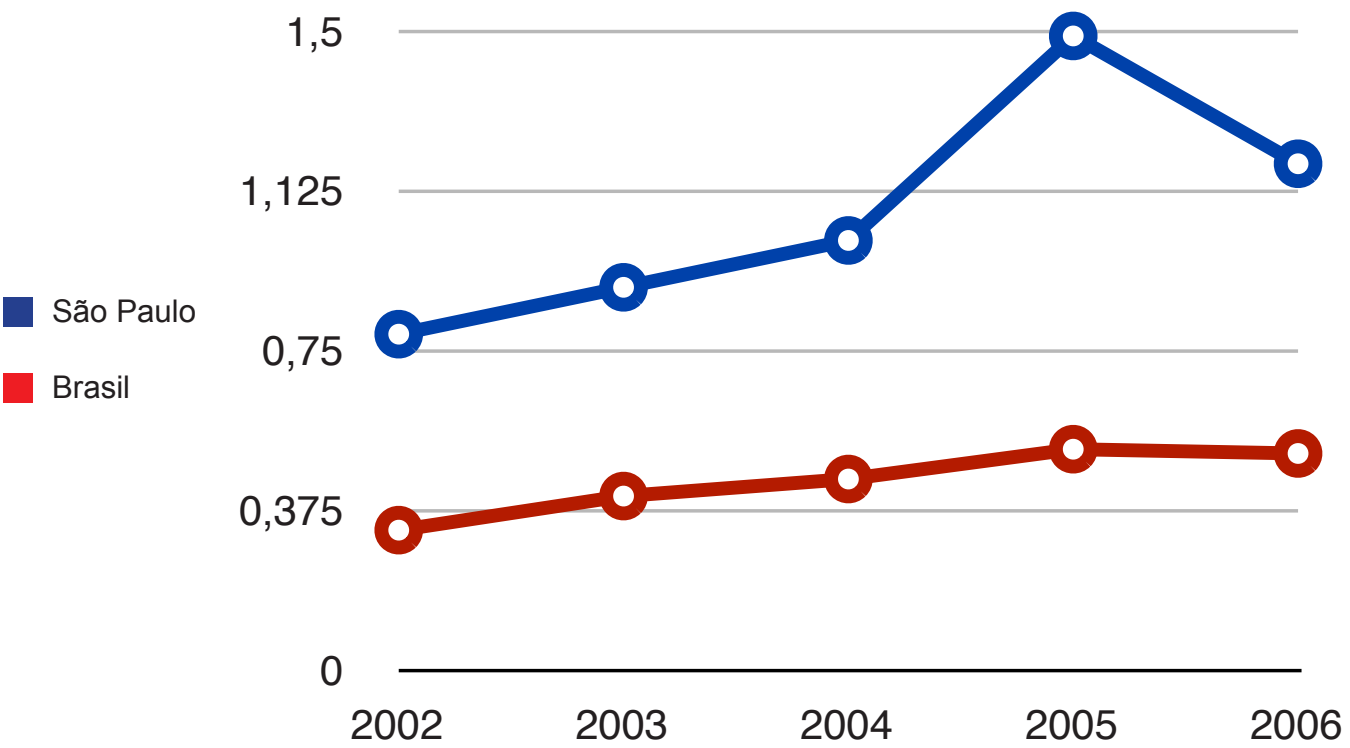
As internações por malformações congênitas do aparelho circulatório embora tenham flutuado, no município de São Paulo, permaneceram com coeficientes de internação praticamente iguais em 2002 e 2006. No Brasil, não ocorreram variações (gráfico 33).

Gráfico 33 - Evolução dos coeficientes de internação hospitalar por malformações congênitas do aparelho circulatório, das crianças de 1 a 4 anos de idade, no município de São Paulo e no Brasil - 2002 a 2006

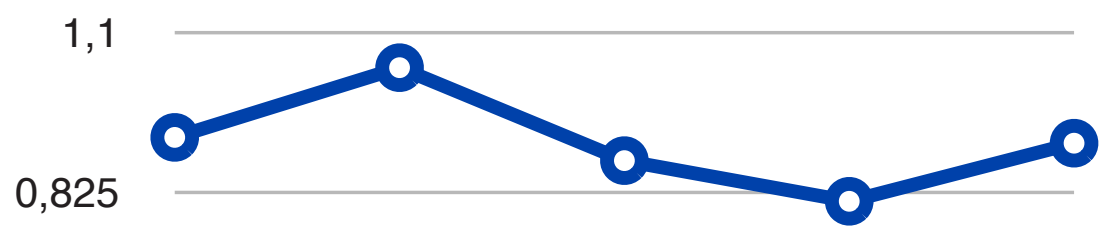

São Paulo

Brasil $\quad 0,55$

0,275
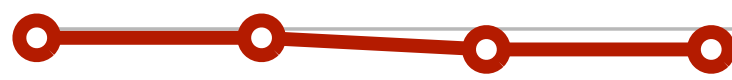

0

$\begin{array}{lllll}2002 & 2003 & 2004 & 2005 & 2006\end{array}$




\subsubsection{As internações das crianças de 5 a 9 anos de idade}

Os coeficientes de internação das crianças de 5 a 9 anos de idade no município aumentaram de 2002 a 2005 e voltaram a cair em 2006, porém não caíram aos mesmos valores iniciais, representando um aumento de $18 \%$ das internações, nessa faixa etária, neste período. No Brasil, estas internações diminuíram 10\% (gráfico 34).

Gráfico 34 - Evolução do coeficiente de internação hospitalar das crianças de 5 a 9 anos de idade, no município de São Paulo e no Brasil - 2002 a 2006

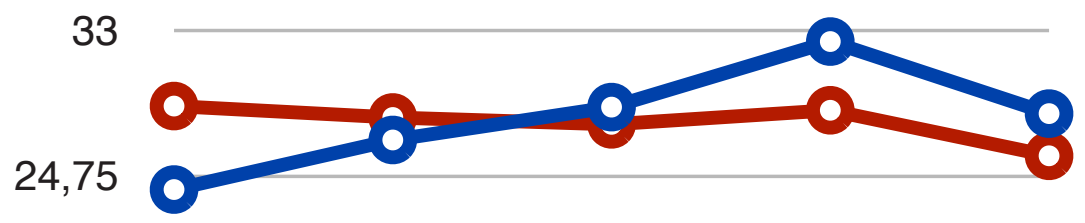

São Paulo

Brasil

\section{6,5}

8,25

$0 \longdiv { 2 0 0 2 \quad 2 0 0 3 \quad 2 0 0 4 \quad 2 0 0 5 \quad 2 0 0 6 }$


As dez principais causas de internação durante os 5 anos estudados, nas crianças de 5 a 9 anos de idade do município de São Paulo estão apresentadas na tabela 15.

Tabela 15 - As dez primeiras causas de internação das crianças de 5 a 9 anos de idade, no município de São Paulo, nos 5 anos estudados - 2002 a 2006

\begin{tabular}{cccc}
\hline Causa & $\begin{array}{c}\text { Número de } \\
\text { internações }\end{array}$ & $\begin{array}{c}\% \text { no } \\
\text { total das } \\
\text { internações }\end{array}$ & $\begin{array}{c}\text { \% entre as } \\
\mathbf{1 0} \text { primeiras } \\
\text { causas de } \\
\text { internação }\end{array}$ \\
\hline Pneumonia & 9.163 & 8,21 & 18,70 \\
\hline Asma & 7.020 & 6,29 & 14,32 \\
\hline $\begin{array}{c}\text { Doenças crônicas de } \\
\text { amígdalas e adenóides }\end{array}$ & 6.442 & 5,77 & 13,14 \\
\hline $\begin{array}{c}\text { Fratura de outros ossos dos } \\
\text { membros }\end{array}$ & 5.798 & 5,20 & 11,83 \\
\hline $\begin{array}{c}\text { Hérnia inguinal } \\
\text { Fimose }\end{array}$ & 4.220 & 3,78 & 8,61 \\
\hline $\begin{array}{c}\text { Outras doenças do sistema } \\
\text { nervoso }\end{array}$ & 3.815 & 3,42 & 7,78 \\
\hline Outras hérnias & 3.340 & 3,26 & 7,42 \\
\hline Doenças do apêndice & 3.204 & 2,82 & 6,89 \\
\hline Traumatismo intracraniano & 2.353 & 2,11 & 4,80 \\
\hline
\end{tabular}


Entre as dez primeiras causas de internação das crianças de 5 a 9 anos de idade, as doenças respiratórias (pneumonia, asma, doenças crônicas de amígdalas e adenóides) corresponderam a $46 \%$ das internações, as hospitalizações por causas cirúgicas (hérnia inguinal, prepúcio redundante, fimose e parafimose, outras hérnias e doenças do apêndice) foram responsáveis por 30\% das internações, as lesões secundárias a causas externas (fratura de outros ossos dos membros e traumatismo intracraniano) por $17 \%$ e as outras doenças do sistema nervoso por $7 \%$ das internações das crianças dessas idades (gráfico 35).

Gráfico 35 - Distribuição (\%) dos agrupamentos das dez primeiras causas de internação das crianças de 5 a 9 anos de idade, no município de São Paulo, nos 5 anos estudados - 2002 a 2006

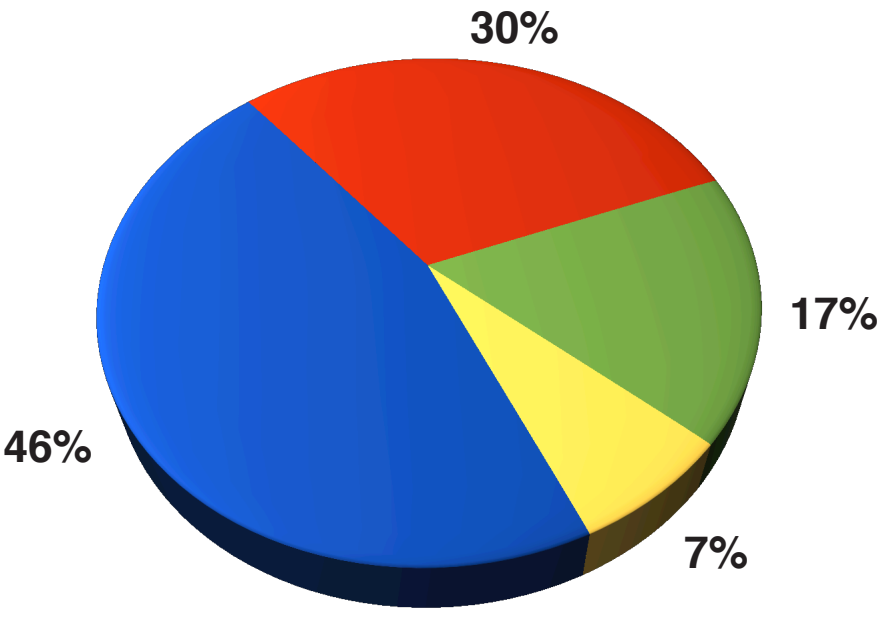

Doenças Respiratórias Lesões secundáriasa causas externas

Causas cirúrgicas

Outras doenças do sistema nervoso 
A evolução dos coeficientes de internação, de cada uma dessas causas, ao longo do período e a comparação com os dados nacionais estão apresentadas na tabela 16 .

Tabela 16 - Evolução dos coeficientes de internação das dez primeiras causas de internação das crianças de 5 a 9 anos de idade, no município de São Paulo, comparativamente ao Brasil - 2002 a 2006

\begin{tabular}{|c|c|c|c|c|c|c|}
\hline \multirow{2}{*}{ Causa } & \multirow{2}{*}{ Região } & \multicolumn{5}{|c|}{$\begin{array}{l}\text { Coeficiente de internação } \\
\text { (por } 1000 \text { crianças) }\end{array}$} \\
\hline & & 2002 & 2003 & 2004 & 2005 & 2006 \\
\hline \multirow{2}{*}{ Pneumonia } & São Paulo & 1,52 & 2,14 & 2,30 & 3,0 & 2,53 \\
\hline & Brasil & 3,95 & 3,65 & 3,47 & 3,44 & 3,24 \\
\hline \multirow{2}{*}{ Asma } & São Paulo & 1,27 & 1,67 & 1,93 & 2,17 & 1,77 \\
\hline & Brasil & 2,89 & 2,61 & 2,46 & 2,47 & 2,05 \\
\hline \multirow{2}{*}{$\begin{array}{c}\text { Doenças crônicas } \\
\text { de amígdalas e } \\
\text { adenóides }\end{array}$} & São Paulo & 1,68 & 1,43 & 1,56 & 1,68 & 1,70 \\
\hline & Brasil & 0,96 & 0,99 & 1,14 & 1,28 & 1,28 \\
\hline \multirow{2}{*}{$\begin{array}{c}\text { Fratura de } \\
\text { outros ossos dos } \\
\text { membros }\end{array}$} & São Paulo & 1,35 & 1,51 & 1,45 & 1,55 & 1,39 \\
\hline & Brasil & 1,76 & 1,86 & 1,88 & 1,96 & 1,75 \\
\hline \multirow{2}{*}{ Hérnia inguinal } & São Paulo & 1,08 & 1,11 & 1,03 & 1,09 & 0,97 \\
\hline & Brasil & 1,10 & 1,06 & 1,08 & 1,06 & 0,92 \\
\hline \multirow{2}{*}{ Fimose } & São Paulo & 0,31 & 1,06 & 1,16 & 1,09 & 1,15 \\
\hline & Brasil & 0,12 & 0,43 & 0,48 & 0,48 & 0,48 \\
\hline \multirow{2}{*}{$\begin{array}{l}\text { Outras doenças do } \\
\text { sistema nervoso }\end{array}$} & São Paulo & 0,56 & 0,66 & 0,84 & 1,18 & 1,27 \\
\hline & Brasil & 0,09 & 0,10 & 0,11 & 0,13 & 0,13 \\
\hline \multirow{2}{*}{ Outras hérnias } & São Paulo & 0,70 & 0,79 & 0,82 & 0,91 & 0,93 \\
\hline & Brasil & 0,59 & 0,64 & 0,68 & 0,69 & 0,63 \\
\hline \multirow{2}{*}{$\begin{array}{l}\text { Doenças do } \\
\text { apêndice }\end{array}$} & São Paulo & 0,59 & 0,75 & 0,86 & 0,99 & 0,82 \\
\hline & Brasil & 0,44 & 0,43 & 0,47 & 0,54 & 0,52 \\
\hline \multirow{2}{*}{$\begin{array}{l}\text { Traumatismo } \\
\text { intracraniano }\end{array}$} & São Paulo & 0,33 & 0,52 & 0,65 & 0,78 & 0,66 \\
\hline & Brasil & 0,40 & 0,45 & 0,46 & 0,46 & 0,37 \\
\hline
\end{tabular}


Nas crianças de 5 a 9 anos de idade, as doenças respiratórias (pneumonia, asma, doenças crônicas de amígdalas e adenóides) aumentaram em São Paulo de 2002 a 2005, apresentando queda em 2006, mas com coeficiente de internação em 2006 maior que em 2002 (4,47 para 6,0). No Brasil, à semelhança do que ocorreu nas demais faixas etárias, houve uma redução nos coeficientes de internação no período estudado (gráfico 36 ).

Gráfico 36 - Evolução dos coeficientes de internação hospitalar por doenças respiratórias, das crianças de 5 a 9 anos de idade, no município de São Paulo e no Brasil - 2002 a 2006

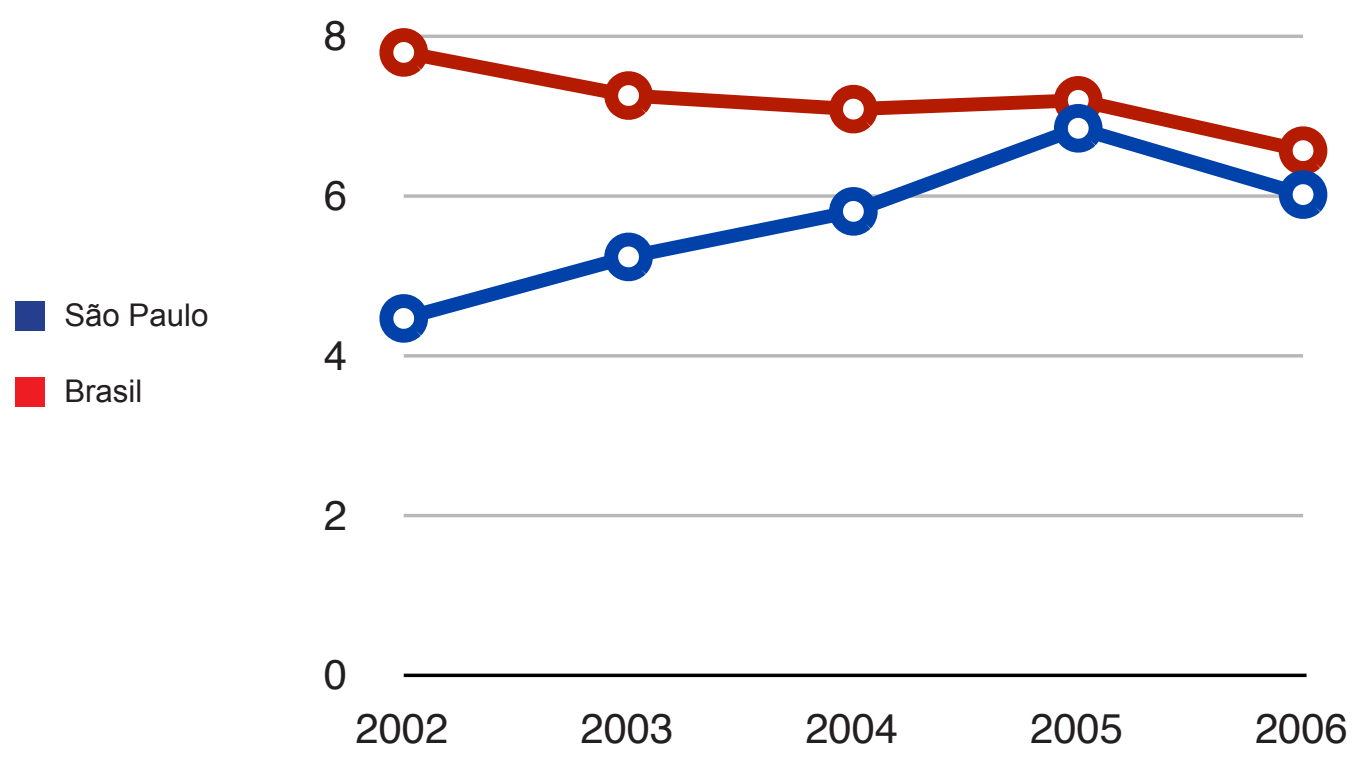

As internações por pneumonia e por asma comportaram-se de maneira similar: aumentaram no município de 2002 a 2005, caíram em 2006, mas apresentaram um aumento ao final do período. No Brasil, os coeficientes de internação de ambas as causas apresentaram queda (gráficos 37 e 38). 
Gráfico 37 - Evolução dos coeficientes de internação hospitalar por pneumonia, das crianças de 5 a 9 anos de idade, no município de São Paulo e no Brasil - 2002 a 2006

São Paulo

Brasil

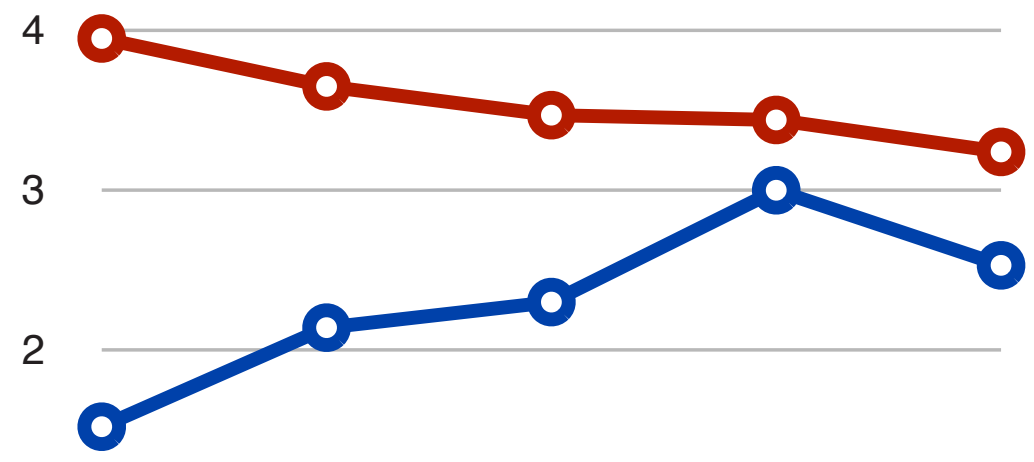

1

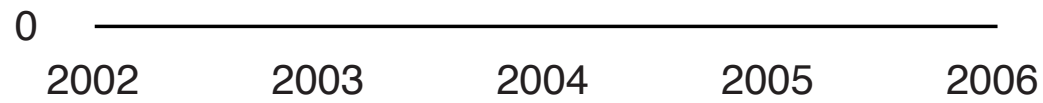

Gráfico 38 - Evolução dos coeficientes de internação hospitalar por asma, das crianças de 5 a 9 anos de idade, no município de São Paulo e no Brasil - 2002 a 2006

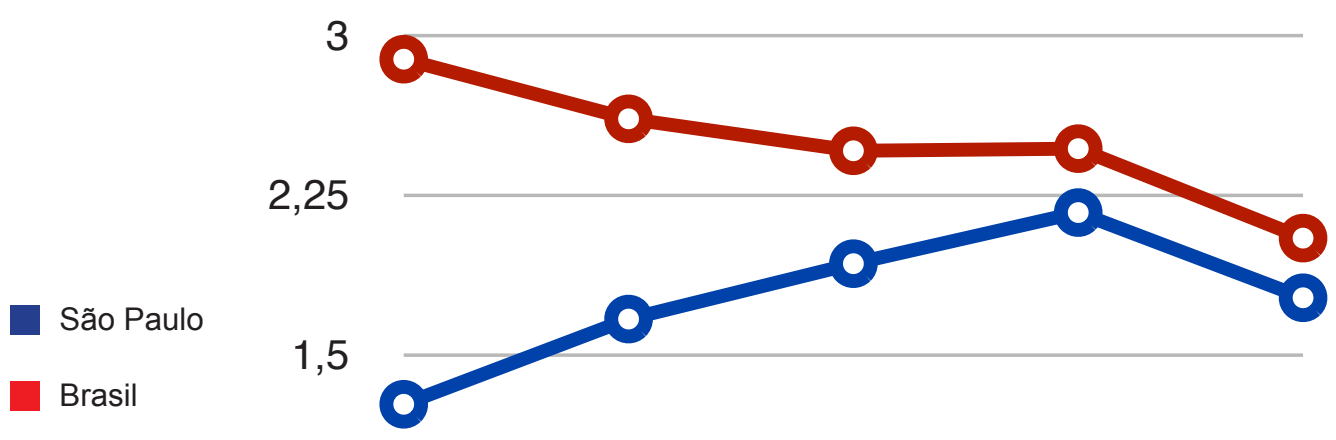

0,75

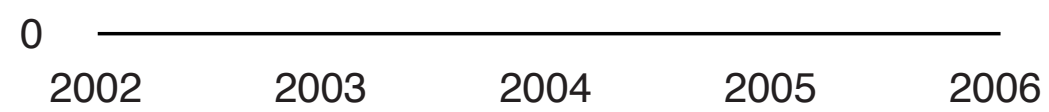


As internações por doenças crônicas de amígdalas e adenóides apresentaram queda em 2003, mas voltaram a aumentar e, em 2006, tiveram coeficiente de internação praticamente igual ao observado em 2002. No Brasil, houve aumento nessas internações (gráfico 39).

Gráfico 39 - Evolução dos coeficientes de internação hospitalar por doenças crônicas de amígdalas e adenóides, das crianças de 5 a 9 anos de idade, no município de São Paulo e no Brasil 2002 a 2006

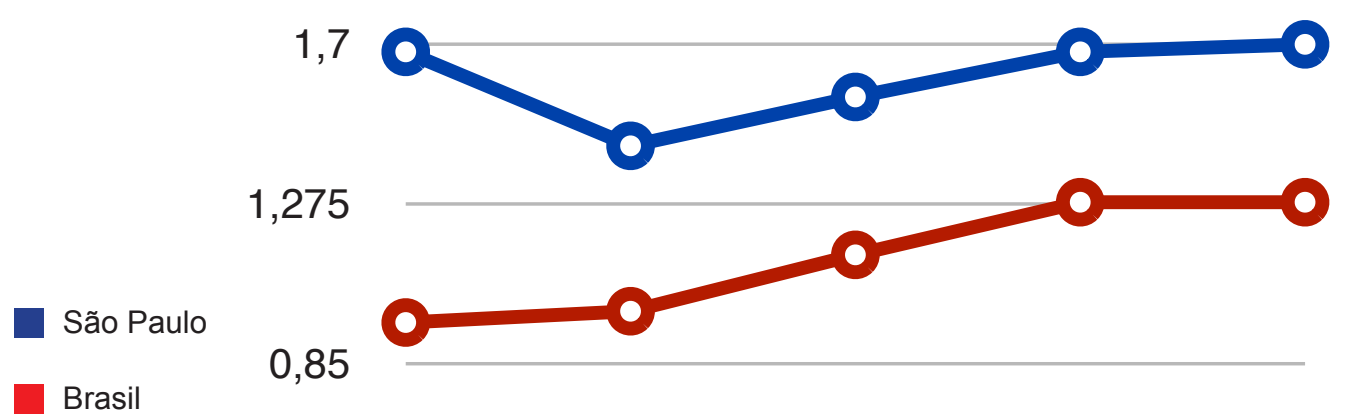

0,425

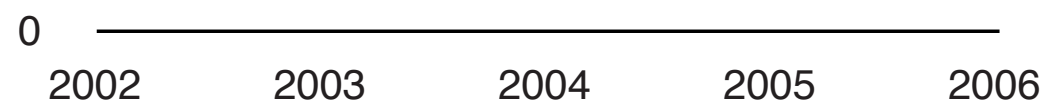


As hospitalizações por causas cirúrgicas (hérnia inguinal, prepúcio redundante, fimose e parafimose, outras hérnias e doenças do apêndice) aumentaram nas duas regiões, mais expressivamente no município de São Paulo (gráfico 40).

Gráfico 40 - Evolução dos coeficientes de internação hospitalar por causas cirúrgicas, das crianças de 5 a 9 anos de idade, no município de São Paulo e no Brasil - 2002 a 2006

5

São Paulo

Brasil

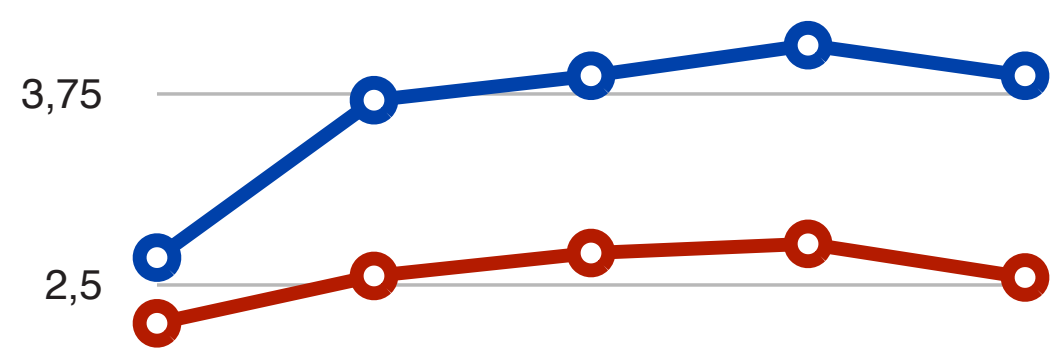

1,25

$0 \longdiv { 2 0 0 2 \quad 2 0 0 3 \quad 2 0 0 4 \quad 2 0 0 5 \quad 2 0 0 6 }$


O grupo das lesões secundárias a causas externas (fraturas de outros ossos dos membros e traumatismo intracraniano) evoluiu de maneira muito similar no Brasil e em São Paulo: aumentaram de 2002 a 2005 e apresentaram queda em 2006. Porém, enquanto no Brasil o coeficiente de internação em 2006 foi praticamente igual ao de 2002 , no município esse valor foi $22 \%$ maior (gráfico 41).

Gráfico 41 - Evolução dos coeficientes de internação hospitalar por lesões secundárias a causas externas, das crianças de 5 a 9 anos de idade, no município de São Paulo e no Brasil - 2002 a 2006

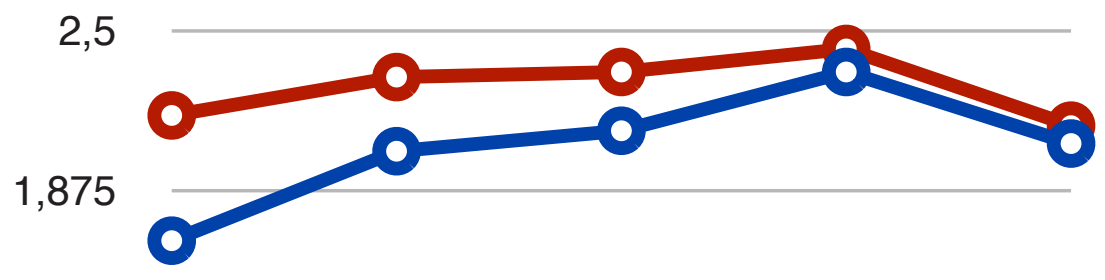

São Paulo

\section{1,25}

Brasil

0,625

$\begin{array}{lllll}0 & 2002 & 2003 & 2004 & 2005\end{array}$


As internações por outras doenças do sistema nervoso aumentaram no município e praticamente não oscilaram no Brasil (gráfico 42).

Gráfico 42 - Evolução dos coeficientes de internação hospitalar por outras doenças do sistema nervoso, das crianças de 5 a 9 anos de idade, no município de São Paulo e no Brasil - 2002 a 2006

1,5

São Paulo

Brasil

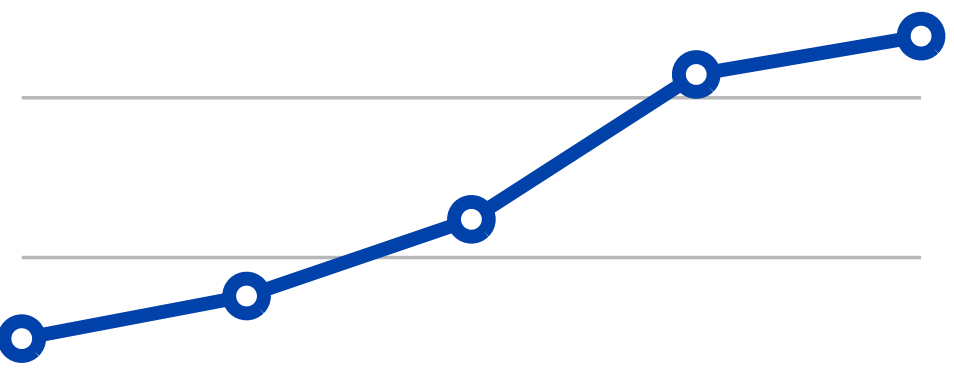

0,375

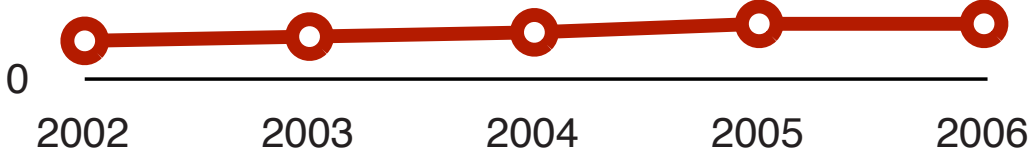


5.DISCUSSÃO 
As taxas de mortalidade infantil evoluíram com declínio progressivo, entretanto, o número de internações hospitalares das crianças não apresentou a mesma evolução, particularmente para algumas condições mórbidas.

A análise dos dados considerará aspectos gerais da população infantil e aspectos específicos por faixas etárias, uma vez que as crianças nas diferentes idades apresentam características diversas no que se refere a hábitos de vida e exposição aos fatores de risco e de proteção aos agravos, à gravidade dos quadros, às possibilidades de recuperação e às doenças apresentadas, condições que influenciam as taxas de hospitalização.

\subsection{CARACTERÍSTICAS DAS INTERNAÇÕES HOSPITALARES NO MUNICÍPIO DE SÃO PAULO E NO BRASIL}

Os resultados mostram que as internações hospitalares em crianças de 0 a 9 anos de idade são muito frequentes, correspondendo a $16 \%$ das hospitalizações no município de São Paulo e 17\% no Brasil. A proporção das internações dessa faixa etária em relação às demais, não mostrou variação ao longo dos 5 anos estudados, nem em São Paulo e nem no Brasil (tabelas 3 e 4$)$.

Em relação à idade, encontrou-se grande predomínio das hospitalizações nos menores de 1 ano de idade (gráfico 5), nas duas regiões demográficas. Esse dado está de acordo com o trabalho de CASTRO et al (2002) que, estudando os fatores associados às internações hospitalares no Brasil com dados da Pesquisa Nacional por Amostra de Domicílios (PNDA) de 1998, descreveram uma diminuição de 13\% na probabilidade de internação hospitalar a cada aumento de 1 ano na idade da criança. Porém, tanto CAETANO et al (2002) como a PNDS de 2006, descrevem maiores taxas de internação entre 
as crianças de 1 a 4 anos de idade. Tal diferença em relação ao presente estudo talvez possa ser atribuída a questões metodológicas, pois os dois estudos citados são inquéritos domiciliares e tratam de internações referidas, abrangendo apenas crianças sobreviventes e as taxas de mortalidade são maiores entre os menores de 1 ano de vida.

A média de permanência hospitalar também foi alta entre os menores de 1 ano de idade, inferiores apenas ao tempo médio de hospitalização dos maiores de 80 anos (tabela 8). O predomínio de internações e a maior média de permanência hospitalar no primeiro ano de vida podem ser reflexos dos motivos de hospitalização e da maior vulnerabilidade dessa faixa etária. Há de se considerar que a imaturidade imunológica e as características anatômicas dessa idade podem determinar quadros mais graves e de recuperação mais difícil.

O predomínio de internações no gênero masculino (gráfico 6) está de acordo com os dados de literatura, que descrevem o sexo masculino como um fator de risco associado à hospitalização de crianças (CAETANO et al, 2002; CASTRO et al ,2002).

\subsection{A VARIAÇÃO DO COEFICIENTE DE INTERNAÇÃO ENTRE 2002 E} 2006

Um primeiro dado importante a ser discutido é o fato do coeficiente de internação ter aumentado $11 \%$ no município de São Paulo enquanto diminuiu 14\% no Brasil, comparando-se os valores de 2002 aos de 2006. É importante ressaltar que o aumento em São Paulo e a diminuição no Brasil representam uma tendência observada ao longo dos 5 anos estudados (gráfico 7). 
A faixa etária das crianças menores de 1 ano além de ter sido a que mais foi internada também foi a que apresentou maior aumento nos coeficientes de internação, comparando-se 2002 a 2006, no município de São Paulo, verificando-se uma variação de $21 \%$ (tabela 5). No Brasil, observou-se diminuição nas três faixas etárias avaliadas, sendo mais expressiva entre as crianças de 1 e 4 anos de idade, com queda de 15\% (tabela 6).

De acordo com LEBRÃO (1999), a análise dos motivos determinantes de mudanças ocorridas na freqüência das doenças é tarefa complexa, em função dos vários fatores que podem estar envolvidos. Para discutir os possíveis fatores que podem ter influenciado a evolução observada nos coeficientes de internação, optou-se por adotar como referencial teórico o modelo comportamental de Andersen (ADAY e ANDERSEN, 1974; ANDERSEN e NEWMAN, 1973). Esse é um modelo considerado clássico e muito empregado pelos estudiosos da utilização de serviços de saúde (CASTRO et al, 2002; PHILLIPS et al, 1998). Esse modelo, que vem sendo desenvolvido por Andersen desde 1968 visa compreender os fatores que influenciam o uso dos serviços de saúde, permitindo avaliar a equidade no acesso, a efetividade e a eficiência dos serviços. Conforme esse autor, a utilização dos serviços de saúde depende da predisposição do indivíduo (fatores predisponentes), de fatores que possibilitam ou impedem esse uso (fatores capacitantes) e das necessidades de saúde. Entre os fatores predisponentes estão as características demográficas, como a idade e o gênero, a estrutura social e os fatores culturais. Como fatores capacitantes, além da oferta de serviços, com leitos, equipamentos e profissionais de saúde, estão os fatores individuais, ou seja, os indivíduos devem dispor de meios e de conhecimento para chegar aos serviços de saúde. Por fim, as necessidades de saúde, que podem ser auto-avaliadas, aquelas percebidas pelo próprio indivíduo, ou avaliadas pelo profissional de saúde (figura 1). 
Figura 1 - Representação esquemática dos fatores envolvidos no uso de serviços de saúde segundo o modelo comportamental de Andersen

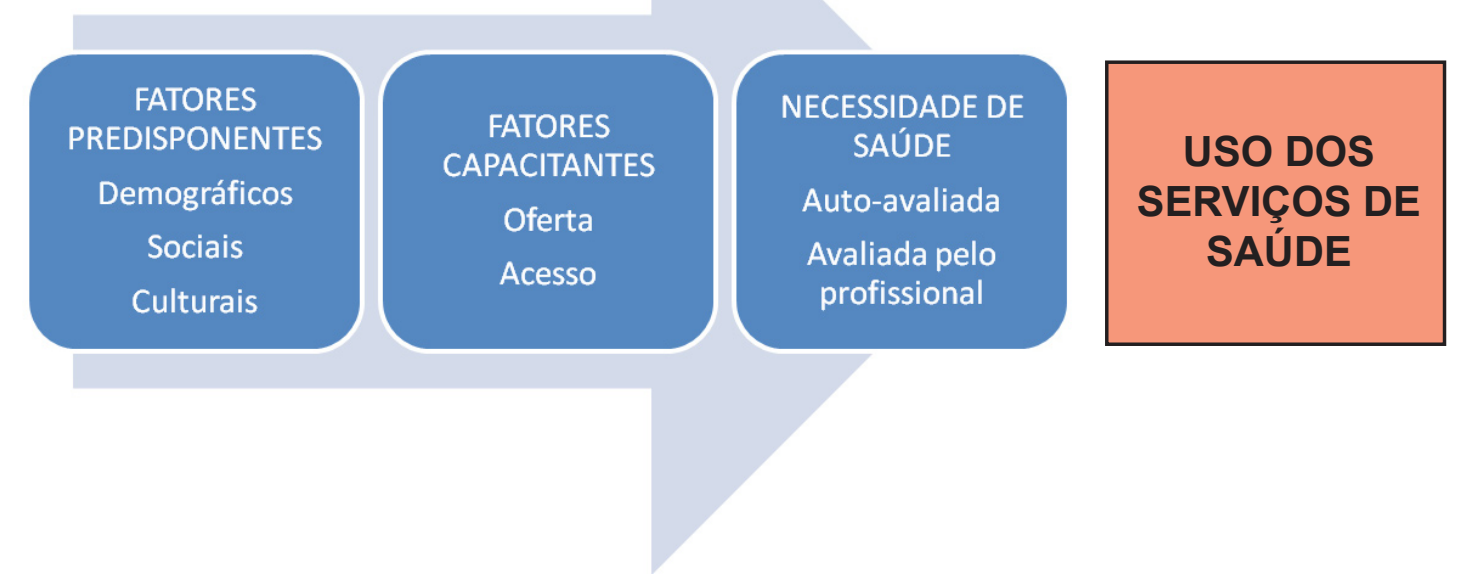

Em revisões posteriores (ANDERSEN, 1995), Andersen amplia os conceitos e passa a utilizar os termos: acesso potencial e acesso realizado. De acordo com o autor, o acesso potencial seria determinado pelos fatores capacitantes, enquanto o acesso realizado seria sinônimo do uso do serviço de saúde e, portanto, incluiria os fatores predisponentes, os capacitantes e as necessidades de saúde. Além disso, acrescenta que o acesso pode ser considerado equitativo se os principais determinantes para o uso dos serviços de saúde forem as características demográficas e as necessidades de saúde e, inequitativo se outros fatores, como os aspectos sociais, por exemplo, estiverem interferindo nesse uso.

Os vários estudos realizados no sentido de identificar os fatores associados a uma maior possibilidade de internação, tais como as publicações de CAETANO et al, 2002; BILLINGS et al, 1996; SILVA et al, 1999; CASANOVA et al, 1996 e STARFIELD, 1992, descrevem como situações de risco: sexo masculino, baixa renda familiar, raça negra, baixa escolaridade materna, baixo peso ao nascer, desmame precoce, desnutrição, residência em área 
urbana, menor acesso ao acompanhamento ambulatorial, baixa resolutividade das consultas, moradia próxima a um hospital, maior disponibilidade de leitos hospitalares, maior densidade domiciliar, exposição ao fumo, frio e umidade, comportamento médico e familiar .

Utilizando o referencial teórico de Andersen, podemos discutir possíveis mecanismos envolvidos nas variações observadas nos coeficientes de internação.

1. Fatores predisponentes: como a faixa etária avaliada, as crianças de 0 a 9 anos de idade, foi a mesma nos 5 anos estudados, não podemos considerar mudanças nas características demográficas. O tempo de estudo, 5 anos, também é um período curto para que tenha havido mudanças sociais e culturais que pudessem explicar as variações observadas nas taxas de hospitalização. Tomando por base os indicadores socioeconômicos da Rede Interagencial de Informações para a Saúde (RIPSA), contidos nos Indicadores e Dados Básicos - Brasil de 2007 (IDB - 2007), as mudanças observadas entre 2002 e 2006 foram no sentido de melhora das condições sociais e, portanto, não poderiam ser consideradas como determinantes do aumento das internações no município de São Paulo. A evolução desses indicadores entre 2002 a 2006, tanto no estado de São Paulo como no Brasil, apontam para: queda na taxa de analfabetismo, aumento no tempo de escolaridade, aumento no PIB per capita, queda na razão de renda, ou seja, diminuição das desigualdades, queda nas taxas de desemprego e discreto aumento na proporção de pobres.

As características sociais e culturais podem explicar as diferenças observadas comparando-se os coeficientes de internação do município 
de São Paulo com os do Brasil, mas não explicam o aumento das internações verificado no município ao longo do período estudado.

2. Fatores capacitantes: são aqueles que atuam impedindo ou facilitando o uso dos serviços de saúde. São relacionados, portanto, à disponibilidade ou oferta de serviços, à distância dos serviços de saúde, ao conhecimento de como utilizar os serviços, entre outros. Esses fatores sofrem influência, direta ou indiretamente, das políticas de saúde adotadas.

Levando-se em consideração o momento histórico do estudo, os primeiros anos do SUS no município de São Paulo, época em que ocorreram muitas mudanças no sistema e nas políticas de saúde, é de se esperar que entre os fatores capacitantes estejam os principais motivos que podem ter exercido influência sobre as variações observadas nos coeficientes de internação nesse estudo. Andersen (1995) já havia descrito que os fatores capacitantes são os mais mutáveis e, portanto, fortemente associados a alterações observadas no uso dos serviços hospitalares.

Um primeiro elemento a ser analisadoé a oferta de leitos hospitalares. CASTRO et al (2005), avaliando o efeito da oferta de serviços de saúde nas internações hospitalares no Brasil, encontraram o que descreveram como "demanda induzida pela oferta", isto é, mesmo ajustando-se para variáveis individuais e de necessidades de saúde, observaram uma maior probabilidadede internação relacionada a um maior número de leitos hospitalares. GOODMAN et al (1994), avaliando o papel de fatores não-clínicos nas hospitalizações pediátricas, demonstraram que a disponibilidade de leitos hospitalares e a proximidade aos hospitais foram fortemente relacionadas às internações, principalmente para condições 
em que havia outras opções de tratamento, que não o hospitalar.

Nesse estudo, o aumento dos coeficientes de internação observado em São Paulo não pôde ser correlacionado a um aumento do número de leitos pediátricos do SUS, pois, conforme dados do Cadastro Nacional de Estabelecimentos de Saúde (CNES), em 2002 haviam 1,15 leitos para cada 1000 crianças e adolescentes de 0 a 14 anos de idade e em 2006, esse número caiu para 0,59. No Brasil também houve uma diminuição no número de leitos pediátricos do SUS, mas em menor proporção, caindo de 1,51 para 1,08 leitos para cada 1000 crianças e adolescentes de 0 a 14 anos de idade. Deve-se levar em consideração que o presente estudo refere-se apenas às hospitalizações realizadas pelo SUS e que a inclusão de internações cobertas por seguros e por planos de saúde provavelmente alteraria os resultados observados, uma vez que os fatores envolvidos nessas internações e as características da população coberta por esse tipo de serviço diferem daqueles observados no SUS.

Outro elemento fundamental a ser considerado é a oferta de atenção ambulatorial e de serviços de atenção básica. É descrito que os cuidados básicos e o seguimento regular em serviços de saúde tanto servem para prevenir o aparecimento de doenças como para evitar o agravamento de condições já existentes, reduzindo o risco de hospitalização. STARFIELD (1992) descreve que países com um sistema de atenção primária bem estruturado têm melhor performance na maioria dos indicadores de saúde em relação aos países cuja atenção primária é falha. CASANOVA e STARFIELD (1995), comparando a Espanha e os Estados Unidos em relação às hospitalizações de crianças e acesso à atenção primária, concluíram que as internações podem ser reduzidas com o maior acesso à atenção primária de qualidade. CASTRO et al (2005) encontraram 
uma associação inversa entre as admissões hospitalares e o número de médicos disponíveis, concluindo haver influência do cuidado ambulatorial sobre o uso do hospital. De acordo com citação de SUCUPIRA (2007), no período compreendido entre 2000 e 2006, verificou-se no Brasil um aumento de $49 \%$ na produção ambulatorial, com redução de 5,2\% nas internações, considerando-se todas as faixas etárias. Esse aumento nas consultas ambulatoriais acompanhado de redução das taxas de hospitalização representa uma tendência mundial.

Vários indicadores podem fornecer medidas indiretas para avaliar a cobertura pela atenção primária. Um dos que têm sido mais utilizados na literatura é o que avalia as hospitalizações que poderiam ter sido evitadas por um seguimento ambulatorial adequado, conhecidas como causas sensíveis à atenção ambulatorial. Esse indicador será discutido adiante, ao serem analisadas as causas de internação hospitalar. Outro indicador é o que avalia a cobertura vacinal. Tomando-se a vacina tríplice, que não é aplicada nos berçários como a vacina BCG e a hepatite $B$ e nem em campanhas, como anti-poliomielite, e, portanto, pode refletir melhor o seguimento das crianças nos serviços de saúde, observou-se, de acordo com dados do IDB - 2007, que no município de São Paulo o percentual de crianças vacinadas variou pouco entre 2002 e 2006, indo de 89,14 para $89,48 \%$. No Brasil, essa cobertura foi de 95,6 para $100 \%$, no mesmo período. Esses dados podem expressar uma boa cobertura de atenção primária.

Outra maneira possível de se avaliar a atenção primária é verificando o número de consulta médicas no SUS por habitante, disponível na mesma fonte de dados. Enquanto no município de São Paulo houve um aumento de 2,6 para 2,9 consultas, no Brasil não houve variações, mantendo-se 
taxas de 2,5 consultas por habitante por ano. A cobertura vacinal, assim como o número de consultas apresentaram uma tendência de melhora na atenção básica, podendo estar associada à melhora nas taxas de hospitalização verificadas no Brasil, mas não explicaria o aumento das internações no município.

Mas então, por que houve aumento das internações em São Paulo? Há de se considerar que a atenção básica pode reduzir as taxas de internação ao melhorar as condições de saúde, mas, por outro lado, pode ter um efeito inverso, no início de um processo de expansão da atenção primária, e aumentar a demanda pelos serviços hospitalares por facilitar o acesso e atuar como porta de entrada para a demanda reprimida ao sistema de saúde, como descrito por OLIVEIRA et al (2004).

Na proposta do SUS, os serviços de saúde devem traduzir, na prática, os princípios da universalidade, integralidade e equidade. Considerando-se que o município de São Paulo passou a integrar o SUS em 2001, é de se esperar que no período estudado, de 2002 a 2006, a implantação, estruturação e propagação do sistema suscitasse um maior acesso aos serviços. Paralelamente à implantação do SUS, a Secretária Municipal da Saúde de São Paulo priorizou o fortalecimento do Programa de Saúde da Família (PSF) como eixo estruturante da atenção básica. Considerando-se o número de famílias cadastradas no PSF em dezembro de 2001 comparado a esse número em dezembro de 2006, verificou-se um aumento de $48,8 \%$ no Brasil e de $369,8 \%$ no município de São Paulo, conforme dados do DATASUS. Essa grande expansão do PSF no município pode ter facilitado a entrada ao sistema de saúde, aumentando os coeficientes de internação. Ainda há poucos relatos na literatura a respeito do impacto do PSF na saúde infantil. RONCALLI 
et al (2006), avaliando o impacto do PSF nos indicadores de saúde da criança em quatro municípios do nordeste, não encontraram diferenças significativas entre os indicadores de áreas cobertas e não cobertas pelo PSF. O único efeito positivo encontrado foi a redução das internações por diarréia. Porém, esses autores notaram que as diferenças no modo de implantação do PSF encontradas em cada município exerceram influência nos resultados. Ao se avaliar o impacto do PSF na taxa de mortalidade infantil, observa-se um efeito mais contundente. MACINKO et al (2006), avaliando o efeito do PSF nessa taxa, encontraram que um aumento de $10 \%$ na cobertura pelo PSF determinou um decréscimo de $4,5 \%$ na mortalidade infantil. SERRA (2005) encontrou impacto benéfico do PSF sobre a mortalidade infantil mesmo em região economicamente mais desenvolvida, como o estado de São Paulo. Em relação às internações, PARCHMAN e CULLER (1994) descreveram que as hospitalizações por condições sensíveis a atenção ambulatorial, tanto entre adultos como entre crianças, foram menores na Pensilvânia, em função da disponibilidade de médicos de família e de generalistas

Muitas condições podem ter exercido influência no aumento das internações no município, mas um dos possíveis fatores que pode ter motivado esse achado seria o maior acesso aos serviços de saúde, propiciado pela expansão da atenção básica atuando como porta de entrada ao sistema de saúde. No Brasil, que de um modo geral apresenta piores condições sociais, comparativamente a São Paulo, talvez o impacto do PSF, que já estava implantado há mais tempo e com maior cobertura, tenha sido maior na prevenção de agravos e de suas complicações e, portanto, reduzindo as taxas de hospitalização. 
Ainda em relação ao conceito de fatores capacitantes é importante caracterizar a influência dos programas de saúde materno-infantil, discussão que será feita posteriormente, por exercerem maiores efeitos sobre causas específicas de morbimortalidade.

3. Necessidades de saúde: são as condições de saúde, percebidas pelo próprio indivíduo ou por profissionais de saúde, que justificam a utilização do serviço de saúde (ANDERSEN, 1995), portanto, refere-se à morbidade. Ao estudar os fatores associados às internações hospitalares no Brasil analisando dados da PNDA de 1998, CASTRO et al (2002) verificaram que as necessidades de saúde foram o fator explicativo mais importante na utilização de serviços hospitalares.

As necessidades de saúde e suas possíveis influências sobre as variações nos coeficientes de internação serão discutidas quando as causas de internação forem analisadas.

A discussão dos possíveis fatores envolvidos nas variações observadas nas taxas de hospitalização foi apresentada seguindo o modelo teórico de Andersen, entretanto, é fundamental considerar que esses fatores interagem entre si de maneira complexa. Além disso, muitos fatores contextuais, não mensuráveis, podem também estar envolvidos na rede de multicausalidade e, consequentemente, na evolução dos coeficientes de internação verificados no presente estudo. 


\subsection{AS CAUSAS DE INTERNAÇÃO HOSPITALAR}

As doenças do aparelho respiratório foram as principais causas de hospitalização das crianças de 0 a 9 anos, no município e no Brasil, correspondendo a 32 e $38 \%$ das internações, respectivamente (tabela 9). As doenças respiratórias são as principais causas de morbimortalidade na infância em países desenvolvidos e naqueles em desenvolvimento, sendo responsáveis por elevadas taxas de consultas médicas e de hospitalizações. CAETANO et al (2002) também relataram as doenças respiratórias como principal causa de internação em crianças menores de 5 anos de idade no município de Embu, região metropolitana de São Paulo, com taxas de 20\%. LENZ et al (2008), estudando as hospitalizações de crianças e adolescentes no território de abrangência de um serviço de atenção primária de Porto Alegre, encontraram que $36 \%$ das internações foram por doenças do aparelho respiratório. Em outro estudo, de base populacional, realizado na região Sul do Brasil, por CESAR et al (2002), as taxas foram ainda mais elevadas. Esses autores verificaram que metade das internações de crianças de 0 a 5 anos foi por infecção respiratória. Em outras regiões do país os achados foram semelhantes. Em Minas Gerais, ABRANTES et al (1998) descreveram internações por doenças respiratórias variando de 17 a $38 \%$, considerando-se, respectivamente, a faixa etária dos escolares e dos lactentes; SILVA et al (1999), no Maranhão, descreveram que a principal causa de internação de crianças de 1 a 4 anos de idade, em um inquérito domiciliar, foi a pneumonia. As doenças respiratórias além de serem as mais importantes causas de internação e mortalidade na infância, são responsáveis por 40 a $50 \%$ das consultas médicas, tanto ambulatoriais como na emergência (BRESOLIN et al, 2003). As crianças são muito susceptíveis a esses quadros devido aos fatores individuais, como a imaturidade imunológica 
e as características anatômicas da árvore respiratória, e aos fatores ambientais, como a exposição aos agentes infecciosos e irritantes de vias aéreas (BRESOLIN et al, 2003).

No município de São Paulo, como segunda causa de internação, aparecem as doenças originadas no período perinatal, correspondendo a $16 \%$ das hospitalizações avaliadas. O estudo de LENZ et al (2008), realizado em Porto Alegre, descreve que $14 \%$ das hospitalizações foram por esse motivo. Possivelmente, essa concordância se deve ao fato das duas regiões possuírem características socioeconômicas semelhantes. O grande número de internações por essas causas no município poderia ser explicado pela concentração de recursos hospitalares especializados, principalmente na área neonatal. Ultimamente, verifica-se maior contingente de prematuros e recém-nascidos com baixo peso, que graças aos avanços tecnológicos, têm sobrevivido necessitando de maior número de internações.

Em São Paulo, as características de morbidade são semelhantes às encontradas em países desenvolvidos: predomínio das causas respiratórias e perinatais, e menor significado para as doenças infecto-contagiosas. Por outro lado, as pesquisas realizadas em outras regiões do país descrevem a diarréia como a segunda causa de internação de crianças (ABRANTES et al, em Minas Gerais, 1998; SILVA et al, no Maranhão, 2002; CESAR et al, no extremo Sul do Brasil, 2002). A importância da diarréia como causa de internação nas demais regiões do Brasil, também pôde ser constatada no presente estudo, uma vez que o capítulo I do CID-10, de doenças infecciosas e parasitárias, que engloba a diarréia e a gastroenterite de origem infecciosa, ficou em $2^{\circ}$ lugar no Brasil, correspondendo a $22 \%$ das internações. No município de São Paulo, esse capítulo foi responsável por um percentual bem menor, de $8 \%$, e semelhante ao descrito na PNDS para internações por diarréia na região Sudeste, ficando 
em $4^{\circ}$ lugar como motivo de hospitalização das crianças de 0 a 9 anos de idade.

Nos últimos 50 anos, observou-se em muitos países uma série de transformações socioeconômicas e demográficas, que foram acompanhadas por importantes mudanças nos perfis de morbimortalidade das diferentes populações. Este fenômeno, conhecido como transição epidemiológica, caracteriza-se basicamente pela diminuição da prevalência das doenças infecto-contagiosas e aumento das doenças crônico-degenerativas. Vários autores, no entanto, têm apontado para as particularidades da transição epidemiológica no Brasil e a caracterizado como "atípica" (TEIXEIRA, 2004; VERMELHO et al, 2001). Os estudos demonstram que as doenças infecciosas e parasitárias ainda ocupam posição de destaque como causa de morbidade, associadas a aumento da importância das causas externas. Além disso, são verificadas importantes variações regionais, o que tem motivado os autores a descreverem o Brasil como um "mosaico epidemiológico" (TEIXEIRA, 2004). O conhecimento dessas singularidades regionais é importante para a gestão em saúde.

Aoanalisarmos os motivos de hospitalização, podemos verificarque metade das internações estudadas, no município de São Paulo, foi ocasionada por 10 causas: pneumonia, asma, outras afecções perinatais, transtornos respiratórios perinatais, prematuridade e baixo peso ao nascer, diarréia e gastroenterite infecciosa, hérnia inguinal, bronquite aguda e bronquiolite, doenças crônicas de amígdalas e adenóides e malformações do aparelho circulatório (tabela 10). Um aspecto geral, importante a ser comentado, é que entre essas dez principais causas, quatro são consideradas "condições sensíveis à atenção ambulatorial": pneumonia, asma, diarréia e bronquite aguda (LENZ et al, 2008). Causas de internação sensíveis à atenção ambulatorial são doenças que, oportunamente 
diagnosticadas, correta e efetivamente tratadas ambulatorialmente, têm seu risco de hospitalização reduzido (PARCHMAN e CULLER, 1994; FLORES et al, 2003). Como anteriormente descrito, as internações por condições sensíveis à atenção ambulatorial têm sido um dos indicadores utilizados para avaliar o acesso e a qualidade da atenção primária, além de permitir a avaliação do impacto de novos programas em saúde (CASANOVA e STARFIELD, 1995; BILLINGS et al, 1996; SILVA et al, 1999; PARKER e SCHOENDORF, 2000; CAMINAL et al, 2004). Essa grande porcentagem de internações por condições sensíveis à atenção ambulatorial encontrada no município de São Paulo, no período de 2002 a 2006, levanta uma questão - o aumento do acesso à atenção primária, provocado pela implantação do SUS no município e pela expansão do PSF, que ocorreram nessa época, foi acompanhado por melhor qualidade na atenção? SILVA et al (1999) também verificaram, em São Luís, uma grande porcentagem de internações por condições sensíveis à atenção ambulatorial, concluindo que, apesar do acesso igualitário, os cuidados ambulatoriais devem ser de baixa resolutividade, principalmente entre os mais pobres.

Uma das maneiras de melhorar a resolutividade e a qualidade da atenção à saúde é a adoção de programas específicos para atender adequadamente as demandas de saúde de determinada população. Um dos exemplos desse benefício foi descrito por CERCI NETO et al (2008), que avaliaram o impacto de um programa (incluindo a capacitação profissional, o fornecimento de medicação e ações educativas na comunidade) para controle das asma em Londrina. Esses autores verificaram uma diminuição nas taxas de internação, por essa causa, após a intervenção, não encontrando outro motivo que justificasse esse decréscimo. No município de São Paulo, não houve, no período estudado, nenhum programa específico que pudesse ter ocasionado a redução das internações por agravos fora do período perinatal. 


\subsection{EVOLUÇÃO DOS COEFICIENTES DE INTERNAÇÃO NAS DIFERENTES CAUSAS}

A seguir, serão discutidas as evoluções dos coeficientes de internação hospitalar, ao longo dos 5 anos estudados, para cada grupo das dez principais causas de internação verificadas nas diferentes faixas etárias.

\subsubsection{Doenças respiratórias}

As doenças respiratórias são as principais causas de morbimortalidade entre as crianças menores de 5 anos de idade, principalmente em áreas urbanas (CHIESA et al, 2008). A grande freqüência dessas doenças deve-se à fácil transmissão dos agentes envolvidos, vírus e bactérias, pelo ar, particularmente entre as crianças que vivem em espaços fechados acompanhadas por adultos e outras crianças (BENGUIGUI, 2003). Desse modo, a frequência à creche, a paridade e as aglomerações domiciliares assumem importante papel como um fator de risco para a transmissão dessas doenças. Além disso, agentes irritantes, como o tabagismo passivo e a poluição ambiental, contribuem para a colonização das vias aéreas. Condições que afetam a imunidade, como a desnutrição, o desmame precoce, a prematuridade e o baixo peso ao nascer influenciam o curso das doenças respiratórias (NASCIMENTO et al, 2004). São também fatores fundamentais na evolução e gravidade desses quadros aqueles que determinam os cuidados recebidos pela criança: a percepção dos pais sobre a doença, o modo de cuidar da criança doente, a capacidade dos pais em perceber a necessidade de buscar auxílio médico, o atendimento médico recebido e a adesão às recomendações (BENGUIGUI, 2003). Nesse sentido, são importantes a escolaridade dos pais, em particular a materna, 
o acesso e a proximidade aos serviços de saúde e as políticas de saúde adotadas.

Um dos exemplos de políticas de saúde é a estratégia AIDPI - Atenção Integrada às Doenças Prevalentes na Infância - elaborada pela OMS, OPAS e UNICEF e adotada pelo Ministério da Saúde em 1996. Essa estratégia sistematizou o atendimento, integrando ações curativas, preventivas e de promoção da saúde, na atenção à criança em nível primário (VIDAL et al, 2003). As doenças respiratórias são uma das principais preocupações na estratégia AIDPI, através da detecção precoce, classificação de gravidade e manejo adequado das crianças doentes. Os estudos avaliando os efeitos da AIDPI têm verificado uma melhora na qualidade da atenção oferecida e impacto nas taxas de mortalidade infantil (VIDAL et al, 2003; BENGUIGUI, 2003). A estratégia AIDPI foi incorporada ao PSF em algumas regiões de São Paulo, entretanto, não há estudos avaliando o seu impacto.

As doenças respiratórias, particularmente a pneumonia, foram as principais causas de internação nas 3 faixas etárias estudadas (tabelas 11, 13 e 15). Além disso, observou-se aumento nos coeficientes de internação, no município de São Paulo, em todas as idades avaliadas: $31 \%$ nos menores de 1 ano, 26\% entre 1 e 4 anos e $34 \%$ naqueles entre 5 e 9 anos de idade. No Brasil, por outro lado, essas hospitalizações diminuíram 11\%, 20\% e 16\%, respectivamente (gráficos 16, 25 e 36). Essas propensões nas taxas de hospitalização diferem dos dados a respeito da mortalidade por infecções respiratórias agudas (IRA). Segundo os dados do IDB - 2007, a proporção de óbitos por IRA em menores de 5 anos de idade em São Paulo diminuíram de 8,78\% em 2001 para 7,98\% em 2005 e, no Brasil, esses valores mantiveramse praticamente constantes, ao redor de 5,6\%. 
O aumento nas hospitalizações e a diminuição da proporção de óbitos podem refletir, possivelmente, um aumento das necessidades de saúde, ou seja, aumento da prevalência das doenças respiratórias, em um contexto de maior acesso aos serviços de saúde. O aumento na prevalência das doenças respiratórias já havia sido descrito por BENÍCIO et al (2000), que compararam as prevalências dessas doenças em inquéritos domiciliares realizados em 1984/85 e 1995/1996, na cidade de São Paulo. Esses autores encontraram melhorias nas condições socioeconômicas e das moradias, as quais teriam efeito inverso ao observado, e atribuíram o aumento na prevalência das doenças respiratórias a um aumento na freqüência às creches e a uma piora na qualidade do ar, embora esse fator não tenha sido diretamente avaliado.

GOUVEIA et al (2006) estudaram o impacto da poluição atmosférica nas taxas de hospitalização por asma em crianças menores de 5 anos de idade na cidade de São Paulo e encontraram um aumento de 4,6\% nessas internações com um aumento de $10 \mu \mathrm{g} / \mathrm{m}^{3}$ no nível de material particulado inalável. Outros estudos, como o de BOTELHO et al (2003) em Cuiabá e o de MOURA et al (2008), no Rio de Janeiro, encontraram associação entre variação climática e de indicadores de poluição atmosférica com o número de internações hospitalares e de atendimento médico de emergência por doenças respiratórias.

O aumento das internações por causas respiratórias verificado, no município de São Paulo, ocorreu principalmente por aumento das internações por pneumonia, embora as internações por asma, bronquite aguda e bronquiolite também tenham aumentado. Apesar do acréscimo no número de internações ter ocorrido principalmente entre as crianças maiores (aumento de $43 \%$ nas crianças de 0 a 1 ano, $49 \%$ nas de 1 a 4 anos e $67 \%$ nas de 5 a 9 anos de idade), as taxas de hospitalização entre os menores de 1 ano de idade ainda 
são muito maiores. Os coeficientes de internação por pneumonia no primeiro ano de vida foram 4 vezes maiores que os verificados para as crianças de 1 a 4 anos de idade e 17 vezes maiores que os observados na faixa de 5 a 9 anos. As crianças menores têm maior risco de desenvolver quadros graves, tanto pela imaturidade imunológica como pelas características anatômicas que aumentam o risco de evolução para insuficiência respiratória, sendo esperado que sejam mais hospitalizadas. Uma das possibilidades para justificar o maior aumento das internações por pneumonia na faixa etária de 5 a 9 anos, pode ser a alta prevalência da asma nessa idade. Sabe-se que, muitas vezes, os quadros de asma são diagnosticados equivocadamente como pneumonia, além disso, os pacientes asmáticos têm probabilidade maior de desenvolver infecções respiratórias (LASMAR et al, 2002).

As internações por asma aumentaram no município, principalmente entre as crianças de 5 a 9 anos (gráfico 38). A asma tem sido bastante estudada pela alta prevalência, por estar associada a grande número de mortes e pela alta taxa de internações (STEIN, 2006). LASMAR et al (2006) também descrevem uma grande freqüência de readmissões hospitalares: $65,3 \%$ das crianças hospitalizadas em Belo Horizonte foram readmitidas, pelo mesmo motivo, no período de 18 meses. LASMAR et al (2002) enfatizam que, embora existam consensos nacionais e internacionais para o manejo da asma, esses conhecimentos não têm sido incorporados na prática clínica e a inexistência de um seguimento ambulatorial regular desloca a demanda para os serviços hospitalares e de emergência. SARINHO et al (2007) aplicaram um questionário sobre o seguimento ambulatorial em crianças internadas por asma no Recife e encontraram baixa freqüência de acompanhamento ambulatorial regular (16\%) e pouca utilização de medicação profilática (13\%) tal como orientado nos consensos. O aumento nos coeficientes de internação por asma observado no 
município de São Paulo poderia ser justificado pelo aumento da prevalência da doença, conseqüente à piora nas condições ambientais, não acompanhado de programas voltados especificamente para esse problema.

Apesar dos avanços ocorridos, observa-se que as internações por bronquioliteaumentaram nasúltimas décadas, mesmo em países desenvolvidos (HALL, 2007). O vírus sincicial respiratório, o principal agente envolvido nessa patologia, é altamente infectante, principalmente entre os lactentes jovens, nos quais tende a provocar quadros mais graves. Estudo realizado em São Paulo por VIEIRA et al (2001) mostrou que 41,8\% das crianças internadas por infecção respiratória inferior tinham pesquisa para esse vírus positiva. Além das condições ambientais e da freqüência às creches, que possibilitam maior disseminação dos vírus, fatores como prematuridade, tabagismo passivo e desmame precoce são implicados como risco para hospitalização por bronquiolite (ALBERNAZ et al, 2003).

Diferindo dos achados no município, no Brasil, à exceção da bronquite aguda e da bronquiolite, nos menores de 1 ano de idade, e das doenças crônicas de amígdalas e adenóides, entre as crianças de 5 a 9 anos, observouse redução nos coeficientes de internação hospitalar por causas respiratórias. Possivelmente, no Brasil, o impacto positivo das melhorias sociais, econômicas, da diminuição da prevalência da desnutrição infantil, da ampliação do PSF e da adoção de políticas, como a estratégia AIDPI, tenham contribuído para a redução das internações por doenças respiratórias. Em São Paulo, são necessários estudos mais aprofundados para compreender as razões para o aumento da prevalência das doenças respiratórias. A poluição deve ter um papel importante. De fato, em São Paulo, o total de poluentes no ar chega a ser praticamente o dobro do observado em outras cidades grandes, como Belo Horizonte, Curitiba, Porto Alegre e Recife. 


\subsubsection{Doenças originadas no período perinatal}

A queda na taxa de mortalidade peri e neonatal tem sido mais difícil e lenta do que a da mortalidade pós-neonatal, passando a ser o principal componente da mortalidade infantil, configurando um desafio para as políticas de saúde no Brasil. A taxa de mortalidade neonatal, principalmente a precoce, mantêm-se em níveis elevados, configurando uma inadequação da assistência prestada à gestante e ao recém-nascido. Enquanto a mortalidade infantil é um indicador das condições de vida e de saúde de uma população, a mortalidade perinatal é um indicador sensível da assistência obstétrica e neonatal (LANSKY et al, 2002). Além da importância da mortalidade perinatal há de se considerar os altos índices de morte materna, ou seja, o óbito da mulher causado por fatores relacionados à gestação ou ao parto. No Brasil, embora a razão de morte materna venha evoluindo com declínio, esses valores ainda são considerados altos, chegando a ser 20 vezes superior aos encontrados nos países desenvolvidos (SCHIRMER, 2000). Diante desse panorama preocupante, como já foi referido anteriormente, o Ministério da Saúde lançou, em 2004, o Pacto Nacional pela Redução da Mortalidade Materna e Neonatal, com a recomendação para a implantação dos Comitês de Prevenção dos Óbitos Infantil e Fetal. Esses comitês deveriam identificar os fatores de risco envolvidos e propor medidas para melhorar a qualidade da assistência prestada, com o objetivo de reduzir esses óbitos (MINISTÉRIO DA SAÚDE, 2004). No âmbito municipal, também já comentado na introdução, a prefeitura de São Paulo adotou, em 2002, o Projeto Nascer Bem, com o objetivo de reduzir a mortalidade materna e perinatal, adotando medidas para promover o pré-natal adequado, o parto seguro, os cuidados à puérpera e ao recém-nascido. De acordo com esse projeto, as unidades básicas de saúde 
eram responsáveis por identificar as gestantes da sua região de abrangência, incentivando o início precoce e o acompanhamento regular no pré-natal e referenciar a gestante a uma maternidade para o parto. Além disso, foram criados protocolos a respeito da periodicidade das consultas, exames a serem realizados, cuidados nutricionais à gestante e condutas nas situações clínicas mais comuns. Em relação aos recém-nascidos, foram criados protocolos de seguimento das crianças de baixo e de alto risco, objetivando a promoção do crescimento e desenvolvimento adequados e a detecção precoce de agravos (CADERNO TEMÁTICO DA CRIANÇA, 2003).

Em termos de indicadores de cobertura de pré-natal, a PNDS revela que o número de mães que não realizou nenhuma consulta de pré-natal diminuiu de $14 \%$, na pesquisa realizada em 1996, para 1\%, em 2006. Além disso, de acordo com os dados do IDB -2007, a porcentagem de gestantes que realizaram 7 ou mais consultas aumentou de $47,39 \%$ em 2001 para 53,63\%, em 2005, no Brasil. Já, em São Paulo, esse aumentou foi ainda mais expressivo, indo de 57,91\% para 71,39\%. Em relação à assistência ao parto, a proporção de partos hospitalares variou, no Brasil, de 96,3\%, em 2001, para 97\%, em 2005 e, em São Paulo, de 99,3\% para 99,6\%, no mesmo período. Em relação aos indicadores de resultados, a taxa de mortalidade por afecções originadas no período perinatal variou, entre 2001 e 2005, de 14,15 para 12,17 (por 1000 nascidos vivos), no Brasil e, de 9,36 para 7,67 (por 1000 nascidos vivos), no estado de São Paulo. A proporção de nascidos vivos com baixo peso ao nascer não apresentou variações, mantendo-se ao redor de $8 \%$, no Brasil, e 9,3\%, no município de São Paulo. O baixo peso ao nascer é considerado a expressão mais direta das condições de saúde no período perinatal por ser o fator mais fortemente associado à mortalidade (TANAKA, 1989). 
Dada a importância da saúde perinatal, a "proporção de internações hospitalares (SUS) por afecções originadas no período perinatal" é um dos indicadores de morbidade e de fatores de risco utilizados pelo Ministério da Saúde. Esse indicador é utilizado com o objetivo de: analisar variações geográficas e temporais na distribuição proporcional dessas internações, permitindo identificar situações de desequilíbrio na concentração de recursos médico-hospitalares, avaliar a qualidade da assistência e subsidiar processos de planejamento, gestão e avaliação de políticas públicas voltadas para a melhoria da qualidade da atenção perinatal e ao parto e para a redução da mortalidade infantil.

Nesse panorama exposto, no presente estudo, verificou-se que as internações por doenças originadas no período perinatal apresentaram aumento de $32 \%$ no município de São Paulo e de $6 \%$ no Brasil (gráfico 11). O aumento observado, no município, foi principalmente decorrente de acréscimo nas internações por transtornos respiratórios, equivalente a 92\%. As internações por outras afecções originadas no período perinatal aumentaram $16 \%$ e aquelas decorrentes de prematuridade e baixo peso ao nascer aumentaram $8 \%$. Apenas as internações por hipóxia intrauterina e asfixia ao nascer apresentaram declínio, com diminuição de $22 \%$ em seus coeficientes (tabela 12). O decréscimo nas internações por hipóxia e asfixia pode representar melhor assistência ao parto. Por outro lado, a manutenção de altas taxas de mortalidade, principalmente a neonatal precoce, e o número de crianças nascidas com baixo peso, assim como o aumento nas internações por causas perinatais podem indicar que o maior acesso à assistência pré-natal não foi, necessariamente, acompanhado de melhor qualidade. Isto talvez seja explicado pelo período abordado no estudo, os anos de início do SUS no município de São Paulo e, portanto, uma época de reestruturação das políticas de saúde e de renovação e contratação de profissionais. 


\subsubsection{Diarréia e gastroenterite de origem infecciosa}

A desidratação secundária à doença diarréica foi, desde o início do século passado, a principal causa de morbimortalidade na infância, principalmente em países em desenvolvimento. Os estudos sobre o metabolismo da água e dos eletrólitos e os avanços no tratamento da desidratação provocaram progressiva diminuição nas taxas de mortalidade, principalmente a partir da década de 1980, quando a OMS passou a preconizar a terapia de reidratação oral (TRO). A introdução da TRO não apenas provocou queda nas taxas de mortalidade como permitiu que o tratamento pudesse ser domiciliar, sem necessidade da admissão hospitalar. Concomitantemente aos avanços terapêuticos observou-se redução na prevalência da diarréia, dadas as melhores condições de vida, com a expansão do saneamento básico e do abastecimento de água, associada à queda na prevalência da desnutrição, um importante condicionante de gravidade da doença diarréica. Assim, embora a diarréia ainda permanecesse como um problema de saúde pública, os estudos começaram a verificar redução na morbimortalidade associada a essa doença. CAMPOS et al (1995) estudando crianças menores de 5 anos de idade, por inquérito domiciliar realizado em São Luis, observaram que o número de episódios de diarréia por criança ao ano reduziu de 6,3, em 1986, para 2,1, em 1989 e que a taxa de mortalidade caiu de 12,8 por mil para 4,9 por mil, no mesmo período. BENÍCIO e MONTEIRO (2000) comparando os resultados dos inquéritos realizados em 1984/85 e 1995/96, na cidade de São Paulo, observaram reduções expressivas tanto na prevalência instantânea da diarréia (declínio de 50\%) como na incidência anual de hospitalizações associadas a ela (redução de 2/3), principalmente no terço mais pobre da população. Esses autores atribuíram aqueda mais significativa na taxa de 
hospitalização do que na prevalência da doença ao emprego mais freqüente e disseminado da TRO. MATIJASEWICH et al (2008), avaliando três coortes de crianças do Rio Grande do Sul, em 1982, 1993 e 2004, também descreveram uma drástica redução nas hospitalizações referentes à diarréia, principalmente pelo uso da TRO. APNDS-2006 descreve que houve uma redução significativa na mortalidade de crianças menores de 5 anos por doenças infecciosas e parasitárias, incluindo a diarréia aguda, pelo uso da TRO, aumento da prática de aleitamento materno, melhora na suplementação de alimentos, melhora na escolaridade materna e melhora das condições de saneamento. Porém, a PNDS destaca que a queda da morbidade por esse motivo não apresentou declínio na mesma intensidade que o observado nas taxas de mortalidade. De acordo com essa pesquisa, 9,4\% das crianças apresentaram diarréia nas 2 semanas anteriores à entrevista e $21,7 \%$ nos últimos 3 meses. A maior prevalência ocorreu em crianças entre 6 e 24 meses de idade e na região Norte e Nordeste do Brasil. Dessas crianças, $40 \%$ foi levada a algum tipo de atendimento médico, sendo que uma pequena minoria não conseguiu obter esse atendimento. A grande maioria, $84 \%$ das crianças, foi atendida por serviços do SUS.

Analisando-se os resultados obtidos no presente estudo, verificamos que a diarréia aguda ainda é freqüente, estando entre as dez principais causas de internação das crianças de 0 a 5 anos e, como era de se esperar, muito mais prevalente no Brasil em relação ao município de São Paulo. Porém, enquanto no Brasil os coeficientes de internação reduziram $16 \%$ entre os menores de 1 ano e aumentaram pouco entre as crianças de 1 a 4 anos, no município de São Paulo esses valores aumentaram 1,5 vezes no primeiro ano de vida e dobraram na faixa etária de 1 a 4 anos de idade (gráficos 21 e 30). Esse dado é bastante expressivo, principalmente ao considerarmos que essa foi a causa 
de internação que teve maior percentual de aumento nos menores de 5 anos de idade, no período avaliado. O que poderia ter motivado esse aumento em São Paulo?

Um dos possíveis motivos implicados nesse aumento seria a mudança no perfil etiológico das diarréias, com redução das causas bacterianas, mais susceptíveis às condições de saneamento básico, e aumento das virais. Essa mudança no perfil etiológico das diarréias já havia sido observado por SOUZA et al (2002), que descreveram um aumento relativo da importância do rotavírus. Portanto, apesar de São Paulo ser um local privilegiado em termos de abastecimento de água (maior que 97\%) e de esgoto (ao redor de 90\%), apresenta condições desfavoráveis quando se fala em infecções virais, como já descrito para as doenças respiratórias. KALE et al (2004) verificaram, no Rio de Janeiro, uma redução tanto nas internações como nos óbitos por diarréia, entre 1995 e 1998, mas também notaram um predomínio da etiologia viral, preconizando a importância da vacina específica. Há de se lembrar, que a vacina contra o rotavírus passou a fazer parte do calendário básico de vacinação a partir de 2006, último ano do período analisado no presente estudo, e somente para crianças no primeiro semestre de vida. A predominância da etiologia viral é importante se for considerado que, embora as internações tenham sido mais freqüentes em menores de 1 ano de idade, foi entre as crianças de 1 a 4 anos que se verificou uma maior ascensão nos coeficientes de internação, isto porque nessa faixa etária deixa de existir a proteção conferida pelo aleitamento materno, além de ser uma idade mais exposta ao risco de transmissão, pela freqüência às creches.

Outro possível motivo para o aumento nos coeficientes de internação seria a inadequação do manejo dos casos de diarréia. BITTENCOURT et al (2002) verificaram, em 1996, no Rio de Janeiro, um excesso de internações 
por diarréia nos hospitais do SUS, concluindo haver hospitalizações desnecessárias e motivadas por falha na assistência prestada. No Ceará também se observou que, em 2005, ocorreu um aumento significativo no número de internações por diarréia, particularmente em alguns municípios. Esse aumento foi atribuído a uma maior oferta de leitos hospitalares associada à conduta dos profissionais do PSF, que priorizaram as internações hospitalares em detrimento da utilização do TRO (GOVERNO DO ESTADO DO CEARÁ, 2006). De fato, de acordo com a PNDS - 2006, a TRO foi proporcionalmente mais utilizada em crianças com idades maiores, principalmente por mães com menor escolaridade e, um dado importante, observou-se uma marcada diferenciação regional no uso da TRO. Essa pesquisa revelou que os estados do Sul e do Sudeste são os que menos utilizam essa forma de tratamento, sendo que menos de $50 \%$ das crianças receberam a TRO. Essa redução no uso da TRO, associada à mudança no perfil etiológico, podem ter influenciado o aumento das hospitalizações por diarréia observado no município de São Paulo.

\subsubsection{Outras causas de internação}

As internações por doenças respiratórias, por doenças originadas no período perinatal e por diarréia aguda mereceram discussão mais detalhada tanto pela importância que têm em termos de número de hospitalizações como pelos vários fatores condicionantes que podem estar envolvidos nessas situações

Em relação às lesões secundárias às causas externas (fraturas e traumatismo intracraniano) verificadas na faixa de 5 a 9 anos de idade, observou-se que no Brasil não foram notadas variações nos seus coeficientes 
de hospitalização e, no município de São Paulo, observou-se aumento nas internações devido às internações secundárias a traumatismo craniano (tabela 16). É importante esse achado porque os acidentes na infância e sua prevenção têm merecido cada vez mais atenção em termos de saúde coletiva. Isto porque além de estarem relacionados a mortes, podem provocar seqüelas, com impacto econômico e social. As consequências das lesões por causas externas assumem uma significância ainda maior ao considerarmos que são evitáveis e passíveis de prevenção.

Os tipos de lesões encontradas, tanto as fraturas como o traumatismo craniano, geralmente são provocadas por quedas ou por acidentes de transporte, que têm assumido importância cada vez maior nos grandes centros urbanos, como São Paulo. Esse talvez seja um fator envolvido no aumento dos coeficientes de internação por traumatismo craniano no município, já que está se considerando as hospitalizações e, portanto, a ocorrência de traumatismos moderados a graves. GASPAR et al (2004), estudando os fatores relacionados a hospitalizações por lesões externas na faixa etária de 0 a 19 anos, encontraram que $9,9 \%$ das internações foram por esse motivo, sendo os acidentes de transporte a principal causa e, as quedas, o segundo motivo relacionado às lesões. AGRAN et al (2001) também relataram os acidentes de transporte como a principal causa de lesão levando á hospitalização em crianças e adolescentes na Califórnia. Os dados da PNDS - 2006 a respeito de acidentes mostram uma grande freqüência de acidentes, sendo que $48 \%$ das crianças avaliadas referiram algum tipo de acidente no ano anterior à pesquisa, principalmente entre 1 e 2 anos de idade. As quedas foram os acidentes mais freqüentes $(81 \%)$ e aconteceram principalmente dentro de casa. Quando considerados os acidentes que ocorreram fora de casa, os mais freqüentes foram os de transporte. Há de se considerar que a PNDS abrange 
crianças em uma faixa etária menor, de até 5 anos de idade, e por ser um inquérito domiciliar, leva em consideração todos os acidentes relatados pelas mães e não apenas os que motivaram hospitalização.

Outro dado importante a ser considerado é que no presente estudo não foram avaliados os adolescentes, caso contrário, seria de esperar uma maior freqüência de internações por causas externas, pela maior ocorrência de lesões secundárias a acidentes de transporte e à violência.

Em relação às internações por causas cirúrgicas (hérnia inguinal, outras hérnias, fimose e doenças do apêndice), constatou-se serem mais frequentes nas crianças maiores de 1 ano. É interessante observar que os coeficientes de internação por hérnias, outras hérnias e doenças do apêndice foram semelhantes, tanto em número como em evolução, no município e no Brasil (tabelas 14 e 16). Essas condições independem de fatores externos e são menos influenciáveis por diferenças de conduta médica e oferta de leitos, por exemplo. Por outro lado, as internações por fimose, uma condição em que pode haver diferenças nas condutas, foram freqüentes em São Paulo, além de terem sido as responsáveis pelo aumento nas internações por causas cirúrgicas, podendo representar internações desnecessárias.

As hospitalizações por malformações congênitas do aparelho circulatório não variaram ao longo do período, por também independerem de fatores externos. A predominância dessas internações no município em relação ao Brasil, provavelmente se deve ao fato de que em São Paulo há disponibilidade maior de tecnologia e de serviços especializados, podendo haver migração desses casos vindos de outros estados do Brasil.

Por fim, em relação às internações por infecções de pele, vale comentar que se verificou um aumento em seus coeficientes, embora, proporcionalmente, menos expressivos. As hospitalizações por outras doenças do sistema nervoso 
apresentaram um grande aumento nos seus coeficientes, tanto entre as crianças de 1 a 4 anos como naquelas de 5 a 9 anos de idade, porém essas internações também são, proporcionalmente, em número menor. A discussão a respeito desse achado é difícil, uma vez que sob esse código do CID encontram-se doenças variadas, como atrofias musculares e espinais, síndromes vasculares cerebrais, polineuropatia inflamatória, hidrocefalia, entre outros e, portanto, com uma ampla gama de possíveis fatores determinantes.

O atendimento hospitalar, dada a concentração de equipamentos, sempre foi o lugar de referência para o diagnóstico e tratamento de grande parte das doenças, em detrimento do cuidado ambulatorial. Porém, o desenvolvimento tecnológico e farmacológico observado nas últimas décadas, tornou possível a realização de inúmeros procedimentos diagnósticos e terapêuticos sem a necessidade de hospitalização. Esse desenvolvimento também foi responsável por um acréscimo considerável nos custos da assistência hospitalar. O aumento dos custos e os riscos associados à hospitalização, como o risco de infecção hospitalar e de iatrogenia, sem falar no impacto psicológico, têm motivado, no mundo todo, o crescimento da atividade ambulatorial.

É fundamental que haja investimento no sentido de melhorar a qualidade do atendimento ambulatorial para que haja redução nas hospitalizações. O conhecimento das causas de internação fornece elementos essenciais para o desenvolvimento de políticas públicas que possibilitem o fortalecimento da atenção primária com conseqüente diminuição no número de hospitalizações. 
6.CONCLUSÕES 
O estudo permite algumas conclusões:

1. As taxas de internação são determinadas pela interação de múltiplos fatores, mensuráveis e não mensuráveis, como os estudados por Andersen em seu modelo teórico sobre o uso dos serviços de saúde.

2. As condições sociais e demográficas não dão suporte para esclarecer o aumento do número de internações observado no município de São Paulo, no entanto, podem ter influenciado a queda nos coeficientes de internação observada no Brasil.

3. O aumento no acesso ao sistema de saúde verificado com a integração ao SUS e com a expansão do PSF pode ter sido um dos fatores condicionantes do aumento do coeficiente de internação observado no município de São Paulo.

4. A proporcionalidade entre as diferentes causas de internação, à exceção das doenças respiratórias, difere entre o município de São Paulo e as demais regiões do Brasil, possivelmente por influência das características socioeconômicas.

5. O aumento das internações por doenças respiratórias verificado no município de São Paulo pode ser decorrente do aumento na prevalência dessas doenças. 
6. O acréscimo no coeficiente de internação por afeç̧ões perinatais pode indicar que o aumento no acesso à assistência pré-natal não foi acompanhado de melhora na qualidade dessa atenção.

7. A mudança no padrão etiológico e, possivelmente, a menor utilização da TRO na região Sudeste do Brasil podem estar associadas ao aumento nas internações por diarréia em São Paulo.

8. O estudo das causas de internação fornece elementos para a qualificação da atenção ambulatorial e pode contribuir com pressupostos para as políticas públicas e a gestão em saúde, reduzindo as hospitalizações. 
7.REFERÊNCIAS 
1. Abrantes MM, Lamounier JA, Faria JF, Diniz CM, Cunha FAF. Causas de internações de crianças e adolescentes nos hospitais do SUS em Minas Gerais entre 1994-1995. Inf Epidemiol SUS 1998; 1: 95-104.

2. Aday LA, Andersen RM. A framework for the study of access to medical care. Health Serv Res 1974; 9: 208-20.

3. Agran PF, Win D, Anderson C, Trent R, Walton-Haynes L. Rates of pediatric and adolescent injuries by year of age. Pediatrics 2001; 108(3): E45.

4. Albernaz EP, Menezes AMB, Cesar JA, Victora CG, Barros FC, Halpern R. Fatores de risco associados à hospitalização por bronquiolite aguda no período pós-neonatal. Rev Saúde Pública 2003; 37(4): 485-93.

5. Andersen RM. Revisiting the behavioral model and Access to medical care: does it matter? J Health Social Behav 1995; 36(1): 1-10.

6. Andersen RM, Newman JF. Societal and individual determinants of medical care utilization in the United States. Milbank Q 1973; 51: 95-124.

7. Barros FC, Victora CG. Maternal-child health in Pelotas, Rio Grande do Sul State, Brazil: major conclusions from comparisons of the 1982, 1993 and 2004. Cad. Saúde Pública, Rio de Janeiro 2008; 24(sup 3): S461S467.

8. Benguigui, Y. Acute respiratory control in the context of the IMCI strategy in the America. Rev bras saúde matern infant, Recife 2003; 3(1): 25-36. 
9. Benicio MHD'A, Cardoso MRA, Gouveia NC, Monteiro CA. Tendência secular da doença respiratória na infância na cidade de São Paulo (19841996). Rev. Saúde Pública 2000; 34(6 supl): 91-101.

10. Benicio MHD’A, Monteiro CA. Tendência secular da doença diarréica na infância na cidade de São Paulo (1984-1996). Rev. Saúde Pública 2000; 34(6 supl): 83-90.

11. Berenstein CK. O perfil etário dos custos de internação na saúde pública no Brasil: uma análise para as capitais nas regiões metropolitanas do Brasil em 2000 [dissertação]. Minas Gerais: Faculdade de Ciências Econômicas da Universidade Federal de Minas Gerais, 2005.

12. Billings J, Anderson G, Newman L. Recent findings on preventable hospitalizations. Health Aff 1996; 239-49.

13. Bittencourt SA, Camacho LAB, Leal MC. O Sistema de Informação Hospitalar e sua aplicação na saúde coletiva. Cad Saúde Pública 2006, Rio de Janeiro, 22(1): 19-30.

14. Bittencourt SA, Leal MC, Santos MO. Hospitalizações por diarréia infecciosa no Estado do Rio de Janeiro. Cad. Saúde Pública, Rio de Janeiro 2002; $18(3) 747-54$

15. Botelho C, Correia AL, Silva AMC, Macedo AG, Silva COS. Fatores ambientais e hospitalizações em crianças menores de 5 anos com infecção respiratória aguda. Cad. Saúde Pública, Rio de Janeiro 2003; 19(6): 1771-80. 
16. Brasil. Ministério da Saúde. Manual dos comitês de prevenção do óbito infantil e fetal. Série A. Normas e manuais técnicos. Brasília/DF. Ministério da Saúde 2004.

17. Brasil. Ministério da Saúde. Organização Pan-Americana da Saúde. AIDPI: manual para acompanhamento e avaliação da atenção integrada às doenças prevalentes na infância. Brasíla/DF: Ministério da Saúde 1999.

18. Brasil. Ministério da Saúde. PNDS 2006: Pesquisa Nacional de Demografia e Saúde da Criança e da Mulher. Relatório. Brasília/DF: Ministério da Saúde 2008.

19. Brasil. Ministério da Saúde. Saúde da família: uma estratégia para a reorientação do modelo assistencial. $2^{\mathrm{a}}$ ed. Brasília/DF: Ministério da Saúde; 1988

20. Bresolin AMB, Kobinger MEBA, Sucupira ACSL. Afecções respiratórias. In: Bresolin AMB, Sucupira ACSL. Caderno temático da criança, Prefeitura do município de São Paulo. São Paulo, 2003.

21. Cadastro Nacional de estabelecimentos de Saúde (CNES). (acessado em 20/03/2009). Disponível: http://www.cnes.datasus.gov.br

22. Caetano JRM, Bordin IAS, Puccini RF, Peres CA. Fatores associados á internação hospitalar de crianças menores de cinco anos, São Paulo, SP. Rev Saúde Pública 2002; 36(3): 285-91. 
23. Caminal J,Starfield B, Sanchez E, Casanova C, Morales M. The role of primary care in preventing ambulatory care sensitive conditions. Eur $J$ Public Health 2004; 14(3): 246-51.

24. Campos GJV, Reis Filho AS, Silva AAM, Novochadio MAS, Silva RA, Galvão CES. Morbimortalidade infantil por diarréia aguda em área metropolitana da região Nordeste do Brasil, 1986-1989. Rev Saúde Pública 1995; 29(2): 132-9.

25. Campos MR, Martins M, Noronha JC, Travassos C. Proposta de integração de dados do sistema de Informações Hospitalares do sistema Único de Saúde (SIH-SUS) para pesquisa. Inf Epidemiol SUS 2000; 9: 51-8.

26. Candiago RH, Abreu PB. Uso do DATASUS para avaliação dos padrões das internações psiquiátricas, Rio Grande do Sul. Rev Saúde Pública 2007; 41(5): 821-9.

27. Carvalho DM. Grandes sistemas nacionais de informação em saúde: revisão e discussão da situação atual. Inf Epidemiol SUS 1997; 5: 7-46.

28. Casanova C, Colomer C, Starfield B. pediatric hospitalization due ambulatory care-sensitive conditions in Valencia (Spain). Int J Qual Health Care 1996; $51-9$.

29. Casanova C, Starfield B. Hospitalizations of children and Access to primary care: a cross-national comparison. Int J Health Serv 1995; 25(2): 283-94. 
30. Castro MSM, Travassos C, Carvalho MS. Fatores associados às internações hospitalares no Brasil. Ciência \& Saúde Coletiva 2002; 7(4): 795-811.

31. Castro MSM, Travassos C, Carvalho MS. Efeito da oferta de serviços de saúde no uso de Internações hospitalares no Brasil. Rev. Saúde Pública 2005; 39(2): 277-84.

32. Cerci Neto A, Ferreira Filho OF, Bueno T, Talhari MA. Redução do número de internações hospitalares por asma após a implantação de programa multiprofissional de controle de asma na cidade de Londrina. J Bras Pneumol 2008; 34(9): 639-45.

33. Cesar JA, Horta BL, Gomes G, Shehadeh I, Chitolina J, Rangel L, Saraiva AO, Oliveira AK. Utilização de serviços de saúde por menores de cinco anos no extremo Sul do Brasil. Cad. Saúde Pública, Rio de Janeiro 2002; 18(1): 299-305.

34. Chiesa AM, Westphal ME, Akerman M. Doença respiratória aguda: um estudo das desiguladades em saúde. Cad. Saúde Pública, Rio de Janeiro 2008; 24(1): 55-69.

35. Comissão Nacional sobre Determinantes Sociais de Saúde. As causas das iniqüidades em saúde no Brasil, Brasília/DF: Ministério da Saúde 2008; 95120. 
36. Figueiredo GLA, Mello DF. Atenção à saúde da criança no Brasil: aspectos da vulnerabilidade programática e dos direitos humanos. Rev Latino-am Enfermagem 2007; 15(6): 1171 - 6.

37. Flores G, Abreu M, Tomany-Korman S, Meurer J. Keeping children out of hospitals: parents' and physicians' perspectives on how pediatric hospitalizations for ambulatory care-sensitive conditions can be avoided. Pediatrics 2003; 112(5): 1021-30.

38. Francisco PMSB, Donalisio MR, Lattorre MRDO. Internações por doenças respiratórias em idosos e a intervenção vacinal contra influenza no Estado de São Paulo. Rev. Bras.epidemiol. 2004; 7 (2), 220-7.

39. Fundo das Nações Unidas para a Infância (UNICEF). Situação da Infância Brasileira 2006. Crianças de até 6 anos. O direito à sobrevivência e ao desenvolvimento. Brasília/DF 2005.

40. Gaspar VLV, Lamounier JÁ, Cunha FM, Gaspar JC. Fatores relacionados à hospitalização por injúrias em crianças e adolescentes. J Pediatr (Rio J) 2004; 80: 447-52.

41. Goldbaum M. Epidemiologia e serviços de saúde. Cad Saúde Pública, Rio de Janeiro 1996; 12(supl. 2): 95-8.

42. Goodman DC, Fisher ES, Gittelsohn A, Chang CH, Fleming C. Why are children hospitalized? The role of non-clinical factors in pediatric hospitalizations. Pediatrics 1994; 93(6): 896-902. 
43. Gouveia N, Freitas CV, Martins LC, Marcílio IO. Hospitalizações por causas respiratórias e cardiovasculares associadas à contaminação atmosférica no município de São Paulo. Cad. Saúde Pública, Rio de Janeiro 2006; 22(12): 2669-77.

44. Governo do estado do Ceará. Secretaria do Planejamento e Coordenação. Instituto de Pesquisa e Estratégia Econômica do Ceará. Texto para discussão $n^{\circ}$ 27. Taxa de internação por diarréia no Ceará: determinantes e ações de controle. Fortaleza/CE, 2006.

45. Hall CB. Therapy for bronchiolitis: when some become none. N Engl J Med 2007; 357(4): 402-4.

46. IBGE - Instituto Brasileiro de Geografia e Estatística. PNDA Pesquisa Nacional por amostra de Domicílios. Acesso e utilização de serviços de saúde 2003. (acessado em 05/03/2009). Disponível: http://www.ibge.gov. br/home/estatistica/populacao/trabalhoerendimento/pnda2003/saude/ default.htm

47. IDB-Indicadores e Dados Básicos-Brasil 2007. (acessado em 05/03/2009). Disponível: http:// tabnet.datasus.gov.br/cgi/idb2007/matriz.htm

48..Kale PL, Fernandes C, Nobre FF. Padrão temporal das internações e óbitos por diarréia em crianças, 1995 a 1998, Rio de Janeiro. Rev Saúde Pública 2004; 38(1): 30-7. 
49. Lansky S, França E, Leal MC. Mortalidade perinatal e evitabilidade: revisão da literatura. Rev Saúde Pública 2002; 36(6): 759-72.

50. Lasmar LMLBF, Camargos PAM, Goulart CMA, Sakurai E. Fatores de risco para readmissão hospitalar de crianças e adolescentes asmáticos. J Bras Pneumol 2006; 32(5): 391-9.

51. Lasmar LMLBF, Goulart E, Sakurai E, Camargos P. Fatores de risco para hospitalização de crianças e adolescentes asmáticos. Rev Saúde Pública 2002; 36(4): 409-19.

52. .Laurenti R. A medida das doenças. In: Foratini OP. Epidemiologia geral. São Paulo: Artes Médicas; 1987: 64-91.

53. Lebrão ML. Determinantes da morbidade hospitalar em região do Estado de São Paulo (Brasil). Rev Saúde Pública 1999; 33(1): 55-63.

54. Lebrão ML. Estudos de Morbidade. São Paulo: Edusp; 1997.

55. Lenz MLM, Pires NV, Stein AT, Flores R. Hospitalizações entre crianças e adolescentes no território de abrangência de um serviço de atenção primária. Revista Brasileira Saúde da Família 2008; 18: 9-14.

56. Macinko J, GuanaisFC, Souza MFM. Evaluation ot the impact of the Family Health Program on infant mortality in Brazil, 1990-2002 J. Epidemiol Community Health 2006; 60:13-9. 
57. Maranhão AGK. Situação de saúde da criança no Brasil. Centro de Informações em Saúde da Criança. (acessado em 27/02/2009). Disponível em: http://saudedacrianca.org.br/cis/indic.htm

58. Matijasevich A, Cesar JÁ, Santos IS, Barros AJD, Dode MASO, Barros FC, Victora CG. Hospitalizations during infancy in three population-based studies in Sourthern Brazil: trends and differentials. Cad. Saúde Pública, Rio de Janeiro 2008; 24(sup 3):S437-S443.

59. Mendes ACG, Albuquerque PC, Lessa FD, Maciel Filho RM, Feitosa sF, Montenegro TO. Sistema de Informações Hospitalares - fonte complementar na vigilância e monitoramento das doenças de transmissão vetorial. Inf Epidemiol SUS 2000; 9: 125-36.

60. Mendonça MHM. O desafio da política de atendimento à infância e à adolescência na construção de políticas públicas eqüitativas. Cad. Saúde Pública, Rio de Janeiro 2002; 18(suplemento): 113-20.

61. Monteiro CA, Benício MHD’A, Ortiz LP. Tendência secular do peso ao nascer na cidade de São Paulo (1976-1998). Rev. Saúde Pública 2000; 34(supl 6):26-40.

62. Monteiro CA, Conde WL. Tendência secular da desnutrição e da obesidade na infância na cidade de São Paulo (1974-1996). Rev. Saúde Pública 2000; 34(supl 6):52-61. 
63. Monteiro CA, França Júnior I, Conde WL. Evolução da assistência maternoinfantil na cidade de São Paulo (1984-1996). Rev.Saúde Pública 2000; 34(supl 6): 19-25.

64. Monteiro CA, Freitas ICM. Evolução dos condicionantes socioeconômicos da saúde na infância na cidade de São Paulo (1984-1996). Rev.Saúde Pública 2000; 34(supl 6):8-12.

65. Monteiro CA, Nazário CL. Evolução dos condicionantes ambientais da saúde na infância na cidade de São Paulo (1984-1996). Rev.Saúde Pública 2000; 34(supl 6):13-8

66. Monteiro CA, Szarfarc SC, Mondini L. Tendência secular da anemia na infância na cidade de São Paulo (1984-1996). Rev.Saúde Pública 2000; 34(supl 6):62-72.

67. Moura M, Junger WL, Mendonça GAS, De Leon AP. Qualidade do ar e transtornos respiratórios agudos em crianças. Rev Saúde Pública 2008; 42(3): 503-11.

68. Nascimento LFC, Marcitelli R, Agostinho FS, Gimenes CS. Análise hierarquizada dos fatores de risco para pneumonia em crianças. J Bras Pneumol 2004; 30(5): 445-51.

69. Oliveira EXG, Travassos C, Carvalho MS. Acesso à internação hospitalar nos municípios brasileiros em 2000: territórios do Sistema Único de Saúde. Cad Saúde Pública, Rio de Janeiro 2004; 20(sup 2): S298-S309. 
70. Parchman ML, Culler S. Primary care physicians and avoidable hospitalizations. J Fam Pract 1994; 39(2): 123-8.

71. Parker JD, Schoendorf KC. Variation in hospital discharges for ambulatory care-sensitive conditions among children. Pediatrics 2000; 106(4): 942-8.

72. Pereira MG. Morbidade. In: Pereira MG. Epidemiologia: teoria e prática. Rio de Janeiro: Guanabara-Koogan; 1995, 76-104.

73. Phillips KA, Morrison KR, Andersen R, Aday LA. Understanding the context of healthcare utilization: assessing environmental and provider-related variables in the behavioral model of utilization. Health Serv Res 1998; 33(3): 571-96.

74. Portela MC, Schramm JMA, Pepe VLE, Noronha MF, Cianeli MP. Algoritmo para a composição de dados de internação a partir do Sistema de Informações Hospitalares do Sistema Único de Saúde (SIH/SUS). Cad Saúde Pública 1997; 13(4): 771-4.

75. Prata PR. A transição epidemiológica no Brasil. Cad Saúde Pública, Rio de Janeiro 1992; 8(2): 168-75.

76. Prefeitura Municipal de São Paulo. Secretária Municipal de Saúde. Implantando o Programa de Saúde da Família no município de São Paulo. Balanço de 20 meses. São Paulo; 2002. 
77. Prefeitura Municipal de São Paulo. Secretária Municipal de Saúde. Caderno temático da criança. São Paulo; 2003.

78. Roncalli AG, Lima KC. Impacto do Programa Saúde da Família sobre indicadores de saúde da criança em municípios de grande porte da região Nordeste do Brasil. Ciência \& Saúde Coletiva 2006; 11(3): 713 - 24.

79. Sarinho E, Queiroz GRS, Dias MLCM, Silva AJQ. A hospitalização por asma e a carência de acompanhamento ambulatorial. J Bras pneumol 2007; 33(4): 365-71.

80. SchirmerJ. Assistência ao parto: novas diretrizes governamentais. Acta Paul Enf. São Paulo 2000; 13(número especial, Parte I): 214-21.

81. Serra RAM. Uma avaliação do impacto do programa da família sobre a saúde infanti no estado de São Paulo. Trabalho submetido ao Prêmio Economia da Saúde, IPEA. Brasília/DF; 2005.

82. Silva AAM, Gomes UA, Tonial SR, Silva RA. Fatores de risco para hospitalização de crianças de um a quarto anos em São Luís, Maranhão, Brasil. Cad Saúde Pública, Rio de Janeiro 1999; 15(4): 749-57.

83. Sistema de Informações Hospitalares do Sistema Único de Saúde (SIHSUS). Disponível: http://w3.datasus.gov.br/datasus/datasus.php 
84. Souza EC, Martinez MB, Taddei CR, Mukai L, Gilio A, Racz MI, Silva L, Ejzenberg B, Okay Y. Perfil etiológico das diarréias agudas de crianças atendidas em São Paulo. J Pediatr (Rio J) 2002; 77(1): 31-8.

85. Starfield B. Primary care: concept, evaluation and policy. New York: Oxford University Press; 1992. 231-4.

86. Stein RT. Asma pediátrica - o impacto das internações hospitalares. J Bras Pneumol 2006; 32(5): xxv-xxvi.

87. Sucupira ACSL. Organização de um serviço ambulatorial. In: Lima EJF, Souza MFT, Brito RCCM (Org.). Pediatria Ambulatorial - IMIP $1^{\text {a }}$ ed, ed. Medbook, 2007-.

88. Tanaka ACd'A, Siqueira AAF, Bafile PN. Situação de saúde materna e perinatal no estado de São Paulo, Brasil. Rev Saúde Pública 1989; 23(1):67-75.

89. Teixeira CF. Transição epidemiológica, modelo de atenção à saúde e previdência social no Brasil: problematizando tendências e opções políticas. Ciência \& Saúde Coletiva 2004; 9(4): 841-3.

90. Vermelho LL, Monteiro MFG, Costa AJL, Kale PL. Transição epidemiológica e indicadores de saúde atuais. Cad. Saúde Pública 2001; 9(2): 111-26. 
91. Vidal AS, Silva EV, Oliveira MG, Siqueira AM, Felisberto E, Samico I, Cavalcante MGS. Avaliação da aplicação da estratégia daAtenção Integrada às Doenças Prevalentes da Infância (AIDPI) por agentes comunitários de saúde. Rev Bras Saúde Matern Infant, Recife 2003; 3(2): 205-13.

92. Vieira SE, Steiwein KE, Queiroz DAO, Durigon EL, Torok TJ, Anderson LJ, Miyao CR, Hein N, Botosso VF, Pahl MM, Gilio AE, Eizenberg B, Okay Y. Clinical patterns and sazonal trends in respiratory syncytial vírus hospitalization in São Paulo, Brazil. Rev Inst Med Trop S Paulo 2001; 43(3): $125-31$. 
ANEXO 


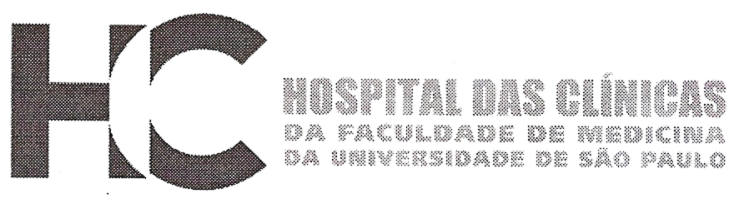

\section{APROVAÇÃO}

A Comissão de Ética para Análise de Projetos de Pesquisa CAPPesq da Diretoria Clínica do Hospital das Clínicas e da Faculdade de Medicina da Universidade de São Paulo, em sessão de 20/02/2008, APROVOU - Protocolo de Pesquisa $n^{\circ}$ 1219/07, intitulado: "ESTUDO DAS CAUSAS DE INTERNAÇĀO HOSPITALAR DE CRIANÇAS DE 0 A 14 ANOS DE IDADE NO MUNICÍPIO DE SÃO PAULO." apresentado pelo Departamento de PEDIATRIA.

Cabe ao pesquisador elaborar e apresentar à CAPPesq, os relatórios parciais e final sobre a pesquisa (Resolução do Conselho Nacional de Saúde n 196, de 10/10/1996, inciso (X.2, letra "c").

Pesquisador (a) Responsável: Profa Dra Sandra Josefina Ferraz Ellero Grisi

Pesquisador (a) Executante: Dra Ana Paula Scoleze Ferrer

CAPPesq, 22 de Fevereiro de 2008

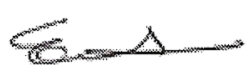

Prof. Dr. Eduardo Massad Presidente da Comissão de Ética para Análise de Projetos de Pesquisa 